\title{
Evaluation of Electric Vehicle Production and Operating Costs
}

by R.M. Cuenca, L.L. Gaines, and A.D. Vyas

Center for Transportation Research, Energy Systems Division,

Argonne National Laboratory, 9700 South Cass Avenue, Argonne, Illinois 60439

November 1999

Work sponsored by the United States Department of Energy,

Assistant Secretary for Energy Efficiency and Renewable Energy,

Office of Transportation Technologies 
This report is printed on recycled paper. 


\section{Contents}

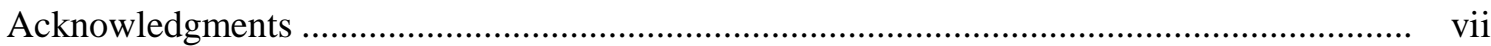

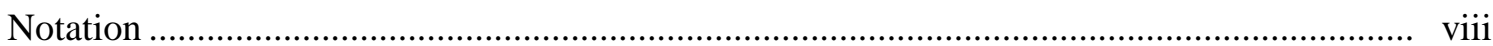

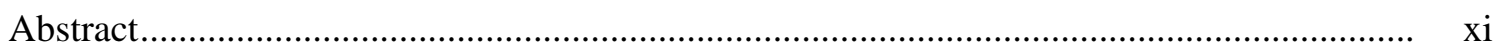

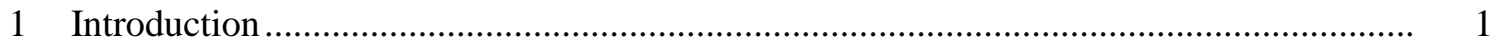

2 Vehicle Manufacturing and Marketing Costs ................................................................. 3

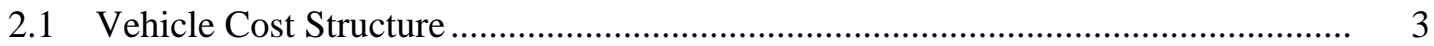

2.2 Costs by Vehicle Component Group ……................................................................. 6

2.3 Description of the Basic Methodology ................................................................. 7

3 Costs of Conventional Systems and Components........................................................ 9

3.1 Manufacturing Cost Structure of Subcompact Car and Minivan ............................ 9

3.2 The Impact of Body Materials ............................................................................... 11

4 Systems and Components for Electric Vehicles …................................................ 13

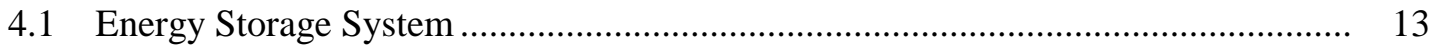

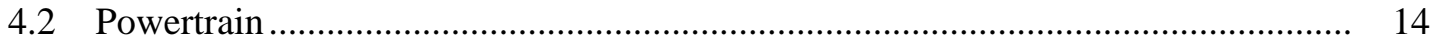

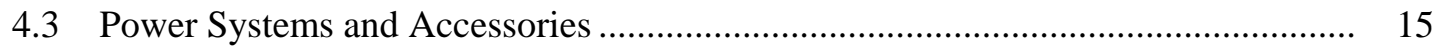

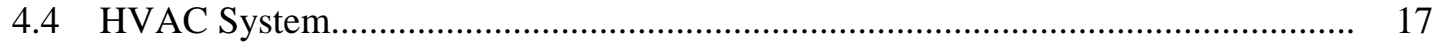

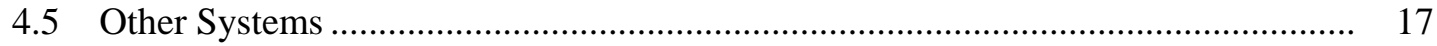

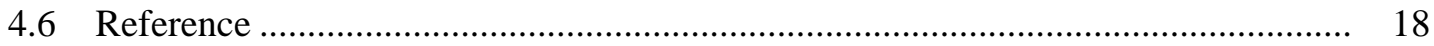

5 Cost Models for Traction Motors and Controllers....................................................... 19

5.1 Overview of the Cost Model for Traction Motors ................................................. 19

5.1.1 AC-Induction Motor ........................................................................... $\quad 20$

5.1.2 Conventional DC Motor ......................................................................... 23

5.1.3 DC-Brushless Permanent Magnet Motor ................................................... 26

5.1.4 Summary of Motor Cost Analysis .......................................................... 28

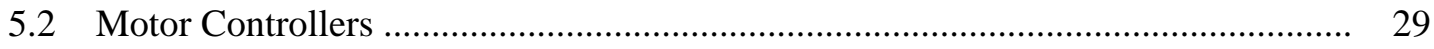

5.2.1 DC Motor Controllers....................................................................... 30

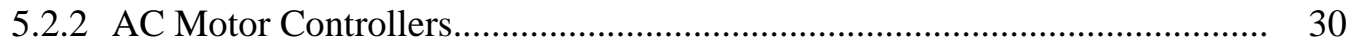

5.2.3 Cost Model for Motor Controllers............................................................ 31

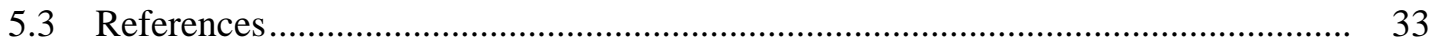




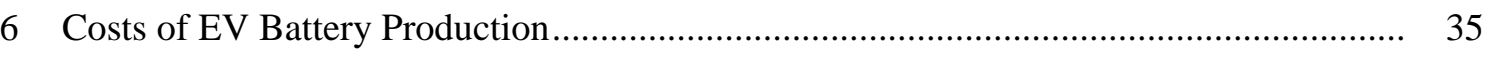

6.1 Battery Materials and Their Costs ................................................................. 36

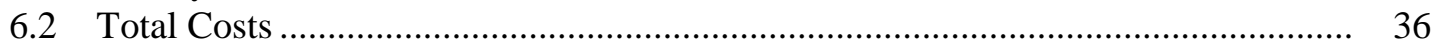

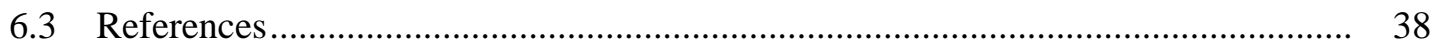

7 The Manufacture of Electric Vehicles ....................................................................... 40

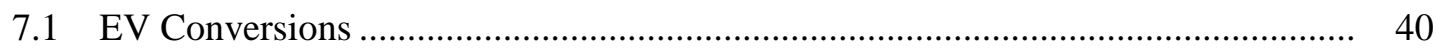

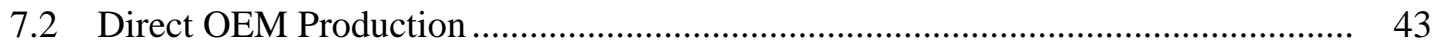

8 Cost Estimates for Selected Vehicles .................................................................. 45

8.1 Cost of Subcompact EV or Minivan Based on Existing Vehicle ........................... 45

8.2 Cost Analysis of Subcompact EV under Alternative Methods............................... 48

8.2.1 Subcompact EV Based on a New Design............................................... 48

8.2.2 Subcompact EV Assembled from a Glider.............................................. 49

8.2.3 Subcompact EV Conversion from a CV ................................................ $\quad 50$

8.3 Summary of EV Costs........................................................................... 51

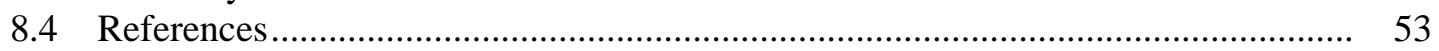

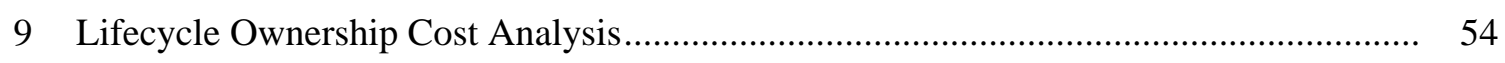

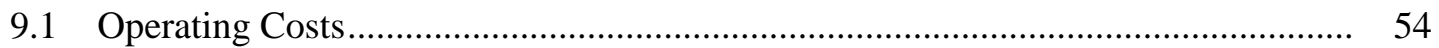

9.1.1 Energy and Maintenance Costs .......................................................... 54

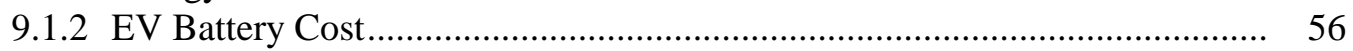

9.2 Amortized Purchase Price ............................................................................ 58

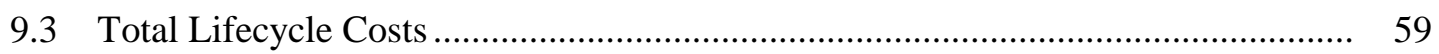

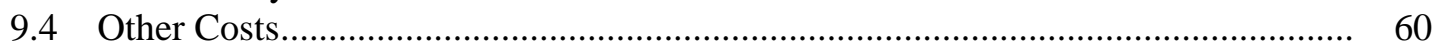

9.5 Summary of Lifecycle Ownership Cost Analysis ............................................. 60

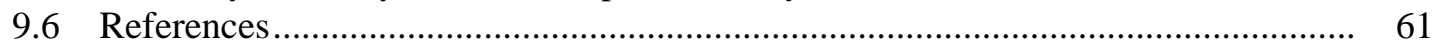

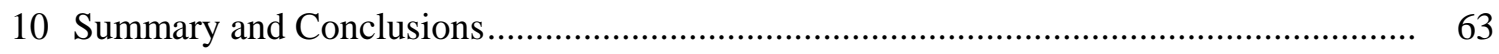

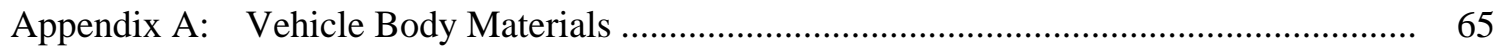

Appendix B: Battery Designs and Materials ….......................................................... 69

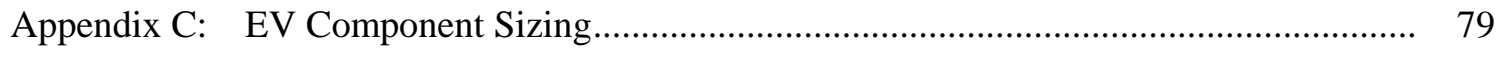

Figures

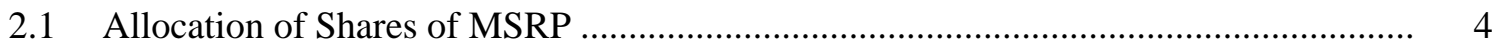

2.2 Historical MSRP and Dealer Margin for Ford Taurus ............................................. 4 
2.3 Historical Dealer Margin as Percentage of MSRP for Ford Taurus.

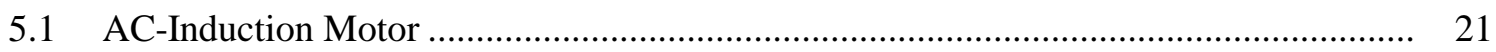

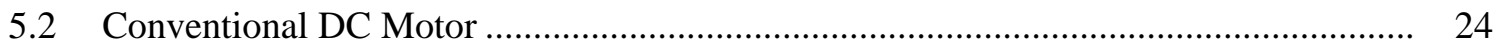

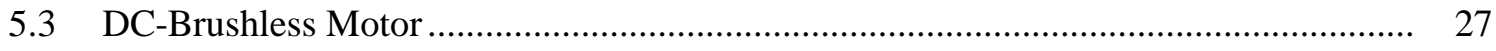

6.1 Nickel-Cadmium Battery Costs at Different Production Levels ................................. 38

C.1 Vehicle Speed and Time Relationship during Acceleration...................................... 80

\section{Tables}

2.1 Typical Vehicle Manufacturing and Retailing Cost Structure ..................................... 6

2.2 Functional Vehicle Manufacturing and Retailing Cost Structure

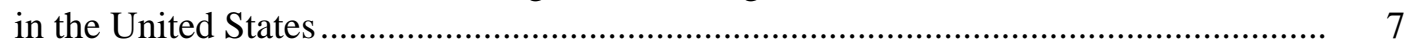

2.3 Typical CV Production Cost Allocation by Component System

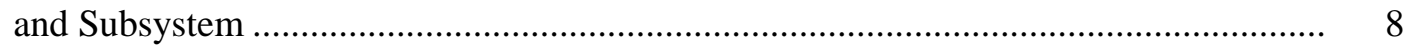

3.1 CVs and EVs: Component Groups and Subgroups ............................................. 10

3.2 Cost Allocation by Group and Subgroup for Conventional Vehicles .......................... 11

5.1 AC-Induction Motor: Material Content and Cost of Components ................................ 22

5.2 AC-Induction Motor: Estimated OEM Cost …........................................................ 23

5.3 Conventional DC Motor: Material Content and Cost of Components .......................... 25

5.4 Conventional DC Motor: Estimated OEM Cost .................................................... 26

5.5 DC-Brushless Motor: Material Content and Cost of Components ............................... 27

5.6 DC-Brushless Motor: Estimated OEM Cost........................................................ 28

5.7 Comparison of Attributes and Costs for Three Traction Motors …............................. 28

5.8 Estimated Cost of Components for 70-kW DC and AC Controllers ............................ 32

5.9 Estimated OEM Cost of 70-kW DC and AC Controllers ........................................... 33

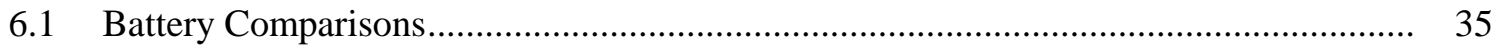




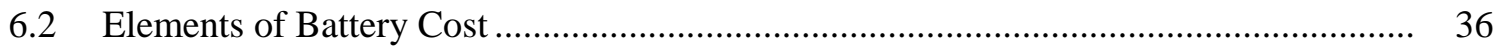

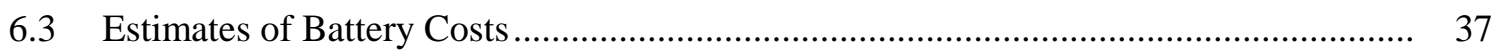

8.1 EV Component Costs to OEM......................................................................... 46

8.2 Estimated MSRP of Electric Subcompact and Minivan

Based on Existing Vehicle .................................................................................... 47

8.3 Estimates of Subcompact EV Cost by Conversion from a CV ….............................. 51

8.4 CV and EV MSRP with 15\% EV Battery Cost Markup............................................ 52

8.5 CV and EV MSRP with 30\% EV Battery Cost Markup......................................... 52

9.1 Estimated Energy and Maintenance Costs of Subcompact CV and EV ...................... 56

9.2 Subcompact EV: Initial and Replacement Battery Pack Costs.................................. 58

9.3 Subcompact EV Powertrain Characteristics and Purchase Price ................................. 59

9.4 Lifecycle Ownership Costs of Subcompact CV and EV .......................................... 59

A.1 Mass Reduction Potential and Costs of Lightweight Materials .................................. 68

B.1 Advanced Lead-Acid Battery Material Costs .............................................................. 70

B.2 Sodium-Sulfur Battery Material Costs .............................................................. 72

B.3 Nickel-Cadmium Battery Material Costs........................................................... 74

B.4 $\mathrm{AB}_{2}$ Nickel-Metal Hydride Battery Material Costs .............................................. 75

B.5 $\mathrm{AB}_{5}$ Nickel-Metal Hydride Battery Material Costs .................................................. 76

C.1 Subcompact EV Physical Characteristics and Design Parameters .............................. 86

C.2 Battery Characteristics for the Subcompact EV ….................................................. 86

C.3 Specific Power and Efficiency Values for Drivetrain Components ........................... 87 


\section{Acknowledgments}

The authors thank Philip Patterson of the Office of Transportation Technologies, U.S. Department of Energy, for his consistent support, valuable guidance, and technical input. We appreciate the guidance and repeated technical reviews by Danilo Santini at Argonne, who made himself available whenever we needed him. Thanks are also due to our external reviewers: Analisa Bevan and her staff at the California Air Resources Board; Mark Delucchi and Tim Lipman at the Institute of Transportation Studies, University of California at Davis; Jon Lutz at Unique Mobility, Inc.; Ed Kjaer and Dean Taylor at Southern California Edison; and Mark Kosowsky at General Motors. Their constructive comments were very helpful and improved the technical contents of this report. Our technical editor, Floyd Bennett, took pains to put the report in its final form, and Argonne's Information and Publishing Division staff prepared the manuscript and graphics; we are thankful to them. Although several persons helped make this report possible, the authors are solely responsible for its contents. 


\section{Notation}

\section{Acronyms}

AAMA American Automobile Manufacturers Association

$\mathrm{ABC}$

Advanced Battery Consortium

ABS

antilock braking system

$\mathrm{AC}$

alternating current

ANL Argonne National Laboratory

CARB California Air Resources Board

CV conventional vehicle

DC direct current

DOE U.S. Department of Energy

EIA Energy Information Administration

EPA U.S. Environmental Protection Agency

EV electric vehicle

FHWA Federal Highway Administration

HVAC heating, ventilation, and air-conditioning

IC internal combustion

IGBT insulated gate bipolar transistor

MOSFET metal oxide semiconductor field-effect transistor

MSRP manufacturer's suggested retail price

MY model year

$\mathrm{Na}-\mathrm{S} \quad$ sodium-sulfur

$\mathrm{Ni}-\mathrm{Cd} \quad$ nickel-cadmium

Ni-MH nickel-metal hydride

NREL National Renewable Energy Laboratory

OEM original equipment manufacturer

OTT Office of Transportation Technologies

$\mathrm{Pb}$-acid lead-acid

PC polymer composite

PM permanent magnet

PWM pulse-width modulation

R\&D research and development

rms root mean square

RTM resin transfer molding

SCR silicon control rectifier

SLI start, light, and ignition

SOC state of charge 


\section{Units}

$\begin{array}{ll}\text { Btu } & \text { British thermal units } \\ \text { in. } & \text { inch } \\ \mathrm{kWh} & \text { kilowatt-hours } \\ \mathrm{L} & \text { liter } \\ \mathrm{lb} & \text { pound } \\ \mathrm{mpg} & \text { miles per gallon } \\ \mathrm{rpm} & \text { revolutions per minute } \\ \mathrm{V} & \text { volt } \\ \mathrm{W} \cdot \mathrm{h} / \mathrm{kg} & \text { watt-hours per kilogram } \\ \mathrm{W} \cdot \mathrm{h} / \mathrm{L} & \text { watt-hours per liter }\end{array}$


$\Delta$ 


\section{Abstract}

This report presents an analysis of the initial cost of electric vehicles (EVs). The manufacturing and retail cost structure of mature conventional vehicles produced at high volume is analyzed first, and the contributions by various cost categories to vehicle price are estimated. The costs are then allocated to such vehicle component groups as body, chassis, and powertrain. The similarities and differences among various component systems are reviewed. In electric vehicles, an electric drive replaces the conventional powertrain, and a battery pack replaces the fuel system. Three types of traction motors are reviewed, and their cost in high-volume production is analyzed. Various components of the motor and controller package are analyzed, and their representative costs are summarized. Four types of EV batteries are reviewed, and their costs are presented. Various alternatives for the low-, medium-, and high-volume production of EVs are evaluated, and some sample costs are presented. A methodology that estimates initial and operating costs on the basis of this analysis is presented. The methodology also estimates the average lifetime cost of owning and operating an electric vehicle. 
$\Delta$ 


\section{Section 1 Introduction}

The U.S. Department of Energy's (DOE's) Office of Transportation Technologies (OTT) sponsors research aimed at improving vehicle energy efficiency and increasing the use of alternative fuels. Ensuring that these research projects also result in vehicles and fuels that minimize adverse impacts on the environment is a major concern for the OTT. Because some states have enacted or are planning legislation requiring the use of vehicles that produce zero tailpipe emissions, OTT has supported research aimed at making such vehicles technologically and economically feasible.

Electric vehicles (EVs) use energy from a storage device, such as a battery, flywheel, or ultracapacitor; consequently, EVs produce no tailpipe emissions, thereby meeting the zero tailpipe emissions requirements mandated by some states. In addition to providing a solution to urban air-quality problems, EVs would provide an alternative to conventional vehicles (CVs), which are powered by internal combustion (IC) engines, for certain personal transportation missions. EV technology, however, is at an early stage of development. Low production volumes and labor-intensive manufacturing processes make the costs of its components high.

The costs of producing EVs in large volumes are not well known. At present, a few manufacturers convert CVs to EVs by replacing their IC engine powertrains with electric powertrains. Because the converted vehicles require additional work and components, their costs are not representative of mass-produced EVs. Although it is possible to obtain some estimate of operating costs from these converted vehicles, they provide little indication of how other costs (initial, battery, etc.) for mass-produced EVs would compare with those for CVs.

Electric vehicles differ from conventional vehicles in several respects. The EV's powertrain does not idle when the vehicle is stopped in traffic, and very little waste heat is available for passenger compartment heating. Several of the CV accessories are operated or actuated by vacuum from the engine or an engine-driven vacuum pump. Aside from the essential accessories, the IC engine also provides power to operate such amenities as defrosting, audio entertainment, and air-conditioning, which have become very common and are important for consumer acceptance. Several options are available to power these accessories in an EV; the options include alternatives that would consume more energy and increase the initial vehicle cost.

When EVs come to be produced in sufficient volume, significant cost reductions will be possible. The EV's electric drive components, which currently have very high costs, could be produced in large quantities at reasonable cost. The EV body can be designed to accommodate batteries, which represent the most likely energy storage device for EVs, without increasing the overall vehicle cost. Several research and development (R\&D) efforts are under way to increase the energy storage capacity and useful life of EV batteries. EVs are expected to have very low 
energy costs because of their efficient use of electricity from batteries. However, such vehicles are likely to require one or more replacement battery packs during their lifetime; these replacement packs would add substantially to the EV's annual operating costs.

This report presents the results of an analysis of the vehicle manufacturing costs and potential initial and operating costs for EVs under different production scenarios. Various components of the electric powertrain are analyzed in detail and their potential costs evaluated.

In introducing a new technology product, a manufacturer would normally price it so as to be able to compete with existing products. Manufacturers often shift a part of the new product cost to existing products or sell at a loss under these initial pricing strategies. Once the new product is accepted by consumers, the benefits it provides allow the manufacturer to price it fully and recover all incurred costs. Because electric drive components would be more expensive initially, EVs are expected to cost substantially more than competing CVs. Thus, EV manufacturers will have to develop price schemes that make their products affordable. Vehicle manufacturers have used similar pricing strategies in the past for such components as air bags and the antilock braking system (ABS). As automated production becomes feasible, increasing production volume normally leads to substantial cost savings. New technical developments could further reduce component costs, leading to lower EV prices. However, the analysis presented in this report already assumes high-volume production employing highly automated methods, as well as some reductions in motor, controller, and battery costs induced by technical development. The EV retail price estimates presented here are representative of first-generation, mass-produced EVs built several years after the introductory period. By then, the EV's benefits (as perceived by consumers) should allow the manufacturers to recover most of the incurred costs. Therefore, the estimated prices in this report represent the prices consumers are likely to pay when EVs are produced in high volumes and the manufacturer recovers the full cost of production. Of course, individual manufacturers could devise alternative pricing strategies. 


\section{Section 2 \\ Vehicle Manufacturing and Marketing Costs}

This report addresses high-volume manufacturing costs of conventional vehicles and derives the most likely vehicle price (the initial cost to the buying public) for electric vehicles if produced at sufficiently high volumes. A vehicle's list price is usually set to cover manufacturing and selling costs, plus other indirect overheads, and a reasonable profit margin. The list price, or more specifically, the "manufacturer's suggested retail price" (MSRP), is the nominal price at which the dealers offer the vehicle to consumers. The retail dealers purchase the vehicle from the manufacturer at the so-called "invoice" price, which is discounted from the list price by a standard amount. The dealership actually sells the vehicle to the public for whatever it can get, generally somewhere between list and invoice prices. Thus, the dealer often gives the buyer a discount from the list price (or shares his discount). The buyer may get an additional discount directly from the manufacturer, the "manufacturer's rebate." The buyer's final discounted price is the "transaction price."

The difference between the actual selling price and the invoice price constitutes the dealer's margin. The dealer also receives a small amount of additional revenue directly from the manufacturer after a vehicle is sold. This is the so-called "holdback," which can be considered a bonus from the manufacturer to the dealer for actually selling the vehicle. In addition to the normal discount and holdback, which are customary, the manufacturer can also give the dealer temporary and/or selective "incentives" in the form of additional cash awards for meeting sales quotas or increasing sales of certain models. In summary, the dealer realizes income from the margin between the actual sales price and invoice, plus the holdback, plus any incentives that apply. The revenue from new vehicle sales to the manufacturer equals the MSRP minus dealer and price discounts. These discounts constitute the fraction of the cost of selling that are absorbed directly by the distribution network.

The manufacturer also incurs such costs of selling as transportation, distribution, advertising, and direct dealer support. The sales revenue net of the total cost of selling provides the funds to cover the expenses of the manufacturing division, other divisional and corporate overheads ( $R \& D$, engineering, corporate staffs, depreciation and amortization, pensions, etc.), and profit. A breakdown of this relationship, with approximate shares, is illustrated schematically in Figure 2.1.

\subsection{Vehicle Cost Structure}

Because information about the breakdown of vehicle manufacturing and retailing costs is proprietary and sensitive due to the competitive nature of the business, it is seldom made public. Cost data are available from the invoice prices published by consumer advice magazines, other similar sources, and annual reports of vehicle manufacturers. These sources can be used to analyze the relationships between various cost components. For example, Figure 2.2 shows the history of MSRP and the invoice discount for the Ford Taurus between 1987 and 1996. 


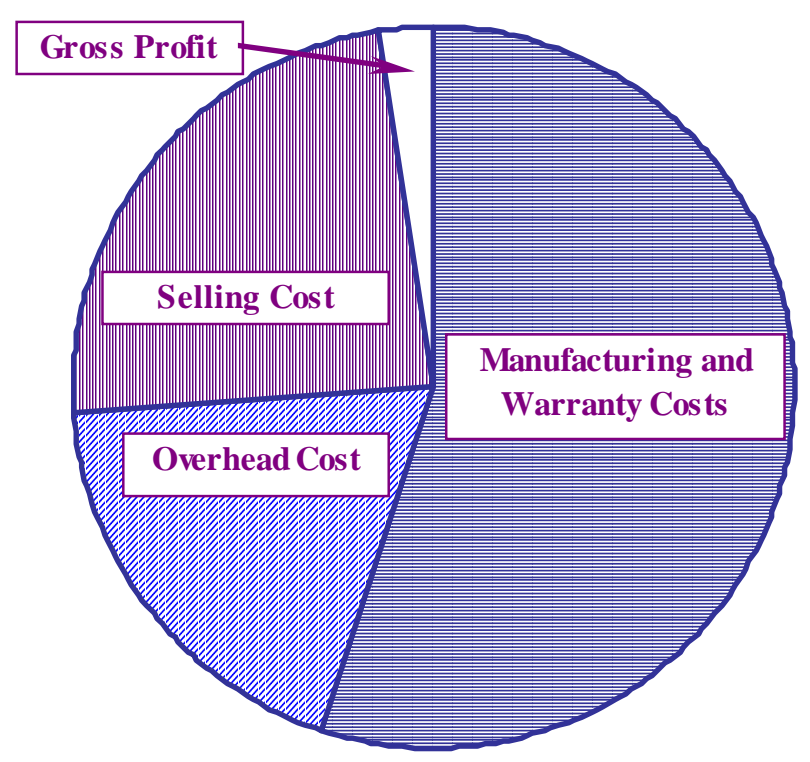

Figure 2.1 Allocation of Shares of MSRP

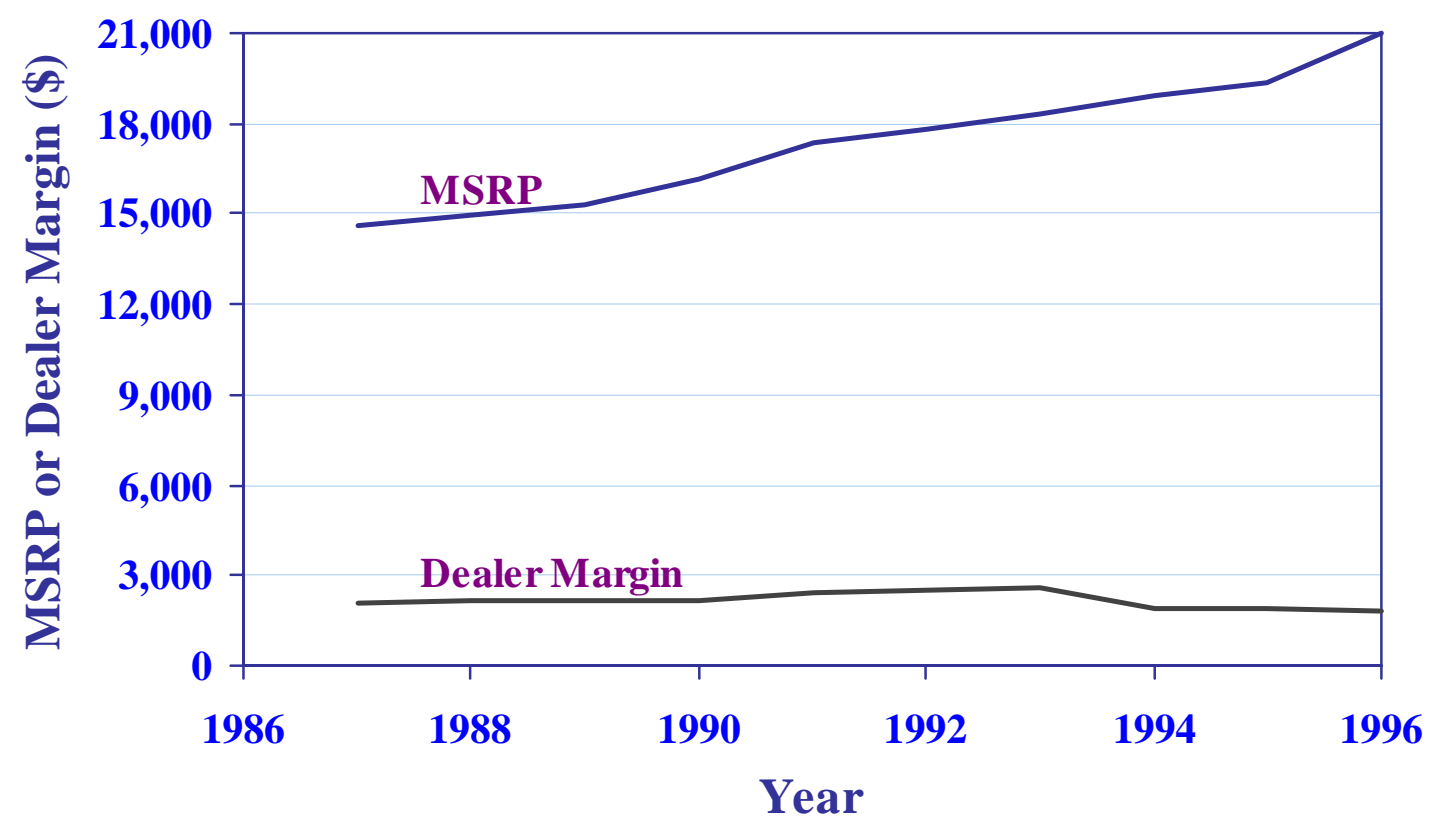

Figure 2.2 Historical MSRP and Dealer Margin for Ford Taurus 
Figure 2.3 shows the dealer discount as a percentage of MSRP since its introduction in modelyear (MY) 1987. Estimates of the incentives and rebates that manufacturers have offered in the last several years are also available. Although there has been some variation in individual cost components (dealer discounts have fallen sharply since 1993), the trend is toward a shift among components rather than a major change in the total cost. The dealer's invoice discount (from MSRP) has decreased from the historical 15-16\% level of a decade ago to 9-10\% today. The holdback has been reasonably steady at nearly $3 \%$, and dealer incentives and direct price incentives (rebates) are around $7 \%$. Therefore, the cost of selling on the distribution channels amounts to approximately $20 \%$ of MSRP. Adding the cost of advertising (at 2\%) and other direct dealer-support costs (1-2\%) yields a share for the selling component of 23-24\% of MSRP.

The costs of design, development, and special tooling for a new vehicle or major component are very high. These investments must be recovered during the time that the product is manufactured. Similarly, the costs of certification, product liability litigation and defense, and many other corporate or divisional services considered necessary to succeed in the automotive business must be recovered. Therefore, every product bears additional corporate and divisional overheads to fund these functions and activities that are not directly related to production. The overhead charges usually include R\&D and engineering (6-7\% of MSRP), depreciation and amortization of tooling and facilities (5-6\%), general corporate overhead (5\%), and retirement and health expenses (2\%). Corporate and divisional overheads total 18-20\% of MSRP.

Subtracting all the costs and charges above from the total MSRP leaves the profit before taxes at about $2.5 \%$. The results are shown in Table 2.1.

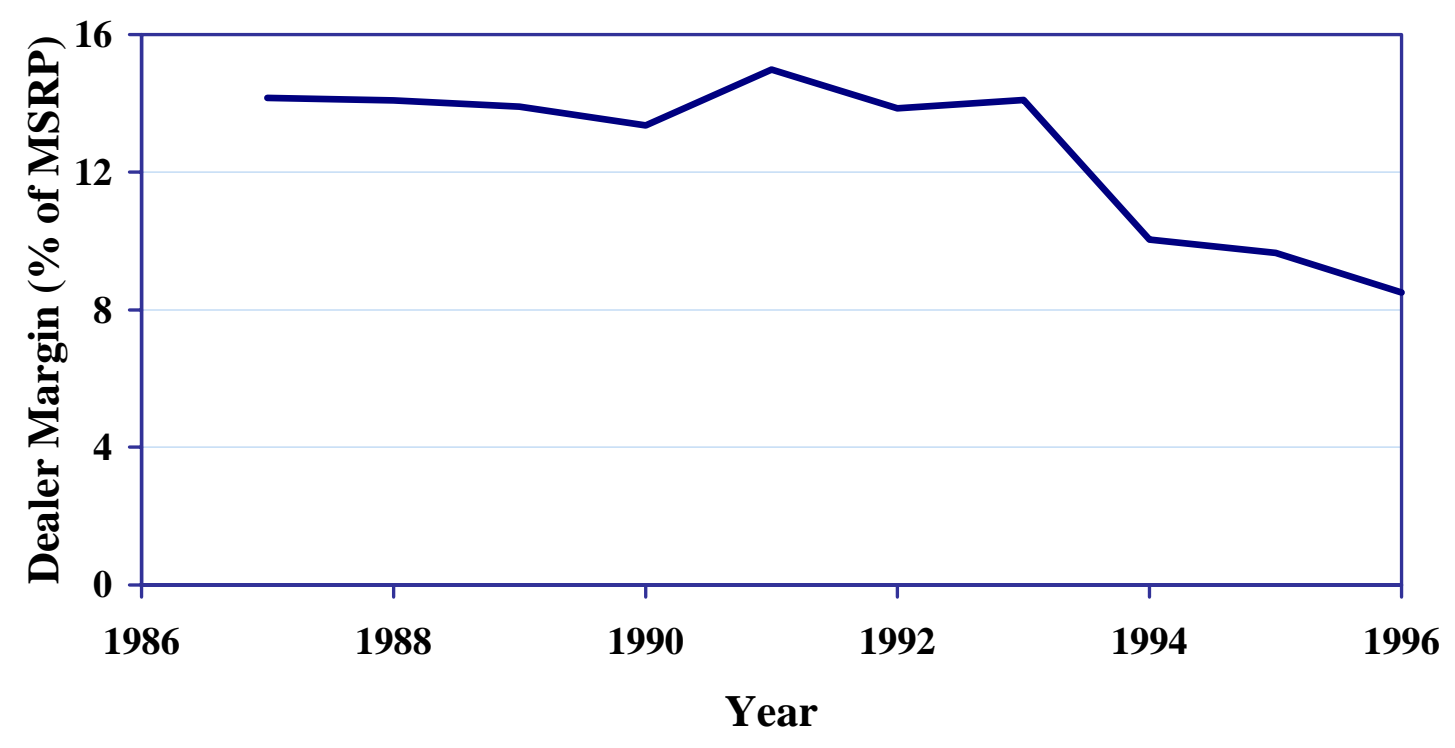

Figure 2.3 Historical Dealer Margin as Percentage of MSRP for Ford Taurus 
Table 2.1 Typical Vehicle Manufacturing and Retailing Cost Structure

\begin{tabular}{|lccc|}
\hline \multicolumn{1}{|c}{ Cost Category } & $\begin{array}{c}\text { Share of } \\
\text { MSRP (\%) }\end{array}$ & \multicolumn{1}{c|}{ Subcategory } & $\begin{array}{c}\text { Share of } \\
\text { MSRP (\%) }\end{array}$ \\
\hline $\begin{array}{l}\text { Manufacture } \\
\text { Warranty }\end{array}$ & 50 & & \\
Overhead & 5 & & \\
& $18-20$ & & $6-7$ \\
& & $\begin{array}{l}\text { R\&D and engineering } \\
\text { Depreciation/amortization }\end{array}$ & $5-6$ \\
& & $\begin{array}{l}\text { Corporate overhead } \\
\text { Retirement and health }\end{array}$ & 5 \\
Selling & $23-24$ & Distribution & 2 \\
& & Advertising and dealer support & $3-4$ \\
Sum of costs (avg.) & 97.5 & & \\
Gross profit & 2.5 & & \\
Total & 100 & & \\
& & & \\
\hline
\end{tabular}

The cost structure in Table 2.1 can be rearranged in terms of such major cost categories as production, sales, and administration. This facilitates the adjustments required later in this study to account for the shifts in components between conventional and electric vehicles, and between those manufactured in-house and those outsourced. Such a rearranged structure is shown in Table 2.2. The total cost of production (fully loaded) includes manufacturing cost, warranty charges, $R \& D /$ engineering, and depreciation/amortization of tooling and facilities. The total cost of selling remains unchanged, while the administrative cost and profit includes general and corporate overhead, retirement and health, and profit.

The information in Table 2.2 is important for estimating the impact of new components on vehicle price. For components unique to electric vehicles, we can analyze material contents, assess production methods, and develop estimates of production costs. Other costs are then computed on the basis of the percentage allocations given in Tables 2.1 and 2.2.

\subsection{Costs by Vehicle Component Group}

Within a vehicle assembly plant, raw materials and components become complete vehicles. It would be logical to account for all the incoming materials, components, labor, supplies, utilities, and other costs and compare them against vehicle output. In reality, the vehicle manufacturers produce many individual components that are supplied to the assembly plant, while independent suppliers also make some components. All these components arrive at the assembly plant, where they are simply considered input "material," without differentiating between in-house (made by the vehicle manufacturer) and outsourced (made by independent suppliers) components. The extent of component manufacturing at the assembly plant is minimal, and the trend is toward its elimination. In most vehicle assembly plants in the United States and Canada, the only component preparation is the body-in-white assembly (welding) and painting. 
Table 2.2 Functional Vehicle Manufacturing and Retailing Cost Structure in the United States

\begin{tabular}{|c|c|c|c|}
\hline \multirow[b]{2}{*}{ Major Category } & \multirow[b]{2}{*}{ Subcategory } & \multicolumn{2}{|c|}{ Share of MSRP (\%) } \\
\hline & & $\begin{array}{l}\text { By Major } \\
\text { Category }\end{array}$ & $\begin{array}{l}\text { By Sub- } \\
\text { category }\end{array}$ \\
\hline \multirow[t]{5}{*}{ Production } & & 67.0 & \\
\hline & Manufacturing & & 50.0 \\
\hline & Warranty & & 5.0 \\
\hline & $R \& D$ and engineering & & 6.5 \\
\hline & Depreciation and amortization & & 5.5 \\
\hline \multirow[t]{3}{*}{ Selling } & & 23.5 & \\
\hline & Distribution & & 20.0 \\
\hline & Advertising and dealer support & & 3.5 \\
\hline \multirow[t]{4}{*}{ Administration and profit } & & 9.5 & \\
\hline & Corporate overhead & & 5.0 \\
\hline & Retirement and health benefits & & 2.0 \\
\hline & Gross profit & & 2.5 \\
\hline Total & & 100.0 & 100.0 \\
\hline
\end{tabular}

The painted body is then sent to the main assembly line, where the rest of the components are incorporated to form the complete vehicle.

One way to account for the manufacturing cost is to sum the cost of the material input (as received at the plant), the plant labor, and the plant overhead charge (expenses for general production supplies, utilities, taxes, service and maintenance, and plant-technical and -personnel support). When the material cost is broken down by system and subsystem, this approach makes it relatively simple to estimate the cost impacts when components are replaced with alternatives. Table 2.3 provides a summary of costs by vehicle component group and subgroup.

\subsection{Description of the Basic Methodology}

An electrically driven passenger vehicle can be viewed as a modification of a conventional vehicle. The differences are primarily in the powertrain and the energy storage system. Both vehicle types have similar bodies, with such components as doors, windows, seats, instrument panels, and controls. They have very similar chassis components, such as brakes, suspensions, wheels and tires, and bumpers. Combined, these components account for $70-80 \%$ of the total vehicle cost. Therefore, EV costs are estimated on the basis of the most similar CVs available, making necessary adjustments for the difference in hardware and process between the two for the remaining parts, which account for only about $20-30 \%$ of the conventional vehicle cost. In other words, we estimate the cost of the components that are unique to the EV, rather than the cost of the entire vehicle.

We use the manufacturing cost structure of the CV body type most similar to the selected $\mathrm{EV}$ as the base and identify all the systems, components, and parts of the CV that would be removed or replaced in the EV. The costs of those removed components are subtracted from the 
Table 2.3 Typical CV Production Cost Allocation by Component System and Subsystem

\begin{tabular}{|c|c|c|c|}
\hline \multirow[b]{2}{*}{$\begin{array}{l}\text { Component } \\
\text { System }\end{array}$} & \multirow[b]{2}{*}{ Subsystem } & \multicolumn{2}{|c|}{$\begin{array}{c}\text { Share of } \\
\text { Manufacturing } \\
\text { Cost (\%) }\end{array}$} \\
\hline & & By System & $\begin{array}{l}\text { By Sub- } \\
\text { system }\end{array}$ \\
\hline \multirow[t]{6}{*}{ Body } & & 26.46 & \\
\hline & Body-in-white & & 13.22 \\
\hline & Paint and coatings & & 0.13 \\
\hline & Glass & & 2.32 \\
\hline & Body trim and components & & 10.30 \\
\hline & Electrical components & & 0.50 \\
\hline \multirow[t]{4}{*}{ Engine } & & 21.53 & \\
\hline & Engine unit & & 18.50 \\
\hline & Engine accessories & & 2.33 \\
\hline & Engine electrical & & 0.70 \\
\hline \multirow[t]{3}{*}{ Transmission } & & 5.03 & \\
\hline & Transmission unit & & 4.95 \\
\hline & Transmission controls & & 0.08 \\
\hline \multirow[t]{13}{*}{ Chassis } & & 25.94 & \\
\hline & Frame & & 1.19 \\
\hline & Suspension & & 4.91 \\
\hline & Steering & & 0.97 \\
\hline & Brakes & & 2.97 \\
\hline & Exhaust system & & 3.01 \\
\hline & Fuel system & & 0.36 \\
\hline & Final drive & & 1.48 \\
\hline & Wheels and tires & & 5.19 \\
\hline & Bumpers, fenders, and shields & & 2.29 \\
\hline & Chassis electrical & & 0.83 \\
\hline & Accessories and tools & & 0.12 \\
\hline & Fluids & & 2.62 \\
\hline Vehicle assembly & & 21.04 & \\
\hline Total & & 100.00 & \\
\hline
\end{tabular}

vehicle cost and the calculated costs of the EV components that replace them are added. Any necessary adjustment to the assembly cost is then made. The result is the cost of manufacturing an $\mathrm{EV}$ produced in comparable volume at a plant similar to that of the base $\mathrm{CV}$. If the $\mathrm{EV}$ is to be produced at much lower volumes, or in a plant with an atypical cost structure, further adjustments are needed.

This methodology is based on high-volume, mature-industry production, on the assumption that the manufacturing processes used do not depart significantly from those for CVs. This limitation is actually an advantage. If EVs are to succeed, they will have to be cost-competitive, which means producing them in volume and using the most cost-effective supply base for components. 


\section{Section 3 Costs of Conventional Systems and Components}

A conventional passenger vehicle includes several thousand individual parts; 35 to 40 main systems/subsystems must be integrated. It is customary to combine these systems and components into four major groups, which, when fully assembled and integrated, add up to the complete vehicle. These major groups are the body, the engine, the transmission, and the chassis. If the various groups and subgroups in a conventional passenger vehicle - say, a subcompact, four-door sedan with a four-cylinder engine, a five-speed manual transmission, and airconditioning — are defined, one obtains a list like that in the first column of Table 3.1.

Many of the groups and subgroups listed in Table 3.1 will be essentially the same in an EV. For instance, the body group would be practically identical, except for some controls and instrumentation. On the other hand, the engine and transmission groups would be replaced entirely by systems of quite a different nature. Some of the chassis group's subgroups would be replaced entirely (such as exhaust, fuel storage, and some fluids); some subgroups would be modified (steering, brakes, and chassis electricals); and the rest would remain essentially unchanged. It is convenient to modify the tabulated list of groups and subgroups in a format that simplifies the operations needed to make the EV calculations. Columns 2 through 4 in Table 3.1 show whether the subgroup is common, somewhat common, or not at all common to both CVs and EVs.

If we now obtain the manufacturing cost structure of the component groups and subgroups listed above, plus the cost of assembly of the entire vehicle, we will have a simple model to facilitate the cost calculations for the EV. In the sections that follow, we present such models for a conventional subcompact car and for a minivan.

\subsection{Manufacturing Cost Structure of Subcompact Car and Minivan}

The cost allocation of a conventional subcompact passenger car, broken down by component groups and systems as described above, is presented in Table 3.2. The subcompact car is a typical four-door sedan with a four-cylinder engine, five-speed manual transmission, and air-conditioning. The minivan has a V-6 engine, four-speed automatic transmission, three-row seats, and air-conditioning. Neither vehicle has any special luxury or performance options.

The cost shares in Table 3.2 indicate the distribution of costs among major groups for the subcompact car and minivan. Although no single group dominates the cost of the vehicle, the body group is clearly the highest-cost contributor. The body and chassis groups have the largest number of subgroups that would be common between CVs and EVs (see Table 3.1). These two groups also contribute substantially to the vehicle mass and, in turn, determine the size of the powertrain. The EV powertrain components would be very expensive during the introductory phase. Reducing the size of the powertrain, which depends on vehicle mass, can lower the vehicle cost. Vehicle mass can be reduced by substituting lightweight materials for conventional steel; however, such substitutions would increase the vehicle cost. 
Table 3.1 CVs and EVs: Component Groups and Subgroups

\begin{tabular}{|c|c|c|c|}
\hline Vehicle Group and Subgroup & $\begin{array}{c}\text { Fully } \\
\text { Common }\end{array}$ & $\begin{array}{l}\text { Somewhat } \\
\text { Common }\end{array}$ & $\begin{array}{c}\text { Not } \\
\text { Common }\end{array}$ \\
\hline \multicolumn{4}{|l|}{ Body group } \\
\hline Body-in-white & $X$ & & \\
\hline Paint and coatings & $\mathrm{X}$ & & \\
\hline Glass & $\mathrm{X}$ & & \\
\hline Interior body trim & $\mathrm{X}$ & & \\
\hline Exterior body trim & $\mathrm{X}$ & & \\
\hline Seats & $\mathrm{X}$ & & \\
\hline Instrument panel & & $\mathrm{x}$ & \\
\hline Restraint system & $\mathrm{X}$ & & \\
\hline Body electrical components & $\mathrm{X}$ & & \\
\hline Heating, ventilating, and air-conditioning (HVAC) & & $\mathrm{X}$ & \\
\hline \multicolumn{4}{|l|}{ Engine group } \\
\hline Base engine & & & $x$ \\
\hline Emissions control & & & $x$ \\
\hline Engine accessories & & & $x$ \\
\hline Engine electrical components & & & $x$ \\
\hline Cooling system & & & $\mathrm{X}$ \\
\hline \multicolumn{4}{|l|}{ Transmission group } \\
\hline Transaxle & & & $x$ \\
\hline Clutch and actuator & & & $x$ \\
\hline Transmission controls & & & $x$ \\
\hline \multicolumn{4}{|l|}{ Chassis group } \\
\hline Frame & $x$ & & \\
\hline Suspension & $x$ & & \\
\hline Steering & & $x$ & \\
\hline Brakes & & $x$ & \\
\hline Exhaust system & & & $x$ \\
\hline Fuel storage & & & $x$ \\
\hline Final drive & $x$ & & \\
\hline Wheels and tires & $x$ & & \\
\hline Bumpers, fenders, and shields & $x$ & & \\
\hline Chassis electrical components & & $x$ & \\
\hline Accessories and tools & $x$ & & \\
\hline Fluids & & $x$ & \\
\hline
\end{tabular}


Table 3.2 Cost Allocation by Group and Subgroup for Conventional Vehicles

\begin{tabular}{|c|c|c|c|c|}
\hline \multirow[b]{3}{*}{ Vehicle Group and Subgroup } & \multicolumn{4}{|c|}{ Share of Vehicle Cost (\%) } \\
\hline & \multicolumn{2}{|c|}{ Subcompact } & \multicolumn{2}{|c|}{ Minivan } \\
\hline & Group & Subgroup & Group & Subgroup \\
\hline Body group & 34.25 & & 40.00 & \\
\hline Engine group & 16.00 & & 14.55 & \\
\hline Transmission group & 4.75 & & 4.32 & \\
\hline Chassis group & 22.00 & & 20.21 & \\
\hline Fuel storage & & 0.45 & & 0.41 \\
\hline Exhaust & & 0.95 & & 0.86 \\
\hline Steering & & 0.53 & & 0.46 \\
\hline Chassis electrical & & 0.62 & & 0.56 \\
\hline Brakes & & 2.24 & & 1.95 \\
\hline Suspension & & 3.94 & & 3.42 \\
\hline Frame & & 1.48 & & 1.29 \\
\hline Final drive & & 1.49 & & 1.29 \\
\hline Wheels and tires & & 6.16 & & 6.32 \\
\hline Bumpers and fenders & & 2.43 & & 2.12 \\
\hline Accessories and tools & & 0.14 & & 0.11 \\
\hline Fluids & & 1.57 & & 1.42 \\
\hline Vehicle assembly & 23.00 & & 20.92 & \\
\hline Total & 100.00 & & 100.00 & \\
\hline
\end{tabular}

\subsection{The Impact of Body Materials}

Conventional vehicles are manufactured primarily from steel for most of the body and chassis components. Although the use of steel provides the required strength and rigidity at reasonable cost, steel is heavy and adds substantially to vehicle mass. Some lightweight materials could easily replace steel in selected nonstructural components; with proper design, they could also replace steel in structural components. Because these lightweight materials cost more and require specialized manufacturing techniques, their use would add to the vehicle cost. Thus, lightweight materials' contribution to reduced vehicle mass would have to be evaluated against the increase in vehicle cost. Electric vehicles depend on batteries for energy storage. Batteries are heavy and bulky compared with most liquid fuels, on the basis of energy content. To obtain adequate range, EVs usually require a large, heavy battery pack. Because increased mass has a strong negative effect on range and performance, it is highly desirable to achieve substantial mass reductions in EV body and chassis components to compensate for the additional mass of the battery pack. Aluminum and polymer composites (PCs) are two lightweight materials that are being considered as replacements for steel. The two are at different stages of development, with aluminum already being used by some manufacturers in selected vehicles.

The impacts of body materials have been analyzed in detail; the results of this analysis are summarized in Appendix A. Aluminum appears to be the leading lightweight material, with a potential to reduce $40-50 \%$ of the body mass for a modest cost increase. Polymer composites 
$\Delta$

have somewhat higher mass-reduction potential (55-60\%), but the projected raw material costs are very high, and production techniques for mass-producing PC bodies have not yet been adequately defined. Therefore, polymer composites are not considered ready for use in highvolume production vehicles. 


\section{Section 4 \\ Systems and Components for Electric Vehicles}

The typical EV uses many of the same types of systems and components as a CV, especially in the body and chassis. However, the powertrain of an EV is completely different, and its energy storage (replacing the fuel tank) becomes a major subsystem. The absence of a continuously running engine affects such accessory systems as heating, ventilation, and air-conditioning (HVAC), steering, and brakes and consequently requires independent (electric motor) drives for them. Moreover, the lack of waste heat (usually available to a CV from the engine) means that an alternative on-board energy source is needed to heat the passenger cabin. Below, we review the differences in system and subsystem requirements between the two types of vehicles.

\subsection{Energy Storage System}

The most likely EV energy storage system is a secondary or rechargeable battery. Primary batteries (such as aluminum-air and zinc-air) that use mechanical replacement of the depleting electrode have been proposed and even tried, but they are not considered to be ready for massproduced EVs. Other storage systems (including flywheels and ultracapacitors) are also being considered, but they are unlikely to replace batteries in the near term.

The battery storage system introduces a number of features that give EVs many of their peculiar characteristics. Batteries store a limited amount of energy per unit mass and volume, so they tend to be bulky and heavy. One gallon of gasoline with a mass of $2.84 \mathrm{~kg}(6.25 \mathrm{lb})$ has the chemical equivalence (low heating value) of $33.85 \mathrm{kWh}(115,540 \mathrm{Btu})$. In comparison, an advanced nickel-metal hydride battery is likely to have a specific energy of $100 \mathrm{~W} \cdot \mathrm{h} / \mathrm{kg}$ and an energy density of $190 \mathrm{~W} \cdot \mathrm{h} / \mathrm{L}$ (Kalhammer et al. 1995). A battery pack with the energy equivalent of 1 U.S. gallon (3.79 L) of gasoline would weigh about $746 \mathrm{lb}(339 \mathrm{~kg})$ and occupy a volume of about 47 gallons $(178 \mathrm{~L})$ or more, depending upon its design. Even if the EV were assigned an energy utilization advantage of 500\%, its energy storage system would still be about 24 times heavier and about 9-10 times bulkier than a CV's fuel tank. Consequently, EVs must dedicate a substantial volume to energy storage and possess the structural strength to carry the additional weight. These requirements pose a challenge to vehicle designers. The EV powertrain will likely be more compact than the CV powertrain, but the difference will not be large enough to alleviate the problem. Also, the additional weight of the batteries affects energy consumption negatively, thereby aggravating a difficult situation.

In the current EVs, the batteries are stored either in the central "tunnel" compartments (between the passengers) or underneath the floor of the passenger compartment. The body must be modified, both in shape and size, in either case. Empty areas have been found within the underbody frame of minivans and in the chassis frame of pickups, but space within the conventional passenger car is more fully utilized. If the design of the battery storage compartment requires additional materials and increases the number of body-group parts and components, it will increase the vehicle cost. One proposed solution is to make the battery storage compartment a major structural member of the body group. This concept has been used in 
few experimental designs (Sundancer, Endura, Elektrek, etc.). However, its ability to meet all the crashworthiness requirements is not proven. It may be more effective to design a strong box under the floor that will carry the batteries and also add strength and rigidity to the body. The practice of placing the batteries in the luggage compartment, so common in the current conversion EVs, is not viewed as an attractive option for EVs designed "from the ground up." EV designers are aware that, compared to the "three-box" (passenger cabin, engine compartment, trunk) CVs, the EVs have a fourth box in the energy storage system. The additional weight of the storage system also has implications for the body design, not only because of the extra load and crashworthiness requirements, but also in terms of a need for mass reduction (to compensate for the heavy battery). The body-in-white is the single largest component in a vehicle, accounting for about $25 \%$ of the mass of a CV. Therefore, it is a strong candidate for mass reduction through material substitution (aluminum or advanced polymer composites) and other possible means (improved design and new manufacturing processes). Some of the newer EV designs (Impact, Sunrise) are already exploring such approaches.

In summary, the body of an EV has to perform all the functions of a conventional vehicle body, but in addition, it must provide a generous amount of space to carry the batteries. There is also strong motivation to make the body lighter to offset the battery weight. Given some of the approaches being considered, the EV body would cost nearly the same as or slightly more than an equivalent conventional body of the same material. If a lightweight material were used for the body (aluminum or polymer composites), a similar cost premium would be incurred for both $\mathrm{CV}$ and EV bodies.

\subsection{Powertrain}

Aside from the energy storage system, the powertrain clearly differentiates the EV from the conventional vehicle. The electric powertrain is a fairly straightforward system, far simpler and much more compact than the equivalent IC engine powertrain. The $\mathrm{CV}$ powertrain requires not only the engine, but also a multispeed transmission, a cooling system, an exhaust system, an emissions control system, and a number of engine subsystems, such as the electrical system (cranking, ignition, etc.), intake, noise and vibration control, and electronic control. The EV powertrain essentially comprises just the electric motor, its electronic control system, and a single-ratio speed-reduction geartrain. In some EV conversions and some proposed EVs, the reduction geartrain provides more than one speed and an ability to reverse the direction. The latter is an arrangement for convenience, an alternative to changing the direction of rotation of the motor (which would be cumbersome for certain types of motors). Also, with the reversing ability switched to the geartrain, the motor can be optimized for efficient operation. In either case, a multispeed transmission is not needed; the electric motor has a more favorable speedtorque relationship than the IC engine, and consequently it is easier to cover the entire vehicle speed range with just one (reduction) gear ratio. It is customary to use the original multispeed transmission in current EV conversions, even though many of the gears are actually removed. On advanced motors designed specifically for EVs, the reduction geartrain is an integral part of the motor housing, thereby achieving significant cost and mass savings. Some motors may need a fluid cooling system, which is easy to accommodate. 
The main choice in the electric powertrain design is what type of motor and controller to use. Three types of motors are being seriously considered: direct-current (DC) commutated (the "conventional" approach for EVs), alternating-current (AC) induction, and DC-brushless. The conventional DC motor was the original choice of EV designers, but its higher cost, larger mass, slightly lower efficiency, and higher service requirements (the brushes tend to wear out and need to be replaced) compared to the other options (AC-induction and DC-brushless) make it less desirable. The AC-induction motor is extremely simple and rugged, is highly efficient, requires practically no service, is easy to cool, is produced in vast numbers, and is the least expensive to manufacture. No motor is ever perfect, however, and the AC-induction option is no exception; its main drawback is that it requires a very complex control system in order to operate from a DC source (batteries). Essentially, EV designers must compare the trade-offs between a simple motor and a complex controller vs. a more complex motor and a simpler controller. An interesting newcomer is the DC-brushless motor. The basic idea is to use permanent magnets for the poles of a DC motor and turn the motor inside out (field inside, becoming the rotor, and armature outside, becoming the stator). With a stationary armature, the commutation function can be done electronically, eliminating the brushes. Unfortunately, the execution of this relatively simple concept is not so easy, and the electronic controls required to make it function properly as a traction motor are just as complex and costly as those for the AC-induction motor. The main advantages of the DC-brushless type of motor are in size and mass, as well as (to some extent) efficiency. The main disadvantage is that it uses expensive permanent magnets, so reduction in mass comes at a price. One more drawback of the DC-brushless motor is that it is not in highvolume production for any application. Manufacturers are reluctant to make the necessary large investments in production facilities without an assured market.

\subsection{Power Systems and Accessories}

In a conventional vehicle, accessories requiring significant power to operate are usually mounted directly on the engine. The alternator, power-steering pump, air-conditioning compressor, and some of the radiator fans are engine-driven, usually through belt-and-pulley drives. Less power-hungry accessories, such as brakes, HVAC valves, etc., are often driven or actuated with vacuum from the engine intake manifold (or from an engine-driven vacuum pump, in the case of diesels). Because the engine runs continuously while the vehicle is in operation, power is available to all the accessories at all times. Those accessories that run intermittently, like the air-conditioning compressor, require a separate clutch control mechanism to regulate their operation.

In the case of an EV, however, because the traction motor does not operate continuously, it is not a convenient drive source for accessories. (The EV motor is turned off when the vehicle is stopped, whereas the $\mathrm{CV}$ engine remains on at idle.) Consequently, power accessories need their own independent drive. Although independent electric drives are generally more expensive than belt drives, they are easier to control and potentially can achieve additional energy savings. For instance, in conventional vehicles the power-steering pump runs continuously, consuming energy whether it is needed or not. Yet the steering system needs pressurized fluid only a small fraction of the time (when the front wheels are changing direction). Furthermore, the pump is oversized to provide the maximum flow rate at very low engine speed (during parking). In general, then, the steering pump is very inefficient at higher engine speeds (when it is least needed). Such an 
inefficient system is tolerated only because it is simple and cheap, and because the total amount of energy expended is not large. An electrically driven power-steering pump, which would be required in an EV, could easily be turned on or off as needed, greatly reducing energy consumption for power steering. With the addition of a pressurized fluid accumulator, the pump (and the driving motor) could be made significantly smaller, increasing the efficiency even more. This is the approach already taken with the radiator fan on most conventional passenger vehicles. The radiator fans used to be engine-driven, but they now use thermostatically controlled electric motor drives that can be easily regulated (used only as needed), with consequent energy and noise reductions.

Several systems and/or power accessories in the EV would require an independent (electric) drive or some alternative form of power. These include the power-steering system, power-brake actuator, air-conditioning compressor, battery temperature control system, and body and chassis electrical systems (lights, HVAC control, sound/entertainment, safety, controls, instruments and displays, small actuators, etc.). The air-conditioning compressor requires a fair amount of power (about 2-3 kW) and should probably have its own independent electric motor drive. Several options are available for actuating the power-steering and power-brake systems. If it is desired to retain the hydraulic foundation brakes and steering gear, an independent electric motor drive for the pumps becomes necessary. The fluid power supply for the brakes and steering systems can be combined into a central hydraulic system, as was first offered in the 1955 Citroen DS. If these systems are electrically actuated, the hydraulic components can be eliminated altogether.

Prototypes of direct electrical servo-systems for both the steering gear and foundation brakes exist, but they have not been used in production. Which approach is used will depend on the relative cost of both systems and on whether all-electric systems find applications in conventional vehicles. More than likely, early EVs will use more traditional, CV-type systems, and as volume increases they may shift to all-electric systems. The battery temperature control system is unique to EVs; its function is to avoid extreme temperatures within the battery. The relatively simple system involves a thermostatically controlled cooling fan and (possibly) resistance heaters. The heaters consume energy, but their use results in a net gain because battery efficiency decreases drastically in cold temperatures. Good insulation around the battery compartment reduces the amount of energy needed to increase its temperature when the environment is cold.

Conventional passenger vehicles use a central-type electric system, with an engine-driven alternator providing the power and a battery (or electric accumulator) providing the energy for starting, transients, and engine-off operation. Many different systems, subsystems, and individual components use this electric power, which is provided on a bus regulated at a nominal 12 volts, for operation. By definition, an EV has a big electric power system, but the voltage is different than that needed for powering normal vehicle components. It would be technically possible to develop components that operate at the main storage battery's voltage level, but it would make little economic sense, at least until EVs become the dominant form of road transport. It appears far more practical to provide a separate power supply, specifically a DC-to-DC converter, that would make $12-\mathrm{V}$ electric power available from the main source. All the normal electrically powered systems and components now available in a conventional vehicle would then be readily usable in EVs, regardless of the main storage system voltage. 


\subsection{HVAC System}

The HVAC system of an EV offers a particularly difficult challenge to designers.

Conventional vehicles have an ample source of waste heat from the IC engine available for cabin heating and windshield defrosting, but there is no equivalent source in the EV. The energy conversion processes, from chemical to electric and from electric to mechanical, are relatively efficient and do not produce much waste heat. The net result is that there is no high-temperature source to tap for cabin and windshield heat. Using energy from the main storage batteries to heat the cabin and windshield is wasteful and tends to have a very deleterious effect on vehicle range, so it must be avoided if at all possible. The solution currently proposed is to use the airconditioning system in reverse, as a heat pump. This concept, which is still far from ideal, implies that an air-conditioning system is available. Use of a heater that burns an auxiliary (liquid) fuel has also been proposed and may yet have to be adopted, especially in frigid climate zones, but it will certainly add cost, weight, and complexity.

The air-conditioning part of the HVAC system also poses problems; power requirements are large, and the consequent negative effects on traveling range are significant. In a conventional vehicle, ample power is available from the engine, and the negative effect on range is insignificant; as a result, the systems are sized for very rapid cooling, with high capacity and high power demand. On the EV, such large systems would be intolerable; high capacity implies a large compressor and motor, high cost, additional mass, and increased energy consumption. While CV air-conditioning systems can employ a "brute force" design, the approach for EVs must rely on cleverness and finesse because they cannot afford the additional energy, cost, and mass requirements. The proposed systems for EVs are usually smaller, and attempts are made to reduce heat loads through the use of high-reflection (coated) glass, better insulation, and precooling of the vehicle while it is still hooked to the charging system. Whether a combination of some or all of these approaches will result in a convenient, cost-effective system remains to be seen. As in the case of heating, the passenger compartment cooling system may require consideration of alternative approaches. One possible alternative is to employ evaporative cooling systems, which normally rely on the latent heat of the fluid to achieve a reduction in air temperature. Such systems are simple, reasonably effective, and energy-efficient, but they require appreciable amounts of fluid; they would add mass, together with the inconvenience of periodic refilling.

\subsection{Other Systems}

A few other EV systems or components are expected to differ from those of conventional vehicles. If ways are not found to decrease their total mass or to live with smaller (and consequently lighter) energy storage systems, EVs will be heavier than equivalent CVs. The additional mass would affect the EV's handling, ride, and braking. With respect to the suspension system, EVs would require larger springs and shock absorbers, and the overall system would need to be tuned appropriately. If EVs were not equipped with wheel motors (which add significant unsprung mass), their ride would be equivalent to or better than that of a comparable $\mathrm{CV}$. Higher mass would require better braking capacity. However, EVs could use regenerative braking, so they would not need bigger foundation brakes than those of CVs. Consequently, the braking system would not add cost or mass to the system. Regenerative braking, too, has some 
limitations; in particular, the foundation brakes must be sized to offer full capability when the battery is fully charged, without overreliance on regeneration.

In summary, several of the systems and subsystems in an EV would be different from those of the corresponding CV. The powertrain is entirely different, and so is the energy storage system. Most of the body components remain the same, but a body compartment will also be dedicated to the energy storage system. The challenge is to provide the necessary space with as little increase in total volume, mass, cost, and body complexity as possible. Within the chassis, many components require modifications, but with the exception of the HVAC system, these changes are not particularly troublesome. The power-steering and power-brake systems will have to use alternative forms of power (direct electric, or electric and hydraulic), and the foundation brakes must either be larger or supplemented by regenerative braking. An additional body-andchassis electric power system (DC-to-DC converter) will have to be used in lieu of the far more complex engine-driven system in CVs. The suspension system will have to accommodate the expected larger mass. Most of these differences are relatively minor and should not result in significant increases in cost, mass, or complexity. None of the HVAC systems tried or proposed so far give any indication of being fully acceptable in performance, energy consumption, cost, mass, and complexity. It is anticipated that some sort of compromise will have to be made, even if cost is removed as a barrier.

\subsection{Reference}

Kalhammer, F.R., A. Kozawa, C.B. Moyer, and B.B. Owens, 1995, Performance and Availability of Batteries for Electric Vehicles: Report of the Battery Technology Advisory Panel, California Air Resources Board, El Monte, Calif. 


\section{Section 5 \\ Cost Models for Traction Motors and Controllers}

Modern electric drive systems are so specialized and sophisticated that the two main elements, motor and controller, are specifically designed to operate with each other. Within the EV powertrain, therefore, the traction motor and its controller must be considered as one system. The typical electric drive includes not only the motor and controller, but also a gear drive that allows the motor to function at its best speed, which is usually much higher than that of the vehicle wheels. Most current drives have a one-speed fixed gear ratio, but two-speed drives also have been proposed. Electric drives do not require as many speeds as conventional vehicles, because the electric motor has a more favorable torque-speed relation (highest torque at lowest speed) than do reciprocating engines. As discussed earlier, EVs could have one of three types of traction motors: DC (both series and shunt), AC-induction, and DC-brushless (using permanent magnets). Controllers used with these motors are usually of the solid-state-electronic, pulsewidth-modulation (PWM) type, with metal oxide semiconductor field-effect transistors (MOSFETs) or insulated gate bipolar transistors (IGBTs) doing the switching. Because motors and controllers are not yet in volume production, it is necessary to develop a model to predict their cost in volume production. Simple cost models, for both motors and controllers of the various types of interest, are developed below.

\subsection{Overview of the Cost Model for Traction Motors}

The cost model for traction motors takes into account three types of designs: DC, ACinduction, and DC-brushless (permanent magnet). The approach taken to develop the cost model is as follows:

1. A representative motor of each type is selected for cost analysis.

2. Each motor is broken down into its main constituent elements.

3. The cost of each element is determined and related to a simple but meaningful parameter, such as mass $(\$ / \mathrm{lb})$.

4. The cost of the complete motor is then determined by adding the individual element costs, plus the cost of assembly and testing.

5. The cost for each motor is normalized on the basis of power delivered to obtain a perkilowatt cost for each design.

The objective of the model is to characterize the cost of traction motors for light-duty EVs and to allow the calculation of original equipment manufacturer (OEM) costs for the three types of motors. The OEM cost is defined as the price an OEM would pay to the supplier for motors and controllers produced in high volumes. It is assumed that the production of these components 
takes place under realistic, favorable economic conditions, with volumes high enough to justify a significant level of automation and full realization of raw-material volume discounts.

Traction motors of all three designs are capable of providing the necessary power and performance required by EVs. However, each motor type has different characteristics that may make an individual type better suited for a specific application. An AC-induction motor is simpler and cheaper to make, has high efficiency and relatively lower mass, but requires complex control systems. A DC motor is easier to control, somewhat heavier, more expensive, and slightly less efficient than an equivalent $\mathrm{AC}$-induction motor. A DC-brushless motor with rare-earth magnets is lighter and is just as efficient as an AC-induction motor; the former uses essentially the same type of controls, but it is more expensive. The traction motor normally operates at a maximum rotational speed of 6,000-15,000 rpm, while the final drive usually turns the vehicle wheels at a speed between 1,000 and 2,000 rpm. Therefore, a reduction drive is inevitable. Also, it is necessary to provide for independent motion of each driving wheel (right and left) in going around curves; consequently, a differential gear is usually included. The speed reduction geartrain is often designed to be an integral part of the traction motor because such an arrangement results in mass, space, and cost savings. The geartrain usually provides a speed reduction of 6-14:1. The lubrication system for the geartrain often doubles as the cooling system for the motor.

Below, each of the three motor types is analyzed at the component level to determine the nature, quantities, and costs of the materials from which they are made. The cost and amount of material are then normalized as a function of unit mass and delivered power. This constitutes a simple characterization, or model, of the given motor design at the component or material level. A series of parameters (in terms of cost, mass, and volume per unit power) are then calculated to characterize each motor type. These parameters provide estimates of cost, mass, and volume for a traction motor of a given type and power. Adjustments, at the component level, for changes in material prices, substitutions, or design changes can be made to further refine the estimate and to test the sensitivity of overall motor cost to changes in component costs.

\subsubsection{AC-Induction Motor}

The AC-induction motor, the most common electric motor, is widely used in industry. A typical AC-induction motor is shown in Figure 5.1. An AC-induction motor can be broken down into the following nine major components:

1. Stator core

2. Stator winding

3. Armature or rotor core

4. Rotor conductors (squirrel cage)

5. Shaft 
6. Frame or housing

7. End caps

8. Bearings and seals

9. Miscellaneous (speed, rotor position, and temperature sensors, plus fasteners and connectors, etc.)

Several motors that represent state-of-the-art AC-induction traction motors were examined for this analysis. This examination revealed that motors that were essentially identical in size and design could have different output ratings, depending on their operating system voltage.

However, the general design characteristics for this type of traction motor were fairly uniform, and most of the examples analyzed showed strong similarities. Consequently, to eliminate the problem introduced by the range of operating voltages, we assumed that high-voltage systems would eventually become the standard (as indicated by the present trend).

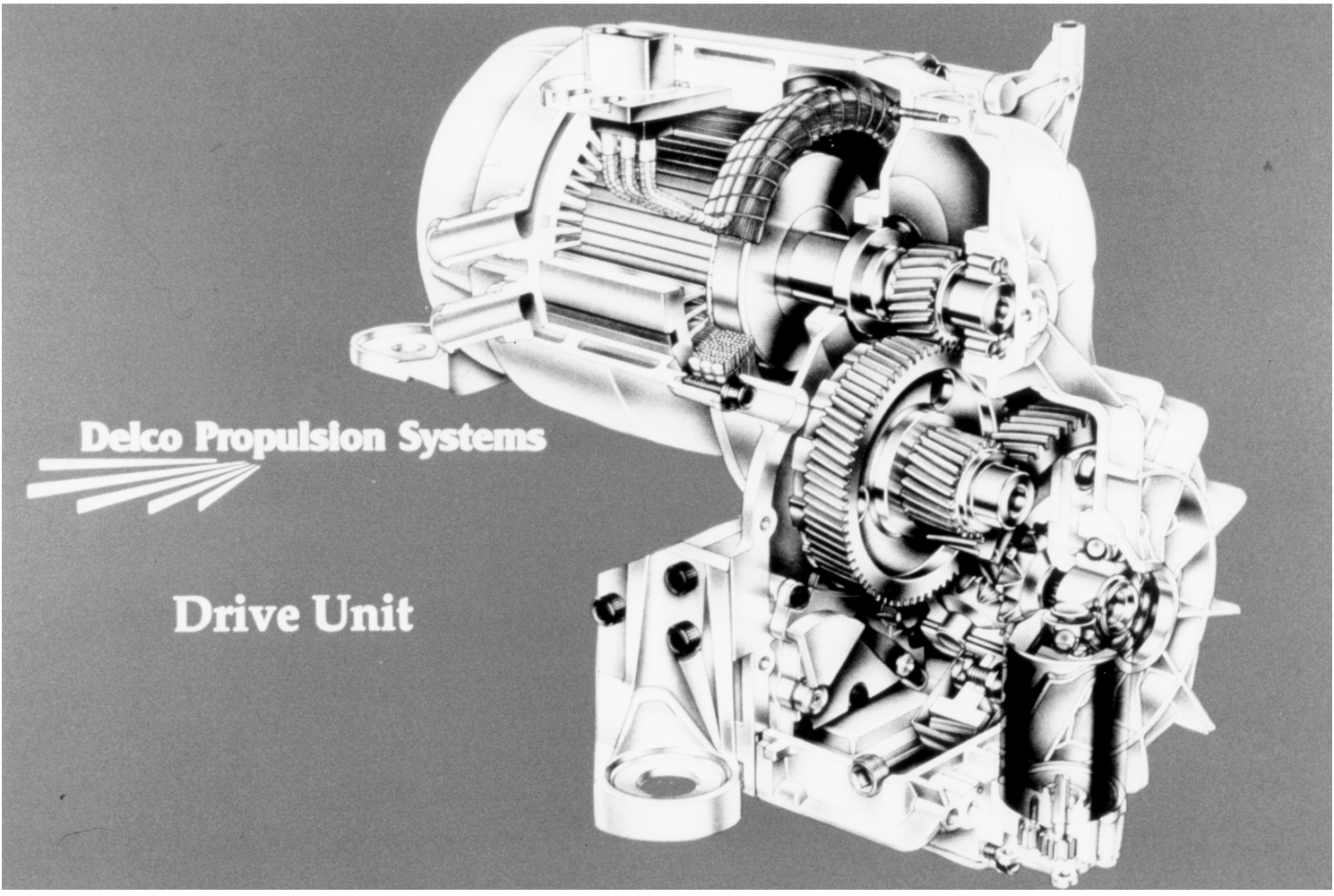

Figure 5.1 AC-Induction Motor (Source: Oswald and Skellenger 1994) 
The typical AC motor is assumed to have a $40-\mathrm{kW}$ continuous (67-kW intermittent) rating when operating at $300+\mathrm{V}$ (open circuit), 13,000-15,000 rpm maximum speed, with a "180" nominal frame size and a 7-in. stack length. Such a motor is usually made of cast aluminum with a squirrel-cage design and is cooled by either forced air or oil. The stator and rotor cores consist of stackings of silicon-steel laminations, stamped and welded together to form a unit. The frame or housing, made in two or three pieces from aluminum or magnesium, includes two bearings and a seal. The stator winding is made from magnet (copper) wire with class $\mathrm{H}$ insulation and includes a temperature sensor. The shaft is turned from cold-rolled steel and includes steps to accommodate the rotor core, the bearings, and a gear or a spline. A fairly accurate and relatively inexpensive (\$30-50) rotor position sensor is also needed. Table 5.1 provides a summary of component masses and costs for AC motors that are produced in high volume.

The assembly of the various motor components is relatively straightforward in high-volume production. The operation would be automated, with specialized tools and automatic equipment for welding, winding, machining, and other assembly tasks. Final assembly and test operations can be either manual or automated. The machining, assembly, and testing phase of the manufacturing is estimated to represent $30-40 \%$ of the total production cost. In addition, a $20 \%$ gross margin is added to arrive at the final OEM price. The final OEM cost estimates for this nominal $40-\mathrm{kW}$ AC-induction motor are provided in Table 5.2. Table 5.1 AC-Induction Motor: Material Content and Cost
of Components

\begin{tabular}{|lrrrrrrr|} 
& \multicolumn{2}{c}{ Mass } & & \multicolumn{3}{c|}{ Cost } \\
\cline { 2 - 3 } \cline { 5 - 7 } \multicolumn{1}{c}{ Component } & $(\mathbf{l b})$ & $\mathbf{( \% )}$ & & $\mathbf{( \$ )}$ & $\mathbf{( \% )}$ & $\mathbf{( \$ / l b )}$ \\
\hline Core laminations, stator & 51.0 & 44.6 & & $110.0^{\mathrm{a}}$ & 37.8 & 2.16 \\
Core laminations, rotor & 28.0 & 24.5 & & $60.0^{\mathrm{a}}$ & 20.6 & 2.14 \\
Field winding (copper) & 12.3 & 10.8 & & 25.0 & 8.6 & 2.03 \\
Housing (magnesium) & 7.3 & 6.4 & & 25.0 & 8.6 & 3.42 \\
Shaft & 7.0 & 6.1 & & 3.5 & 1.2 & 0.50 \\
Rotor conductor (aluminum) & 3.7 & 3.2 & & 7.5 & 2.6 & 2.03 \\
Miscellaneous & 5.0 & 4.4 & & 60.0 & 20.6 & 12.00 \\
Total & 114.3 & 100.0 & 291.0 & 100.0 & 2.55 \\
& & & & & \\
\hline
\end{tabular}

a Based on initial sheet material, not net after stamping.

b If made of aluminum, the housing's mass would be $11.5 \mathrm{lb}$ and its cost would be $\$ 20$ ( $\$ 1.75 / \mathrm{lb})$. 
Table 5.2 AC-Induction Motor: Estimated OEM Cost

\begin{tabular}{|lccc|}
\hline \multicolumn{1}{|c|}{ Cost Contributor } & $\begin{array}{c}\text { Avg. } \\
\text { Cost (\$) }\end{array}$ & $\begin{array}{c}\text { Avg. } \\
\text { Share (\%) }\end{array}$ \\
\hline Material cost & 291 & 291 & 53.9 \\
Assembly and testing (30-40\% of mfg. cost) & $125-194$ & 159 & 29.4 \\
Total mfg. cost & $416-485$ & 450 & 83.3 \\
Gross margin @ 20\% of mfg. cost & $82-97$ & 90 & 16.7 \\
OEM price & $498-582$ & 540 & 100.0 \\
& & & \\
\hline
\end{tabular}

\subsubsection{Conventional DC Motor}

The conventional DC motor is similar to the AC-induction motor, but it differs significantly in the stator design and requires a commutator and brushes to transfer electric power to the armature (rotor). A typical DC traction motor is shown in Figure 5.2. The major components of a DC motor are as follows:

1. Frame

2. Pole cores

3. Pole windings

4. Armature or rotor core

5. Rotor winding

6. Commutator

7. Shaft

8. Brushes and holders

9. End caps or flanges

10. Bearings and seals

11. Miscellaneous

The stator of a DC motor consists of an even number of poles or electromagnets (usually four), each with a core made from a stacking of silicon-steel laminations and a magnet wire (copper) winding. These poles are usually attached to a steel cylinder (the frame) with bolts. The nature of the pole windings is a function of the motor circuit, heavy wire with few turns for a series-type motor and fine wire with many turns for a shunt-type motor. Also, the housing or frame is part of the magnetic circuit, so it must be made from steel (not aluminum or 
magnesium). The rotor core and shaft are very similar to those of the AC motor, but the conductors are different, requiring a true magnet wire winding. Also, the winding is connected to a copper commutator press-fitted over the shaft. Although no rotor position sensor is needed, the additional parts make the DC rotor longer and heavier, as well as more complex and costlier to produce.

The power and torque-speed characteristics of DC motors differ from those of the ACinduction motor. For instance, a series-type DC motor normally can achieve an intermittent power level (for a short time) of more than three times its rated (continuous) power; AC motors achieve a peak (intermittent) power level that is only about twice the rated continuous power. Also, DC motors operate at much lower speeds $(6,000-7,000$ revolutions per minute $[\mathrm{rpm}])$ than do the equivalent $\mathrm{AC}$ motors (up to 15,000 rpm). Thus, the ratings of $\mathrm{AC}$ and $\mathrm{DC}$ motors are not directly equivalent, especially for EV applications, where peak power is a critical parameter. Even DC motors of various types have different torque-speed relations; shunt-wound DC motors have much less torque at low speed than do the corresponding series-wound motors. Therefore, one of the trends in DC-powered EVs is to use separately excited shunt-wound motors, where the voltage and current of the field are externally controlled (independent of the rotor), so the motor can have the best characteristics of both series and shunt designs over the entire operating range.

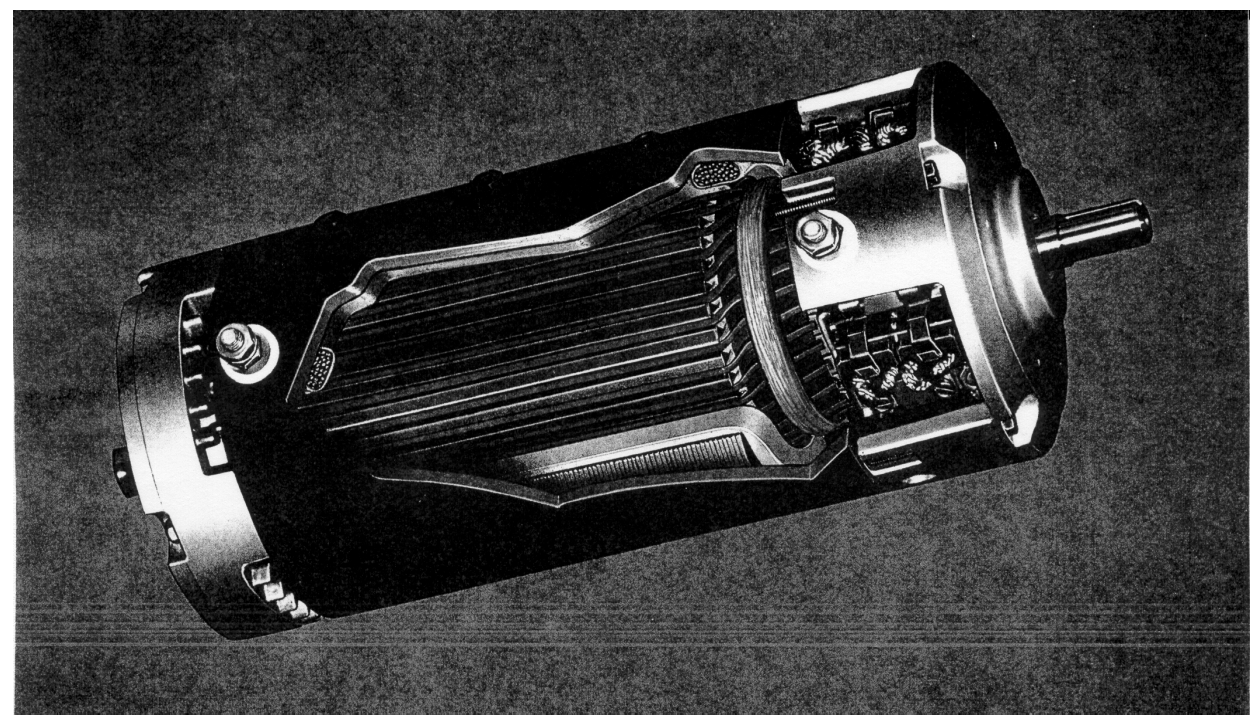

Figure 5.2 Conventional DC Motor (Source: Cuenca 1995) 
The DC series motor selected for analysis is rated at a much lower voltage (up to $144 \mathrm{~V}$ ) and develops much lower power at high speeds than does the AC-induction motor considered above. However, the former still can be considered almost equivalent, because of its high peak power at low speed. The peak (intermittent) power rating of the previously discussed AC motor is $67 \mathrm{~kW}$, while that of this sample DC motor is $52 \mathrm{~kW}$. The rated continuous power of the AC motor is $40 \mathrm{~kW}$, and that of the DC motor is only $20 \mathrm{~kW}$ (the motors are not even rated to the same standard; in fact, there are no standards at all for EV motor ratings). Taking the two performance levels into account, the DC motor could be considered to be at least $60 \%$ equivalent, and probably more like $70 \%$, because of the higher utilization at lower speeds. The particular DC motor analyzed was chosen primarily because its data were readily available. A larger, separately excited shunt-wound motor would have been preferred. However, the motor chosen is close enough in performance to the others that, with proper power correction factors, it would yield quite comparable results. Table 5.3 indicates component masses and costs for conventional DC motors.

The assembly of the DC motor is rather similar to that of the AC one. The main differences are that the armature is wound from magnet wire (instead of being die-cast aluminum) and that the winding must be soldered to the commutator. The pole windings, however, are far simpler than in the equivalent AC stator. Even though the DC motor is more complex and requires more operations to produce, the assembly and testing phase still represents $30-40 \%$ of the total manufacturing cost, because its material and part costs are also higher. As in the case of the AC motor, a 20\% gross margin is added to obtain the final OEM price. The final estimated OEM cost for this DC series motor is shown in Table 5.4.

Table 5.3 Conventional DC Motor: Material Content and Cost of Components

\begin{tabular}{|c|c|c|c|c|c|}
\hline \multirow[b]{2}{*}{ Component } & \multicolumn{2}{|c|}{ Mass } & \multicolumn{3}{|c|}{ Cost } \\
\hline & (lb) & $(\%)$ & $(\$)$ & $(\%)$ & $(\$ / l b)$ \\
\hline Core laminations, rotor & 33.3 & 23.4 & $85^{a}$ & 29.8 & 2.55 \\
\hline Core laminations, poles & 29.5 & 20.7 & $65^{a}$ & 22.8 & 2.20 \\
\hline Frame & 29.0 & 20.4 & 20 & 7.0 & 0.69 \\
\hline Armature winding & 10.3 & 7.2 & 21 & 7.4 & 2.04 \\
\hline Poles winding & 9.5 & 6.7 & 19 & 6.7 & 2.00 \\
\hline Commutator & 10.5 & 7.4 & 30 & 10.5 & 2.86 \\
\hline Shaft & 9.3 & 6.5 & 5 & 1.8 & 0.54 \\
\hline Housing (end-cap) flanges & 5.0 & 3.5 & 10 & 3.5 & 2.00 \\
\hline Miscellaneous & 6.0 & 4.2 & 30 & 10.5 & 5.00 \\
\hline Total & 142.4 & 100.0 & 285 & 100.0 & 2.00 \\
\hline
\end{tabular}

${ }^{a}$ Based on initial sheet material, not net after stamping. 
Table 5.4 Conventional DC Motor: Estimated OEM Cost

\begin{tabular}{|c|c|c|c|}
\hline Cost Contributor & Cost (\$) & $\begin{array}{c}\text { Avg. } \\
\text { Cost (\$) }\end{array}$ & $\begin{array}{c}\text { Avg. } \\
\text { Share (\%) }\end{array}$ \\
\hline Material cost & 285 & 285 & 53.7 \\
\hline Assembly and testing ( $30-40 \%$ of $\mathrm{mfg}$. cost) & $122-190$ & 156 & 29.6 \\
\hline Total mfg. cost & $407-475$ & 441 & 83.3 \\
\hline Gross margin @ $20 \%$ of mfg. cost & $81-95$ & 88 & 16.7 \\
\hline OEM price & $488-570$ & 529 & 100.0 \\
\hline
\end{tabular}

\subsubsection{DC-Brushless Permanent Magnet Motor}

The DC-brushless permanent magnet (PM) motor is quite different from both the ACinduction and conventional DC motors. It is basically a DC motor, in which the poles are replaced with permanent magnets (PMs) and the stator and rotor trade places. Consequently, the magnetic field, which is usually on the stator, is supplied through permanent magnets on the shaft, with the stationary armature surrounding it. This configuration eliminates the commutator and brushes, hence the term "DC-brushless." One popular type of DC-brushless motor is shown in Figure 5.3. The main components of such a motor are as follows:

1. Rotor

2. Magnets

3. Attachment band

4. Shaft

5. Stator core

6. Stator winding

7. Housing

8. Miscellaneous

This type of motor operates optimally with a large number of poles (usually 16 or 18); therefore, it tends to be larger in diameter, but shorter, than conventional motors of equivalent power. In this design, the rotor is just a steel drum with a shaft, and the permanent magnets (made from neodymium-iron-boron) are mounted on its periphery and held securely by a thin titanium attachment band. The stator has a conventional, but rather large-diameter, core made from laminations or from a sintered powder metal. Its winding is conventional and made from magnet wire. A simpler, cheaper rotor position sensor (compared with that used in induction motors) is needed; usually, this would be a Hall-effect device. The housing, which is usually 
made from aluminum, includes the bearings, seals, connectors, etc. It also includes fins if it is aircooled, or internal fluid passages if it is liquid-cooled.

The specific motor analyzed is rated at $32-\mathrm{kW}$ continuous and $53-\mathrm{kW}$ intermittent power. It operates with a recommended battery voltage of $270-336 \mathrm{~V}$, and its maximum speed is $8,000 \mathrm{rpm}$. Its power-speed relation is rather flat compared to the two previously discussed motors (specifically, the conventional DC motor). The DC-brushless motor is relatively light and shows good efficiency, which peaks at medium speeds. Analyzing the individual elements of the motor for mass, material content, and cost, we obtain the results shown in Table 5.5.

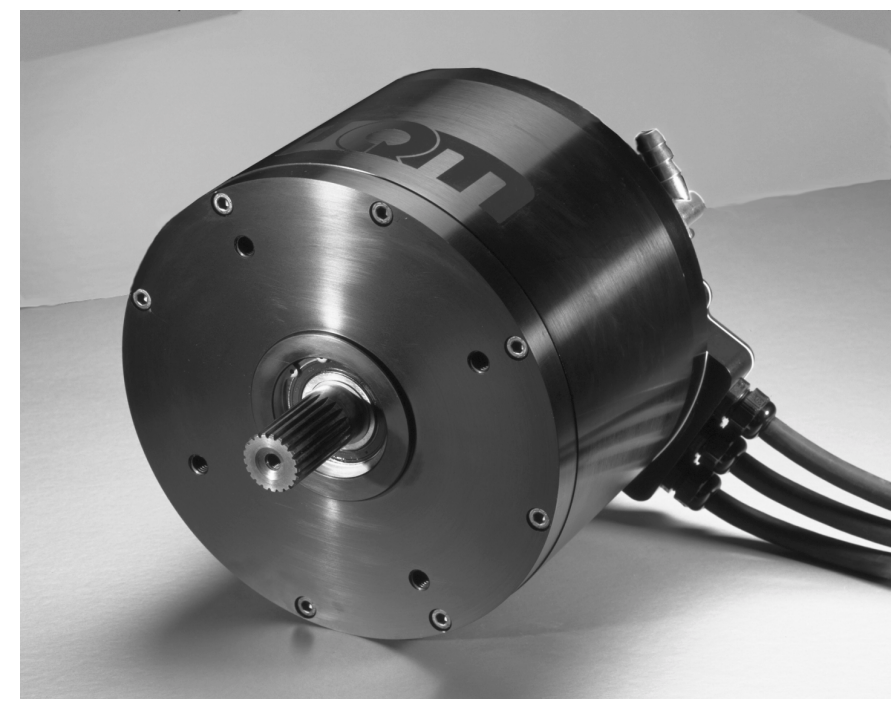

Figure 5.3 DC-Brushless Motor (Source: Unique Mobility, Inc. Used with permission)

Table 5.5 DC-Brushless Motor: Material Content and Cost of Components

\begin{tabular}{|c|c|c|c|c|c|}
\hline \multirow[b]{2}{*}{ Component } & \multicolumn{2}{|c|}{ Mass } & \multicolumn{3}{|c|}{ Cost } \\
\hline & (Ib) & (\%) & $(\$)$ & $(\%)$ & $(\$ / l b)$ \\
\hline Stator core & 24.0 & 27.4 & $68^{a}$ & 17.4 & 2.83 \\
\hline Stator winding & 11.0 & 12.6 & 22 & 5.6 & 2.00 \\
\hline Housing & 21.0 & 24.0 & 50 & 12.8 & 2.38 \\
\hline Rotor & 16.0 & 18.3 & 26 & 6.7 & 1.63 \\
\hline Magnets & 3.5 & 4.0 & 175 & 44.9 & 50.00 \\
\hline Attachment band & 0.5 & 0.6 & 6 & 1.5 & 12.00 \\
\hline Shaft & 5.5 & 6.3 & 3 & 0.8 & 0.55 \\
\hline Miscellaneous & 6.0 & 6.8 & 40 & 10.3 & 6.67 \\
\hline Total & 87.5 & 100.0 & 390 & 100.0 & 4.46 \\
\hline
\end{tabular}

a Based on initial sheet material, not net after stamping. 
The assembly of the DC-brushless motor is different from that of the AC or conventional DC motors. The stator is somewhat similar, the rotor is totally different, and the magnet attachment process is unique. Since the DC-brushless motor uses more expensive material but has fewer parts to assemble, this phase of the manufacturing operation should be less expensive. Consequently, assembly and test cost is assumed to represent only 20-30\% of the total production cost. A $20 \%$ gross margin is also added to obtain the final OEM price. The final estimated OEM cost for this motor is shown in Table 5.6.

Table 5.6 DC-Brushless Motor: Estimated OEM Cost

\begin{tabular}{|c|c|c|c|}
\hline Cost Contributor & Cost (\$) & $\begin{array}{c}\text { Avg. } \\
\text { Cost (\$) }\end{array}$ & $\begin{array}{c}\text { Avg. } \\
\text { Share (\%) }\end{array}$ \\
\hline Material cost & 390 & 390 & 62.2 \\
\hline Assembly and testing (20-30\% of mfg. cost) & $97-167$ & 132 & 21.1 \\
\hline Total mfg. cost & $487-557$ & 522 & 83.3 \\
\hline Gross margin @ 20\% of mfg.cost & $97-111$ & 104 & 16.7 \\
\hline OEM price & $584-668$ & 626 & 100.0 \\
\hline
\end{tabular}

\subsubsection{Summary of Motor Cost Analysis}

The results of the cost analysis for the three traction motors are summarized in Table 5.7, which provides previously computed mass values and cost ranges. Some physical attributes of the motors are listed, and estimates of average cost and cost per kilowatt are given at the bottom.

Table 5.7 Comparison of Attributes and Costs for Three Traction Motors

\begin{tabular}{|c|c|c|c|c|}
\hline Attribute Type & Attribute & $\begin{array}{c}\text { AC- } \\
\text { Induction }\end{array}$ & $\begin{array}{c}\text { DC-Series/ } \\
\text { Shunt }\end{array}$ & $\begin{array}{c}\text { DC- } \\
\text { Brushless }\end{array}$ \\
\hline \multirow[t]{4}{*}{ Physical } & Length (in.) & 14 & 15.6 & 9 \\
\hline & Diameter (in.) & 8 & 9 & 11 \\
\hline & Volume (in. ${ }^{3}$ ) & 703 & 992 & 855 \\
\hline & Mass (lb) & 115 & 142 & 87.5 \\
\hline \multirow[t]{2}{*}{ Power } & Maximum (kW) & 67 & 52 & 53 \\
\hline & Specific power (W/lb) & 583 & 366 & 606 \\
\hline \multirow[t]{3}{*}{ Mfg. cost } & Material cost $(\$)$ & 291 & 285 & 390 \\
\hline & Assembly and testing (\$) & $125-194$ & $122-190$ & $97-167$ \\
\hline & Total $(\$)$ & $416-485$ & $407-475$ & $487-557$ \\
\hline Overhead and profit & Gross margin (\$) & $82-97$ & $81-95$ & $97-111$ \\
\hline \multirow[t]{2}{*}{ OEM cost } & Cost range $(\$)$ & $498-582$ & $488-570$ & $584-668$ \\
\hline & Average $(\$)$ & 540 & 529 & 626 \\
\hline \multirow[t]{3}{*}{ Other } & Cost per peak kilowatt $(\$)$ & 8.1 & 10.2 & 11.8 \\
\hline & Mass per peak kilowatt (lb) & 1.7 & 2.7 & 1.65 \\
\hline & Volume per peak kilowatt (in. ${ }^{3}$ ) & 10.5 & 19.1 & 16.1 \\
\hline
\end{tabular}


The cost model resulting from this analysis makes use of the parameters listed in Table 5.7 to estimate the cost, mass, and bulk of a traction motor of a given type and power. The calculations can then be fine-tuned with the fractional (percent) distribution of the cost and mass of the elements of each motor type. While it is not always true that the power of a motor is a direct function of its mass, the two variables are related (Levi and Panzer 1974). Over a small range of power, the error introduced by our implicit assumption of linearity is very small, and the use of the model for prediction of cost and mass parameters for EV traction motors $(30-80 \mathrm{~kW}$ or so) should be adequate. The examples below explain the procedure.

The characteristics of a DC-brushless motor with $67-\mathrm{kW}$ peak power are computed first:

Cost: $\quad$ From Table 5.7, the cost per kilowatt for such a motor is $\$ 11.80$; applying this rate to $67 \mathrm{~kW}$, the cost would be $\$ 11.80 \times 67=\$ 791$

Mass: $\quad$ From Table 5.7, the mass per kilowatt for such a motor is $1.65 \mathrm{lb}$; the mass of a $67-\mathrm{kW}$ motor would be $1.65 \mathrm{lb} \times 67=111 \mathrm{lb}$

Volume: From Table 5.7, volume per kilowatt for such a motor is $16.1 \mathrm{in}^{3}$; the volume of a $67-\mathrm{kW}$ motor would be 16.1 in. $^{3} \times 67=1,079$ in. $^{3}$

We can also estimate what the cost of this motor would be if the price of permanent magnets were to drop from $\$ 50 / \mathrm{lb}$ to $\$ 30 / \mathrm{lb}$ :

From Table 5.6, the cost of permanent magnets constitutes $44.9 \%$ of the material cost.

A reduction in the permanent magnet cost from $\$ 50 / \mathrm{lb}$ to $\$ 30 / \mathrm{lb}$ represents a $40 \%$ drop, which translates into $0.4 \times 0.449=0.18$, or $18 \%$ of material, and $0.18 \times 0.622=0.112$, or $11.2 \%$ reduction in the OEM cost.

The new OEM cost of the 67-kW motor considered above would be $\$ 791 \times$ $(1-0.112)=\$ 702$.

\subsection{Motor Controllers}

The electric vehicle normally employs a controller to regulate the torque and/or the speed of the traction motor. The motor controller allows the vehicle's driver to vary the torque of the traction motor at will. The traction motor of an untethered EV (i.e., one not connected to an external power supply similar to that for electric trains and streetcars) runs on the internal electric power supplied by the storage system, usually a battery pack. Batteries are essentially constant-voltage devices (although the actual voltage at the terminals is a function of current demand and state of charge, depending on battery type). Therefore, the function of the controller is to vary or modify the basic system (battery) voltage so that the motor receives the appropriate amount of current needed to generate the amount of torque desired by the driver. Because current-torque relationships and torque-speed relationships differ for different types of motors, a given controller must be tuned to the specific needs of the motor in use. However, the basic 
principle of control - varying either the voltage (DC motors) or the voltage and/or frequency (AC motors) - is always the same.

\subsubsection{Motor Controllers}

Batteries are DC devices, so it is not surprising that DC motors powered all early EVs. A DC traction motor is relatively easy to control, especially if it is of the series-wound type. Varying the voltage applied to the motor terminals provides an effective means of torque control. The torque-speed relation of this motor is quite favorable for typical driving. When torque demand increases, the motor slows down; this tends to increase the output torque, resulting in very stable and controlled operation. However, its operation during regenerative braking is a different story. In the early days of EVs, applied voltage was controlled by such mechanical means as rheostats and battery bank switches, but with the advent of solid-state electronics, it became possible to control voltage efficiently by the method known as "pulse width modulation" (PWM). In this system, the steady DC voltage is "chopped" into a series of pulses (essentially, turned on and off rapidly), and the duration of the "on" and "off" segments of each pulse is carefully regulated to obtain the desired "pulse width." The net result is a controlled, rapidly discontinuous DC "system" voltage, which to a given electrical device appears similar to a steady DC input of lower voltage. Essentially, the electrical device averages out the pulsed input, and the result is an effective average (actually integrated, or root mean square) voltage that is a function of the relative width of the on and off segments of the power pulses. With their use of solid-state elements (silicon control rectifiers, thyristors, MOSFETs, IGBTs, etc.) as high-speed switches, PWM-type motor controllers quickly became the preferred solution for practically all EVs, including industrial vehicles (such as forklift trucks).

Although DC motors in general, and series-wound DC motors in particular, have characteristics that make them easier to apply and control in EVs, they have some disadvantages. DC motors do not reverse direction simply by reversing motor lead polarity; one has to reverse the current flow of the field relative to the armature. Although reversing current flow is not a big problem, it requires more complex high current switching. Because they are unstable when run as generators, series-wound motors cannot be used when regenerative braking is desired. Also, this type of machine tends to speed up excessively, or "overspeed," when the load is reduced to zero. These problems, however, can be reduced or eliminated by changing the field winding to a parallel or shunt configuration. Shunt-wound DC motors run well as generators, and their speed is almost constant with load (eliminating the overspeeding problem at low loads), but they do not match the vehicle torque-speed requirements as well as the series motors. The best compromise for an EV is to use the shunt-wound configuration, but control the field independently of the armature. This requires a more complex control system, but it removes the overspeeding danger and allows regenerative braking (with more complex controls); it also practically duplicates the performance of series motors, with only a modest loss in maximum starting torque.

\subsubsection{AC Motor Controllers}

The technology that made DC motor control via applied voltage far more efficient also made it possible for AC motors to become an alternative for battery-powered EVs. AC-induction motors have many advantages that make them very desirable for EV operation, but the very 
complex problem presented by operating from a DC power source (battery) had made their use impractical in the past. Several steps are required to make a three-phase AC-induction motor operate from a battery source. First, the steady direct current must be converted into three-phase alternating current. This requires a high-frequency chopper, or rather three choppers - one for each phase, each similar to the one used in the DC motor controller. However, the power pulses must now vary in width periodically (while also switching the voltage to opposite sides to simulate the reversal of polarity) in order to simulate the sinusoidal shape of the AC pulses. Three such choppers, working 120 degrees out of phase, provide an output that is reasonably equivalent to three-phase AC power. The devices that can modify DC power in such a fashion are called inverters. While this power output would indeed run a three-phase AC-induction motor, it must do more in order to control the speed as required in vehicle operation. Induction motors are essentially constant-speed machines, with the revolutions per minute (rpm) being a function of the number of poles and the frequency of the alternating current. Therefore, in order to control the speed of the motor, it is necessary to vary the frequency of the inverter output. Similarly, in order to control the torque, it is necessary to vary the amplitude of the voltage wave. As a result, the controller for an AC-induction traction motor is based on a variable-frequency, variable-amplitude solid-state inverter. Such a device is necessarily rather complex, especially when all the required protection and high-frequency noise-control equipment are taken into account. As a result, most modern AC-induction motor controllers use specially built microprocessors that incorporate all the commutation, triggering, oscillator timing, and other control functions, as well as logic circuits to protect the motor from (externally sensed) fault conditions.

\subsubsection{Cost Model for Motor Controllers}

The typical solid-state traction motor controller would have the following elements:

1. Microprocessor control board

2. Driver stage board (for solid-state switches)

3. Power (switching) module

4. Auxiliary DC-to-DC converter

5. Current sensor

6. Ripple capacitors

7. Hardware, chassis, and cooling devices

The controller is housed in a box with the necessary chassis, connectors, cooling devices (fans, heat sinks, etc.), and other mechanical hardware required for the electronic components to function. All the logic and externally sensing and controlling functions are included in the control board, which includes the connections to all the external sensors and controls, such as manual switches and the accelerator pedal position sensor (potentiometer). The driver stage 
board includes all the discrete electronic elements needed to integrate the firing circuits for the solid-state switches. The actual solid-state switches usually consist of IGBT modules (three for a DC motor, six for an AC motor), connected in a bridge circuit, with the high current (input) connections to the battery and (output) to the motor. The current sensor is a simple component, but its high current rating makes it fairly expensive. The ripple capacitors, used to recover and control some of the higher-frequency current pulses, are fairly large and, thus, costly. Finally, the auxiliary DC-to-DC converter is a simple, relatively low power inverter used to condition the auxiliary system voltage so that the various electrically powered low-voltage accessories in the vehicle can function properly.

The cost of these individual elements can be estimated rather easily, because most are already in high-volume production, except that a few (IGBTs in particular) are not in as highvolume production as they would be if EVs themselves were in high-volume production. A set of estimated high-volume costs of individual components for a controller for a 70-kW motor is shown in Table 5.8 .

Table 5.8 Estimated Cost of Components for 70-kW
DC and AC Controllers
\begin{tabular}{|lcc|}
\hline & \multicolumn{2}{c|}{ Cost $\mathbf{( \$ )}$} \\
\cline { 2 - 3 } & DC & AC \\
\hline \multicolumn{1}{|c}{ Controller Element } & 100 & 100 \\
Microprocessor control board & 80 & 80 \\
Driver stage board (for solid-state switches) & $200-300$ & $400-600$ \\
Power switching module & 70 & 70 \\
Auxiliary DC-to-DC converter & 100 & 100 \\
Current sensor & 50 & 50 \\
Ripple capacitors & 100 & 100 \\
Hardware, chassis, and cooling devices & $700-800$ & $900-1,100$ \\
Total cost & & \\
\hline
\end{tabular}

In addition to the basic component cost, the complete controllers would have to be assembled and tested. Also, if an independent supplier (as expected) performs this operation, his reasonable profit margin would have to be included. The estimated cost of assembly and testing (including labor and plant overhead) is about $\$ 100$ per unit, and the gross profit margin (including recovery of tooling, design and development, etc.) would be in the $20 \%$ range. The resulting OEM high-volume costs of the controllers are summarized in Table 5.9. 


\section{Table 5.9 Estimated OEM Cost of 70-kW DC and AC Controllers}

\begin{tabular}{|lcc|} 
& \multicolumn{2}{c|}{ Cost (\$) } \\
\cline { 2 - 3 } \multicolumn{1}{c}{ Cost Contributor } & DC & AC \\
\hline Component costs & $700-800$ & $900-1,100$ \\
Assembly cost & 100 & 100 \\
Total mfg. cost & $800-900$ & $1,000-1,200$ \\
Supplier's margin @ 20\% & $160-180$ & $200-240$ \\
Total OEM cost range & $960-1,080$ & $1,200-1,440$ \\
Cost range per kilowatt & $13.7-15.4$ & $17.1-20.6$ \\
& & \\
Average cost & 1,020 & 1,320 \\
Average cost per kilowatt & 14.6 & 18.9 \\
& & \\
\hline
\end{tabular}

The estimates in the table indicate that the controller, as currently envisioned, will be a fairly expensive component for EVs. Also, the cost for the conventional DC motor controller will be lower than for the corresponding AC motor controller, primarily because fewer high-power switches (IGBTs) are required.

From the individual component costs shown in Tables 5.8 and 5.9, it is easy to see that the OEM cost of the complete controller is dominated by the high-power switching elements, which constitute about $40 \%$ of the total for AC and $25 \%$ for DC. The costs of some of these components (electronic switches, ripple capacitors, etc.) are functions of power capacity, while many others are not (microprocessor board, etc.). Therefore, the controller cost is not a very direct function of rated capacity. Also, it is likely that at a few discrete power ratings, the cost would be more competitive because of the components' proper sizes (their capacity fully utilized). Because the microprocessor and other related components have nearly fixed costs, a favorable cost bias toward higher capacity controllers is likely to develop. The biggest factor affecting the cost of motor controllers, however, would be the cost of the basic power switching elements (IGBTs, etc.). It is still not clear from the available information what the cost of these elements will be in the future. These elements are already produced at high volume, so the potential for further cost reduction related to manufacturing scale may not be significant. On the other hand, the automotive industry is well known for inducing suppliers to make cost reductions when none seem possible. Taking all these factors into consideration, one could speculate that, barring a new development that introduces new and inherently lower-cost technology, motor controllers for EVs would remain high-cost items, on the order of \$1,300 for AC motors and $\$ 1,000$ for DC motors.

\subsection{References}

Cuenca, R.M., 1995, "Simple Cost Model for EV Traction Motors," in Proceedings of the Second Annual World Car Conference, University of California at Riverside, Calif., Jan. 22-24, 1995, pp. 214-229. 
Levi, E., and M. Panzer, 1974, Electromechanical Power Conversion, Dover, New York, N.Y., p. 136.

Oswald, L.J., and G.D. Skellenger, 1994, "General Motors Corporation Research and Development Center Hybrid Propulsion Systems Development Program," in Proceedings of the Annual Automotive Technology Development Contractors' Coordination Meeting 1994, Dearborn, Mich., Oct. 22-24, 1994, sponsored by U.S. Department of Energy, Society of Automotive Engineers Publication P-289, pp. 57-69. 


\section{Section 6 Costs of EV Battery Production}

Although much has been written about the performance characteristics of batteries for electric vehicles, information about the materials and their production costs is less readily available. The designs and processes are still in flux, and much of the information is proprietary. However, studies of health and environmental effects provide some useful data on battery materials, and material costs can be estimated. This section summarizes available information on the materials costs and total costs of four types of advanced electric vehicle batteries: advanced lead-acid ( $\mathrm{Pb}$-acid), sodium-sulfur (Na-S) nickel-cadmium (Ni-Cd), and nickel-metal hydride (Ni-MH). These are the battery types for which the best information is available; they are most likely to be available in the near term. Some features of these batteries are shown in Table 6.1, including estimated costs for the major materials.

Table 6.1 Battery Comparisons

\begin{tabular}{|c|c|c|c|c|}
\hline Item & Pb-Acid & $\mathrm{Na}-\mathrm{S}$ & $\mathrm{Ni}-\mathrm{Cd}$ & Ni-MH \\
\hline Electrode materials & Lead on fiberglass mesh & $\begin{array}{l}\text { Molten sodium and } \\
\text { sulfur }\end{array}$ & $\begin{array}{l}\text { Nickel hydroxide } \\
\text { and cadmium/iron }\end{array}$ & $\begin{array}{l}\text { Nickel hydroxide } \\
\text { and metal hydride }\end{array}$ \\
\hline Electrolyte & Sulfuric acid & $\begin{array}{l}\text { Beta alumina } \\
\text { ceramic }\end{array}$ & $\begin{array}{l}\text { Potassium } \\
\text { hydroxide }\end{array}$ & $\begin{array}{l}\text { Potassium } \\
\text { hydroxide }\end{array}$ \\
\hline $\mathrm{E}$ density $(\mathrm{W} \cdot \mathrm{h} / \mathrm{kg})$ & 50 & 100 & 57 & 75 \\
\hline Weight for $25 \mathrm{kWh}(\mathrm{kg})$ & 500 & 250 & 439 & 330 \\
\hline Material cost $(\$ / \mathrm{kWh})$ & $13-16$ & $635-794$ & $139-188$ & $104-263$ \\
\hline Significant emissions & Lead particulates & $\begin{array}{l}\text { Iron oxide } \\
\text { particulates }\end{array}$ & Cadmium fumes & Unknown \\
\hline Comments & $\begin{array}{l}\text { Can use existing } \\
\text { infrastructure, requires } \\
\text { replacement }\end{array}$ & Operates at $350^{\circ} \mathrm{C}$ & Cd easy to recycle & $\begin{array}{l}\text { MH recycling } \\
\text { process unknown }\end{array}$ \\
\hline
\end{tabular}

The batteries will make up a significant fraction of the vehicle mass ( 20-40\%) and cost. The impact is magnified because some of the batteries are expected to have shorter lifetimes than the vehicles, and therefore will need to be replaced at least once. The electrode and electrolyte materials for all types except advanced lead-acid are nonstandard automobile materials (although some cadmium has been used in coatings and pigments), for which little information is available. However, a significant fraction of the battery mass is made up by casings, separators, and connectors, which are generally made of more common materials, such as steel and polypropylene. Since these are well characterized, the uncertainty in battery material costs is reduced.

\footnotetext{
${ }^{1}$ Since this writing, development of sodium-sulfur batteries has been discontinued.
} 


\subsection{Battery Materials and Their Costs}

Materials are the key cost element for most batteries. Argonne has previously estimated the material composition of these battery types in order to determine energy requirements and emissions from production and recycling (Gaines and Singh 1995). In this analysis, we take the previously determined material compositions and use them to estimate the costs of battery materials. Some of the materials are standard commodities for which prices are known, although they may fluctuate with market conditions; others are new products, and their price can be expected to come down as processes and infrastructure for their production are developed. Supply is another important consideration for future prices of some battery materials. Since this information was compiled, more detailed material price information has become available for $\mathrm{Pb}$ acid and Ni-MH batteries; the interested reader is referred to Lipman (1999).

Technical descriptions of battery designs and materials, as well as cost information for specific materials, can be found in Appendix B.

\subsection{Total Costs}

Total costs include materials plus manufacturing, overhead, etc. Numerous investigators have provided estimates of costs, but there is a large range because of uncertainties and because of differences in designs, materials, and processes considered. In addition, different bases, not always specified, are used, including time frame, stage of development, and, most important, production scale. These factors all have large impacts on the projected costs. Most of the estimates are presented only as totals, with no breakdown. Sometimes the assumed production scale or state of technological development is specified, but not always. One source did break the costs down by contributions for three of the battery types (assuming technical advances and high volume production; see Table 6.2), and another estimated materials for one battery type in some detail. Several insights can be obtained from the cost breakdown. First, as the largest single contributor to total cost, materials are the best target for cost reduction. There is a large variation in the absolute materials costs, but on a percentage basis these costs are less variable, constituting 50-70\% of the total battery cost. Manufacturing costs, which are not expected to differ greatly by battery type, represent a relatively small component of the total cost.

Table 6.2 Elements of Battery Cost $(\$ / \mathrm{kWh})$

\begin{tabular}{|lccl|}
\hline $\begin{array}{c}\text { Cost } \\
\text { Element }\end{array}$ & Na-S & Ni-Cd & $\begin{array}{c}\text { Sealed } \\
\text { Pb-Acid }\end{array}$ \\
\hline Materials & $110(60 \%)$ & $251(69 \%)$ & $47(50 \%)$ \\
Manufacturing & 22 & 14 & 21 \\
Overhead & 20 & 39 & 11 \\
Profit & 31 & 61 & 15 \\
Total & 183 & 365 & 94 \\
& & & \\
\hline
\end{tabular}

Source: Hirabayashi et al. 1992. Used with permission from ISATA, Epsom House, 10C East St., Epsom, Surrey, KT17 $1 \mathrm{HH}, \mathrm{U} . \mathrm{K}$. 
We compared cost estimates from the literature. The estimates are shown in Table 6.3, which also includes our estimates of the material costs and totals that could be inferred from them. The notation represents any information on the assumed production scale or stage of development.

Table 6.3 Estimates of Battery Costs $(\$ / k W h)^{a}$

\begin{tabular}{|c|c|c|c|c|}
\hline Source & Na-S & $\mathrm{Ni}-\mathrm{Cd}$ & Pb-Acid & Ni-MH \\
\hline Cooper and Moseley (1998) & & & $\{100\}$ & \\
\hline Kalhammer et al. (1995) & $\{1000\}[150]$ & $\{1000\}[300-350]$ & $\{300\}[120-150]$ & $\{450-500\}[150]$ \\
\hline Hirabayashi et al. (1992) & {$[183]$} & [365] & {$[94]$} & \\
\hline NREL web entry (1996) & & $600[110]$ & $125[75]$ & $540[115]$ \\
\hline $\begin{array}{l}\text { Klein and Salkind (materials) } \\
\text { (1993) }\end{array}$ & & & & 190 \\
\hline SAFT (1994) & & $\{800-900)[300]$ & & \\
\hline Cook and Morrow (1992) & 120 & 400 & 170 & \\
\hline Morrow (1994) & $\{2100\}[500]$ & $\begin{array}{c}\{900-1000\} \\
{[200-400 \text { or } 250]}\end{array}$ & $\begin{array}{l}\{400-800\} \\
{[200-400]}\end{array}$ & $\{3000\}[800]$ \\
\hline Varta (1995) & & & & $\{6500\} 300-500$ \\
\hline O'Connor (1993) & & & & [200] \\
\hline Auxer (undated) & {$[130-245]$} & & & \\
\hline Silent Power (undated) & {$[>200]$} & & & \\
\hline $\begin{array}{l}\text { EV Progress (1994)/ } \\
\text { Bus. Week (1994) }\end{array}$ & $200-1200$ & $525[350]$ & $70-200$ & $230-1000$ \\
\hline \multicolumn{5}{|l|}{ Estimate basis } \\
\hline Materials only & $\{630-790\}$ & $160-190$ & $13-16$ & $105-140$ \\
\hline Materials/0.6 & $\{1050-1317\}$ & $267-317$ & $22-27^{b}$ & $174-233$ \\
\hline Materials +150 & $\{780-940\}$ & $310-340$ & $163-166^{c}$ & $255-290$ \\
\hline
\end{tabular}

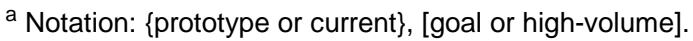

${ }^{b}$ Low material cost makes this method inappropriate for lead-acid batteries.

c Simple, established production methods dictate addition of a lower fixed amount for lead-acid batteries.

We used two estimation methods to convert materials costs to total costs. In the first, we assumed that raw materials constituted $60 \%$ of the total cost. A similar method was used by Klein and Salkind (1993) for Ni-MH batteries. They estimated that fabricated materials cost 1.5 times as much as raw materials, and that manufacturing batteries from the fabricated materials again multiplied the cost by a factor of 1.5 . The raw materials then constituted $44 \%$ of the final total cost. This method escalated the costs of battery types with high raw material costs much more (on an absolute basis) than those with low material costs, whereas actual manufacturing costs were likely to be more or less constant for all battery types. In the other estimation method, a fixed sum was added to the materials cost. Results of both estimation methods are included in Table 6.3. Because of the uncertainties and the reductions expected with $\mathrm{R} \& \mathrm{D}$, sensitivity to battery costs will be examined later. 
It is clear that the $\mathrm{Pb}$-acid battery is, and will remain, the least expensive one. The $\mathrm{Na}-\mathrm{S}$ battery would appear to be very expensive because of the high cost of the ceramic electrolyte, but there is no reason the cost cannot be significantly reduced. The Ni-Cd and Ni-MH batteries are less expensive, but they offer no prospect for large reductions in material costs. The expected decline of Ni-Cd costs with production volume is shown in Figure 6.1. Although there is a very large variation of cost estimates for each battery type, it is clear that only the advanced $\mathrm{Pb}$-acid battery (and perhaps the Na-S battery) would be likely to achieve the mid-term cost goal of $\$ 150 / \mathrm{kWh}$ set by the Advanced Battery Consortium (ABC). In comparing batteries, one should keep in mind that the $\mathrm{Pb}$-acid battery is likely to require one or more replacement(s) over the lifetime of the vehicle; therefore, its actual cost must be multiplied by at least two.

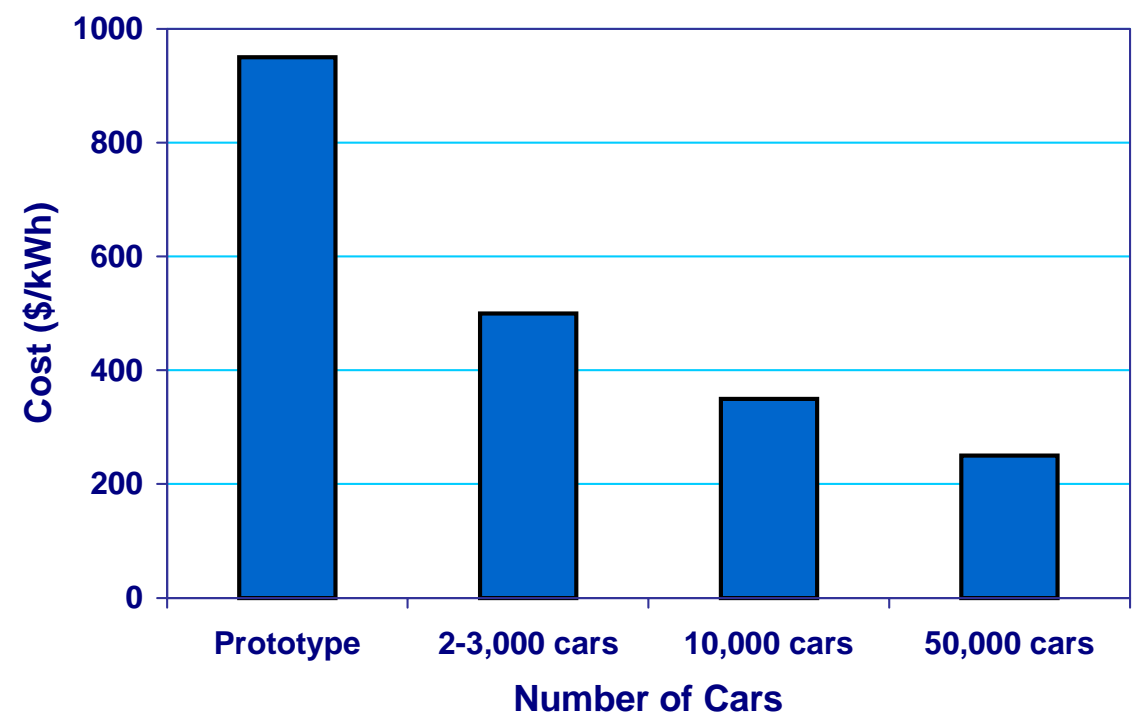

Figure 6.1 Nickel-Cadmium Battery Costs at Different Production Levels

The estimated total costs for these batteries can be compared to the total cost of the vehicles that will use them. If a canonical battery size of $25 \mathrm{kWh}$ is chosen (typical of a small car battery), the total cost of a battery pack would range from a minimum of $\$ 3,750$, if some technology could achieve the ABC goal, to $\$ 12,500$ (at $\$ 500 / \mathrm{kWh}$ ) or more. Because battery costs can be comparable with those of the rest of the vehicle, it is important to focus R\&D on both reducing battery costs and increasing battery lifetime, to minimize the number of battery replacements that will be required.

\subsection{References}

Auxer, W., undated, "Sodium Sulfur Battery — Status of Development," in Silent Power, Inc., press pack, Wayne, Penn.

Business Week, 1994 (May 30). 
Cook, M., and H. Morrow, 1992, "Market Prospects for Nickel-Cadmium Batteries in Electric Vehicles," Metal Bulletin Monthly (April).

Cooper, A., and P. T. Moseley, 1998, "Lead Acid Electric Vehicle Batteries — Improved Performance of the Affordable Option," Proceedings of the Fifteenth International Electric Vehicle Symposium and Exhibition, Brussels, Belgium.

Electric Vehicle Progress, 1994 (April 15).

Gaines, L., and M. Singh, 1995, "Energy and Environmental Impacts of Electric Vehicle Battery Production and Recycling," SAE 1995 Total Life Cycle Conference and Exposition, Vienna, Austria (Oct. 6-19).

Hirabayashi, T., S. Furuta, and H. Satou, 1992, "Cost Estimation on Advanced Batteries for Electric Vehicle,” 1992 ISATA Proceedings, SAE Paper 920238.

Kalhammer, F.R., A. Kozawa, C.B. Moyer, and B.B. Owens, 1995, Performance and Availability of Batteries for Electric Vehicles: Report of the Battery Technology Advisory Panel, California Air Resources Board, El Monte, Calif.

Klein, M., and A.J. Salkind, 1993, "Design and Cost Analysis of a Nickel-Metal Hydride EV Battery," in Extended Abstracts, 183rd Electrochemical Society Meeting, Honolulu, Hawaii (May).

Lipman, T.E., 1999, The Cost of Manufacturing Electric Vehicle Batteries, University of California at Davis Report UCD-ITS-RR-99-5, Davis, Calif. (May).

Morrow, H., 1994, "Nickel-Cadmium Batteries: the Performance Choice for Electric Vehicles," $11^{\text {th }}$ International Seminar on Primary and Secondary Battery Technology and Applications, Deerfield Beach, Fla. (March 1).

National Renewable Energy Laboratory, "Hybrid Electric Vehicle Program: Batteries" [url http://www.hev.doe.gov/components/batteries.html (as of May 1996)], Golden, Colo.

O’Connor, L., 1993, "Energizing the Batteries for Electric Cars,” Mechanical Engineering, p. 73 (July).

SAFT, 1994, "SAFT Producing NiCads for EVs in the United States," Electric Vehicle Progress, p. 4 (Sept. 15).

Silent Power, Inc., undated, Breakthrough in Electric Vehicle Battery Technology, brochure.

Varta, 1995, "Varta R\&D on a Wide Range of Battery Types for EVs," Electric Vehicle Progress, 17(5):1 (March 1). 


\section{Section 7 \\ The Manufacture of Electric Vehicles}

Earlier in this report, it was indicated that the components of an EV that are expected to remain essentially the same as those of a conventional passenger vehicle account for about $70 \%$ of the total manufacturing cost (including assembly) of the base vehicle. Several of the systems that require substantial modifications (amounting to an additional 7\% of manufacturing cost) are still expected to share many components and/or processing steps with conventional vehicles. Therefore, the bulk of the manufacture of EVs will likely fall within the currently defined boundaries of the automotive industry, where the most cost-effective base for the production of those components exists. The so-called "EV industry," as we know it today, includes all the major conventional vehicle manufacturers and those who produce electric variants or conversions of conventional vehicles. An electrically powered passenger vehicle is still a passenger vehicle; the important question is how to make the truly different components - the motor, controller, and battery pack. It seems reasonable to anticipate that the traditional vehicle manufacturers will end up making the bulk of the vehicle and will outsource these three components.

Certainly, the conventional vehicle manufacturers are capable of assembling EVs, but if EV production volume is very low, they may not want to do so directly. An approach that is often taken with low-volume specialty vehicles and components, such as high-performance limited editions, sun roofs, T-tops, convertibles, etc. - is to have them made by independent contractor shops; the contractor takes a standard vehicle and makes the necessary additions or modifications. The most efficient way to obtain these outsourced modifications is by assembling a special "incomplete" vehicle that includes all the parts needed but excludes those that must be disassembled or removed in the conversion process. For example, when production of convertibles was resumed in 1982, the standard procedure was to send a fully assembled hardtop car to a contract modification shop, which would cut the top off and add the rag-top and other components. As the production volume of convertibles increased, the manufacturers started making special "convertible bodies" that did not have to be cut up at the modification shop. When the production volume increased even more, they stopped sending the work to modification shops and started making convertibles at their own assembly plants. It is possible that one or more CV manufacturers turned EV manufacturers would follow the same approach as with the convertibles, preparing special "gliders" (vehicles without a powertrain) for independent modification shops to finish and assemble into complete EVs. During the introductory period, before EVs become high-volume products, all three manufacturing approaches - conversions from complete vehicles, glider conversions, and complete OEM production - may be used.

\subsection{EV Conversions}

During the early introductory period, the limited availability of EV models will require that a number of conversion vehicles be available to supplement the OEM offerings. Conversion from a complete vehicle is the most economical process to produce a small number of EV versions of a particular conventional vehicle. When the number of vehicle conversions increases to a significant number (a few hundred units per year), it will be more economical to produce a 
special glider to reduce the cost of conversions. An EV conversion from a conventional vehicle includes removal of the IC engine and its supporting subsystems, replacement with an electric motor and controller, and addition of enough battery capacity to provide a reasonable range. Space for the batteries is usually found in the engine compartment, the luggage or cargo space, the passenger compartment, or some combination of these. The main disadvantage with EV conversions from conventional vehicles is that no specific space is dedicated for the energy storage system, so space must be taken from other dedicated areas, of which the least critical is the luggage or cargo area. The conversion process introduces a number of inefficiencies that increase the cost of producing an EV well above that of an equivalent vehicle designed "from the ground up." However, it is not possible to justify an original design for a very small number of vehicles. Therefore, even with the inherent inefficiencies, conversions have their proper place when the number of units to be produced is very low. The main inefficiencies of this process are associated with duplication of work and material. The original vehicle is assembled with the conventional powertrain, which then has to be removed and replaced with the electric powertrain. The material removed is downgraded in the process (because it is used, however briefly, and is also occasionally damaged), and its full value cannot be recovered. In addition, modifications to the vehicle and/or its components often have to be made, which the low volumes involved tend to make labor-intensive and thereby costly. Finally, extra parts (not normally required) often have to be used to make components fit properly (adaptations), simply because the components were not originally designed for the purpose. Many of these inefficiencies can be reduced or eliminated with the use of gliders.

The term "glider" originated in the heavy-duty truck industry; most OEMs offer the glider as a complete truck, except for engine, transmission, and rear axle. The purpose of gliders in this market is to provide an alternative to fixing wrecked trucks. A major accident to a heavy truck (such as rolling over) usually wipes out the cab and often damages the chassis frame beyond repair. Because frames are heat-treated, they cannot be straightened once they are bent. However, the engine, transmission, and rear axle usually survive. These are very valuable components, representing one-third or more of the total cost of the truck, so it makes sense to salvage them and put them in a new glider, thus producing essentially a new truck. It is easy to see the similarity between truck and EV gliders. Ideally, a glider should include all the standard components that are usable by an EV and exclude those that are not. In reality, a glider may include a number of unwanted components, either because they are difficult to leave out of the assembly process or because they are integrated with others that are needed. The instrument panel and controls area, for example, is one system that may be particularly difficult to sort out. Still, we can assume that a glider for EVs will come without the following systems:

1. Engine (including electronic controls)

2. Engine accessories (alternator, power steering pump, air-conditioning compressor)

3. Transmission

4. Exhaust system (including the catalytic converter)

5. Fuel storage and evaporative emissions control system 


\section{Engine cooling system}

7. Starter, battery, and charging control system

On the other hand, some of the systems that are needed by the EV may be only partially included, since parts of them may be integrated into excluded major components (like the engine). The following are examples of such systems:

1. Power steering (the pump is normally mounted on and driven by the engine)

2. Heating, ventilation, and air-conditioning system (the heat source is the engine, and the air-conditioning compressor is also mounted on and driven by the engine)

3. Braking system (the booster is powered by vacuum from the engine)

Finally, some of the systems or individual components in the standard (IC-engine) vehicle may not be optimal for the EV and may need to be changed or fine-tuned. Special components may be installed right at the OEM assembly line and may later require exchange after assembly, depending on how the logistical details are worked out. Examples of this type of component include the following:

1. Suspension springs and shocks

\section{Wire harnesses}

3. Battery trays or attachment brackets

\section{Motor mounting frame}

Whether the glider is truly optimized for EV conversion or not depends on the volume of demand. If the demand is only for a few hundred vehicles per year, the glider would be a "deleteonly" version in the form of a standard IC-engine vehicle with a few major systems deleted (engine, transmission, exhaust, fuel tank, etc.). However, if the demand is at 3,000-5,000 units per year, it then makes sense to actually design and develop a special variant of this platform with its own "bill of materials," including the correct type of suspension, wire harnesses, instrument panels, HVAC components, brackets for EV components, etc. This latter kind of glider, which would need only the assembly of its special electric traction and energy storage components, represents the most efficient manufacturing alternative. Such a glider is more representative of what a vehicle OEM will do in-house for its own production (such as Chrysler, with the electric version of its minivan). The glider going out to an independent converter would probably be somewhere in between, mostly a "delete-only" version but with a few special components that are easy alternatives, such as suspension springs and shocks, wheels and tires, etc. In general, one does not expect the vehicle OEMs to design new platform versions or re-equip the assembly plants and retrain their workers significantly to handle these special models unless the volumes are attractive; rather, the OEMs try to minimize negative impacts on their assembly plant production efficiency. Even deleting components during the assembly 
process introduces inefficiencies, because the workers who normally perform the deleted functions cannot easily be eliminated or diverted to other useful functions. Thus, the labor cost of assembly will not be decreased by much, and the savings are limited mainly to the cost of the deleted parts. However, even a suboptimal glider would still reduce many of the inefficiencies of the conversion process, including much of the duplication of material and the additional labor required to remove the IC-engine-related components. To eliminate most or all of the inefficiencies of the conversion, it would be necessary to perform all or most of the required modifications at the OEM level; in essence, this means developing a special glider bill of materials with all the correct components for an EV.

\subsection{Direct OEM Production}

When the OEMs decide to produce their own EVs, they will have to choose between a totally new, "ground-up" design and a modification of an existing vehicle. From the cost and performance standpoint, an original design would be the preferred solution, if the production volume were high enough to justify it. However, during the early years of their introduction, EV production volumes are expected to remain modest at best. Therefore, it is expected that most OEMs will opt for an EV based on an existing vehicle; the only question is how far they will differ in their chosen design. For instance, Chrysler offers an EV based on its minivan, with minimal changes from the conventional vehicle except for the powertrain. On the other hand, Honda's initial EV offering in California (CUV-4) was based on its Civic hatchback model, but with a highly modified body floor to accommodate a battery compartment underneath the passenger cabin. The Chrysler vehicle incorporates only minor changes in the body, whereas the Honda vehicle requires a totally different floor and significant alterations to many of the external main panels. Needless to say, investment differences between these two approaches are significant, because body tooling is extremely expensive, even when limited to short-run prototype dies.

The OEMs must find a way to introduce EV technology without making extensive highvolume tooling investments, because initial demand is expected to be very low. Minivans and compact pickup trucks in fleet vehicles do not require much modification to produce a reasonably plausible EV, but that market is very limited. Eventually, the OEMs will have to offer an EV that the general public can buy; otherwise, the demand will never reach its full potential. The tooling and development cost associated with a totally new design, such as the GM EV-1, is in the hundreds of millions of dollars. The production capacity that such a tooling investment would buy is on the order of 50,000 units per year, far in excess of the initial need. The approach in the case of the Honda example seems to require a much lower investment. If the EV is produced as a variant of an existing vehicle, the investment required would be comparable with that needed for an additional model, such as a convertible or a station wagon based on an existing platform. The greater portion of the additional investment would be directed toward making the necessary body changes, with some going to new, specialized components. The necessary investment might then be in the tens of millions rather than hundreds of millions. The EVs would use many of the conventional vehicle's body-in-white parts, practically all of the interior components, and most of the chassis components. The electric vehicles could also be assembled in the same plant as their conventional counterparts, although not necessarily on the same assembly line. 
In summary, during the early introduction years, EVs will likely be manufactured by using as many as three different production systems, depending on the volume required. These three approaches - conversions, conversions from gliders, and complete (ground-up) OEM production - may coexist for some time. In the long run, when the demand grows to a significant level, EVs should be produced the same way as any other vehicle. Conversion from conventional vehicles is a process suitable only for very low volumes, about 100-400 units/yr. Conversion from a glider may be preferred for modest volumes of 500-4,000 units/yr. Complete OEM production based on an existing vehicle would require fairly significant volumes, 5,00040,000 units/yr. Complete OEM production from an entirely original design would require volumes in excess of 50,000 units/yr.

The vehicles produced via these three processes would not necessarily be equivalent. Clearly, the conversions from CVs will have some significant limitations, particularly with regard to luggage and passenger capacities. EVs based on existing vehicle platforms may turn out to be quite competitive, at least during the early years. To get a truly optimized EV, with a lightweight body, will require an original design. If the specialized EV components (traction motors, controllers, batteries, etc.) from independent suppliers become available to OEMs and converters at reasonable prices, the actual differences in cost for EVs among the three production systems likely will not be as great as the difference between CV and EV prices. Eventually, as demand volume grows significantly, OEM production will become the predominant mode because of its lower cost (and, possibly, better quality). 


\section{Section 8 \\ Cost Estimates for Selected Vehicles}

An EV produced by the OEM will have a lower cost than one produced by external conversion, although the difference in cost may not be great. The most likely approach an OEM could use during introduction is production of an EV model based on an existing conventional vehicle or platform. Eventually, however, the OEMs would shift to fully dedicated EV designs that optimize the potential of this highly specialized class of vehicles. We examine here the likely cost structure of the manufacturing options already discussed, to illustrate the methodology developed in this study.

\subsection{Cost of Subcompact EV or Minivan Based on Existing Vehicle}

We estimate the manufacturing cost and MSRP of an EV based on an existing subcompact conventional passenger car or on a minivan, which is expected to have considerable potential for fleet use. The EV model would use as many common components as possible, but the body structure of the subcompact would be modified as necessary to provide an adequate battery compartment without infringing on passenger or luggage space; the minivan would require less modification in this respect. A concept vehicle example is the Chrysler NS EV, where the battery compartment is located under the floor, requiring minimal changes. The EV body and chassis would be designed for assembly in the same facility, possibly on the same lines, as their conventional counterparts.

Earlier, we showed that the average manufacturing cost was $50 \%$ of the MSRP, and we also broke down the manufacturing cost by components (see Tables 2.2 and 3.2). If the costs of the conventional powertrain, the fuel storage and exhaust subsystems, some of the fluids, and the start, light, and ignition (SLI) battery are eliminated, the remaining vehicle cost amounts to $77 \%$ of the original total cost for the subcompact and $79 \%$ for the minivan. Assuming that the EV will use all the common components, we add to these percentages the cost of the EV-specific components (the electric powertrain, battery, etc.) and additional cost premiums for components that must be modified for EV operation (such as the body, power steering, HVAC, and brakes). The direct manufacturing cost (material, labor, and plant overhead) for the EV body would be the same as that for the $\mathrm{CV}$, assuming the use of good design and production practices. The designers are expected to find some advantageous structural use for the additional material needed to provide the battery compartment, resulting in no net addition of material (an optimistic, but plausible, assumption). We assume that the EV steering and brake subsystems can be supplied at essentially the same cost as the conventional components, because electrically powered components (such as power steering and brakes) are inherently no more costly than hydraulically or vacuum-actuated ones. However, the HVAC system will be more complex, and a small premium can be expected. Using the manufacturing cost guidelines developed in the previous sections, together with these assumptions, we obtain the high-volume production costs listed in Table 8.1.

The battery is treated separately, because it is costly and choices are available. We assume that the subcompact will have an energy storage capacity of $15 \mathrm{kWh}$, and the minivan, $27 \mathrm{kWh}$. 
Table 8.1 EV Component Costs to OEM (\$)

\begin{tabular}{|lrrrrrr} 
& \multicolumn{2}{c}{ Subcompact } & & \multicolumn{2}{c|}{ Minivan } \\
\cline { 2 - 3 } \cline { 5 - 6 } \multicolumn{1}{c}{ EV Component } & Pb-Acid & Ni-MH & & Pb-Acid & Ni-MH \\
\cline { 2 - 3 } Motor $^{\mathrm{a}}$ & 445 & 445 & & 650 & 650 \\
Controller $^{\mathrm{a}}$ & 1,040 & 1,040 & & 1,510 & 1,510 \\
Gear drive & 225 & 225 & & 315 & 315 \\
Air-conditioning drive & 75 & 75 & & 75 & 75 \\
Total EV drive components & 1,785 & 1,785 & & 2,550 & 2,550 \\
Components common with CV & 5,005 & 5,005 & & 8,100 & 8,100 \\
Total cost excluding battery & 6,790 & 6,790 & & 10,650 & 10,650 \\
Battery cost & 2,475 & 4,125 & & 4,455 & 7,425 \\
Total cost & 9,265 & 10,915 & & 15,105 & 18,075 \\
& & & & & \\
\hline
\end{tabular}

a Costs of AC-induction motor and controller are from Tables 5.7 and 5.9, assuming a $55-\mathrm{kW}$ motor for the subcompact and an $80-\mathrm{kW}$ motor for the minivan.

b Assumed MSRPs of CVs are $\$ 13,000$ for the subcompact and $\$ 20,500$ for the minivan. The OEM cost is taken at $50 \%$ (Table 2.2), with common component shares of 77 and $79 \%$, respectively, for the two EVs.

The energy storage capacity is selected regardless of battery type, although in Appendix C we show that an EV equipped with the nickel-metal hydride battery is lighter and has longer range for the same zero-to-60-mph acceleration time. We consider two different battery technologies, advanced lead-acid (Pb-acid), and nickel-metal hydride (Ni-MH). For the baseline estimates, the $\mathrm{Pb}$-acid battery is assumed to have $50 \mathrm{~W} \cdot \mathrm{h} / \mathrm{kg}$ specific energy, $300 \mathrm{~W} / \mathrm{kg}$ specific power, and $\$ 165 / \mathrm{kWh}$ cost; the Ni-MH battery is assumed to have $75 \mathrm{~W} \cdot \mathrm{h} / \mathrm{kg}$ specific energy, $250 \mathrm{~W} / \mathrm{kg}$ specific power, and $\$ 275 / \mathrm{kWh}$ cost. These data come from Tables 6.1 and 6.3 and from a Delphi study by Vyas et al. (1997).

In the above calculation, we used the OEM battery costs per unit of energy storage as material plus $\$ 150$, from Table 6.3. As explained in Tables 2.1 and 2.2, overhead, dealer support, and other costs are added to these OEM costs. We assume that the electric drive components and the air-conditioning drive will be procured from outside suppliers. The suppliers will bear the production-related costs in Table 2.2. To convert the OEM cost of these components to MSRP, we need to apply a multiplier (MSRP factor) of 1.5 (1/0.67, from Table 2.2). Furthermore (and importantly), we assume that the MSRP factor for the batteries is lower than that for the other outsourced components, 1.15 instead of 1.5. This markup is lower because a higher value for batteries could result in the development of an alternative supply source (independent of the OEM) directly from battery manufacturers to the vehicle buyer, causing OEMs to burden the batteries less and demand lower margins from the distributors as well. In other words, we assume a very competitive battery market, with business entities separate from the vehicle OEMs competing in that market.

We calculate the costs for the two vehicle sizes for two battery types and two volume cases: high (100,000 units per year) and low (10,000 units per year). In the high-volume case, the 
additional capital cost incurred for development, facilities, and tooling related to production of the EV is assumed to be recovered at the same rate as the CV investment and is already included in the overhead allocation described in Section 2. In other words, the additional capital investment for the EV will balance the additional (EV) capacity, so the net result is similar to an increase in the CV capacity. In the low-volume case, the EV capital recovery will be spread over a much smaller number of vehicles, and consequently, an overhead rate correction is needed.

The MSRP of the EV would be the sum of the cost of the common components (between $\mathrm{CV}$ and EV) times 2 (Table 2.2), the EV component manufacturing cost times 1.5 (Table 2.2), and the battery cost times 1.15 . For the low-volume case, the MSRP of the EV is equal to that of the high-volume case (assuming that the volume of the EV components is large enough to cause their cost to remain unchanged) plus the correction for spreading capital recovery over fewer units. The additional capital investment is assumed to be $\$ 100$ million for the subcompact and $\$ 50$ million for the minivan. In the high-volume case, the recovery rate is $\$ 200 /$ unit $\$ 100$ million over 5 years, 100,000 units/yr). For the low-volume case, the recovery rate becomes $\$ 2,000 /$ unit ( $\$ 100$ million over 5 years, 10,000 units/yr). Therefore, the low-volume case incurs an $\$ 1,800 /$ unit additional cost that should be added to overhead. The resulting MSRPs for the two vehicle types, equipped with two battery types, at low and high volumes are shown in Table 8.2. Because the minivan can be easily modified to accommodate electric drive and batteries, the cost premium to the OEM for its low-volume production would be half that for the subcompact, or $\$ 900$ per unit.

Table 8.2 shows that, even with the lowest-cost battery, the high-volume subcompact EV would be almost $20 \%$ more expensive than the subcompact CV. With the higher-performance battery, the premium would be over $34 \%$. The estimated premiums are slightly higher for the minivan, $23 \%$ and $39 \%$, respectively. The basic EV, excluding batteries, would cost about the

Table 8.2 Estimated MSRP of Electric Subcompact and Minivan Based on Existing Vehicle

\begin{tabular}{|c|c|c|c|c|c|c|c|c|}
\hline \multirow[b]{2}{*}{ Volume } & \multirow[b]{2}{*}{ Item } & \multirow[b]{2}{*}{$\begin{array}{l}\text { MSRP } \\
\text { Factor }\end{array}$} & \multicolumn{3}{|c|}{ Subcompact $(\$)^{\mathrm{a}}$} & \multicolumn{3}{|c|}{ Minivan $(\$)^{\mathrm{b}}$} \\
\hline & & & $\begin{array}{l}\text { OEM } \\
\text { Cost }\end{array}$ & $\begin{array}{l}\text { MSRP, } \\
\text { Pb-Acid }\end{array}$ & $\begin{array}{c}\text { MSRP, } \\
\text { Ni-MH }\end{array}$ & $\begin{array}{l}\text { OEM } \\
\text { Cost }\end{array}$ & $\begin{array}{l}\text { MSRP, } \\
\text { Pb-Acid }\end{array}$ & $\begin{array}{c}\text { MSRP, } \\
\text { Ni-MH }\end{array}$ \\
\hline \multirow[t]{6}{*}{ High } & EV drive & 1.50 & 1,785 & 2,680 & 2,680 & 2,550 & 3,825 & 3,825 \\
\hline & Common items & 2.00 & 5,005 & 10,010 & 10,010 & 8,100 & 16,200 & 16,200 \\
\hline & Basic vehicle & & 6,790 & 12,690 & 12,690 & 10,575 & 20,025 & 20,025 \\
\hline & $\mathrm{Pb}$-acid battery & 1.15 & 2,475 & 2,845 & & 4,455 & 5,125 & \\
\hline & Ni-MH battery & 1.15 & 4,125 & & 4,745 & 7,425 & & 8,535 \\
\hline & MSRP & & & 15,535 & 17,435 & & 25,150 & 28,560 \\
\hline \multirow[t]{3}{*}{ Low } & Vol. premium & 1.00 & 1,800 & 1,800 & 1,800 & & 900 & 900 \\
\hline & Basic vehicle & & & 14,490 & 14,490 & & 20,925 & 20,925 \\
\hline & MSRP & & & 17,335 & 19,235 & & 26,050 & 29,460 \\
\hline
\end{tabular}

a MSRP, excluding batteries, is $\$ 12,690$. CV MSRP is $\$ 13,000$.

b MSRP excluding batteries is $\$ 20,025$. CV MSRP is $\$ 20,500$. 
same as the comparable CV, even though the IC engine with all its ancillary systems and complex transmission is more costly than the electric traction motor and its simple gear drive. The very expensive electronic power supply and control system of the EV almost makes up for the difference, being about four to five times more expensive than the equivalent IC-engine control. The difference in cost is primarily in the power stage, which has no equivalent in the $\mathrm{CV}$. If the OEM cost of the EV electronic control system could be sharply reduced (say, to well below $\$ 1,000$ per unit), the electric powertrain would become significantly cheaper than the conventional one, although not nearly enough to make up for the additional cost of batteries. Even if the cost of the EV electronic control system were a couple of hundred dollars, the savings would barely pay for one-half the cost of the cheapest battery available ( $\mathrm{Pb}$-acid).

To summarize, an EV produced in a cost-effective fashion is likely to cost almost the same as an equivalent $\mathrm{CV}$, plus the cost of the batteries. Clearly, the high cost of the batteries represents an almost insurmountable handicap for EVs; a premium in the range of $20-40 \%$ is very difficult to justify, even with significant operating cost savings. Furthermore, the batteries, with limits on their calendar and cycle lives, will likely require replacement(s) during the vehicle's lifetime. It appears unlikely that average customers would pay such a significant premium without any hope for a rapid payback from lower operating cost. In addition, the range of the $\mathrm{EV}$ will be considerably less than that for the $\mathrm{CV}$, and battery recharging will take much longer than CV refueling. Given the current fuel costs and emissions situation, it appears that an EV's disadvantages (high first cost, short range, long refueling time, poor acceleration, need to replace batteries) more than outweigh its key advantages (low energy cost, quiet operation, zero tailpipe emissions).

\subsection{Cost Analysis of Subcompact EV under Alternative Methods}

The values in Table 8.2 provide an estimated MSRP for two EVs when they are produced as variants of existing vehicles. Earlier, we summarized other methods by which the EVs could be produced. In this section, we estimate the MSRPs for subcompact EVs produced by using three alternative methods.

\subsubsection{Subcompact EV Based on a New Design}

The manufacture of a subcompact EV based on a new (ground-up) design is essentially the same as that for one based on an existing vehicle, except that the capital investment (including development) is much higher. On the other hand, the design optimizes the EV characteristics, offering additional performance and operational benefits not possible with a compromised design based on an existing vehicle. A new vehicle development and manufacturing program (including engineering, plant facilities, and tooling) aimed at high-volume production (100,000 units/yr) requires a total investment of about $\$ 800$ million. A lower-volume new-vehicle development and manufacturing program $(10,000-20,000$ units/yr) may require a capital investment of \$250 million.

In the high-volume case, amortizing the $\$ 800$ million investment over five years at a production rate of 100,000 units per year (assuming the cost of conventional and electrical components to be unchanged from the previous case), the amortization per unit would be $\$ 1,600$. 
However, a \$200/unit amortization is already included in the MSRP of the EV electric drive, and another \$500/unit is included in the CV common component MSRP. The resulting net addition is estimated at $\$ 900 /$ unit. Similarly, in the low-volume case, amortizing the $\$ 250$ million over 10,000 units per year gives a net addition to the MSRP of about $\$ 4,300$ per unit. Therefore, total vehicle MSRPs for these cases (excluding batteries) would be $\$ 13,590$ (high volume) and $\$ 16,990$ (low volume). The base cost of the EV, excluding batteries, was calculated earlier at $\$ 12,690$, and the incremental capital costs of $\$ 900$ and $\$ 4,300$ are simply added to this value.

\subsubsection{Subcompact EV Assembled from a Glider}

If the subcompact-size glider provided by the OEM is assembled according to an EVspecific bill of materials, it will be delivered to the final assembler (in-house, subcontractor, or independent business) ready to be finished, without any parts to remove or modify. This manufacturing process is almost as efficient as that of the full OEM assembly case. Additional costs due to assembly operations occurring at two different locations are transportation and work-in-process inventory required by the transfer of materials between the plants. To simplify the analysis, we assume that the cost of assembling the glider is the same as that of a complete vehicle. This is reasonable because the workers at the assembly plant will be paid the same whether they install a component in a vehicle or not (glider). The plant overhead will also be the same. Therefore, the only savings associated with the glider are achieved on the material side (reduced number of parts), rather than from the assembly. The costs of installing the electric powertrain and batteries, final testing, etc. are additional. For simplicity, we ignore the additional transportation and work-in-process inventory costs, assume that the cost of electrical components is the same as that obtained by the OEM, and assume that the cost of additional assembly is proportional to the cost of the components being installed in the same proportion as for the OEM. Since final assembly accounts for about $23 \%$ of the total cost, and the electric powertrain and associated components account for about $33 \%$ of the component cost of the complete EV, the additional assembly cost should be $0.33 \times 0.23=0.076$, or $7.6 \%$ of manufacturing costs.

When the cost of installing batteries is included, the additional manufacturing cost of final glider-based EV assembly will probably be nearly $10 \%$, which must be factored into the base EV cost calculated earlier. Manufacturing cost constitutes 50\% of the MSRP, so a $10 \%$ increase would represent a 5\% increase in MSRP. The EV components are outsourced and are subjected to a lower multiplier to arrive at the MSRP. The base EV subcompact would cost $\$ 12,690$, excluding batteries (Table 8.2). Thus, the final MSRP of a basic subcompact EV sedan (without batteries) made from an OEM-provided glider would be $\$ 12,690 \times 1.05=\$ 13,325$.

If the glider is not assembled with all the required EV parts, the additional components must be removed or modified, causing significant inefficiencies in the assembly process. A "deleteonly" glider that is assembled as a conventional vehicle without engine, transmission, fuel storage, exhaust, and cooling systems would still require many modifications to electrical-wire harnesses, motor mounts, battery trays, auxiliary motors, and other components. These laborintensive processes could double, or even triple, the cost of final EV assembly. Therefore, the case discussed above represents a lower bound. If the additional assembly costs were doubled, a $20 \%$ manufacturing cost increase for the final EV assembly would be added. This would provide an upper bound for the cost of a glider-based EV at $\$ 12,690 \times 1.1=\$ 13,960$. 


\subsubsection{Subcompact EV Conversion from a CV}

If the $\mathrm{EV}$ is produced by conversion from a conventional vehicle, additional inefficiencies add significantly to the manufacturing cost and MSRP. Even if the vehicle is sourced at the maximum discount (dealer discount plus incentives, or about 20\%), and the electrical components are obtained at the same price the OEM pays, significant increases in final cost occur because of the higher initial cost of the vehicle. The cost of removing unnecessary conventional components and the additional modification and adaptation work required for fitting the EV parts into a CV increase the MSRP of such vehicles substantially.

The cost of removing the conventional powertrain components will be higher than that of original assembly. The availability of specialized equipment and optimization of processes make the OEM assembly operations very efficient, but the conversion or modification shop would not have such facilities. For simplicity, we assume that the cost of removing the components will be the same as that of original assembly, and that assembly cost is still proportional to component cost. The cost of assembly for a conventional subcompact was found to be $23 \%$, and the cost of the not-common and somewhat-common components and associated systems was also $23 \%$ (Table 3.2). Thus, the cost of assembly (and disassembly) of those components would be $0.23 \times 0.23=0.053$, or $5.3 \%$.

The additional cost of assembling the electrical components is assumed to be the same (10\%) as that for assembling them on a glider. But before the electrical components can be installed on the stripped conventional vehicle, small modifications are generally required (drilling holes, light machining, welding, adding mounting brackets and battery trays, etc.) to facilitate the installation of components that the vehicle was not originally designed to accept. The costs will be different for each model. An estimate for one specific vehicle (Ford Escort) indicates that, even when it is produced in significant numbers (a few thousand units/yr), the cost of the preparation plus the adaptation kits (brackets, battery boxes, additional machining, etc.) could be around $\$ 3,000-4,000$ (Ohba 1997). We assume the preparation and adaptation can be performed for $\$ 3,000$ (manufacturing level).

The value of the conventional components removed (which constitute $23 \%$ of the vehicle manufacturing cost) must be credited against the vehicle cost. However, the assembly and disassembly processes reduce their value to some extent, since they are no longer new. We assume a credit for half the original OEM cost for these components. The OEM costs for components and assembly constitute $50 \%$ of the MSRP, and the assembly contributes $23 \%$ of that (see Tables 2.2 and 3.2). The costs of assembly and overhead would not be recovered, so we divide MSRP by the overhead factor of 2 and subtract the assembly cost. The resulting credit would be $(\mathrm{MSRP} / 2 \times 0.23 \times(1-0.23)) \times 0.5=0.0443$, or $4.43 \%$ of MSRP.

The cost of the EV made by conversion is equal to the sum of five cost items: net cost of the $\mathrm{CV}$ (original cost less the credit for components removed), the cost of stripping (cost of removing the conventional components), the cost of adapting the vehicle for the EV components, the cost of the EV components, and the cost of installing the EV components (final assembly). In estimating the MSRP of the converted vehicle (excluding batteries), we assume the conversion shop overhead factor to be 2 and subject the outsourced electric drive to a factor of 1.5. 
Table 8.3 Estimates of Subcompact EV Cost by Conversion from a CV

\begin{tabular}{|llrr|}
\hline \multicolumn{1}{c}{ Cost Item } & \multicolumn{1}{c}{ Estimation Method } & Formula & Cost (\$) \\
\hline Net Cost of CV & $\begin{array}{l}\text { 80\% of CV less credit for removed } \\
\text { components }\end{array}$ & $0.8 \times 13,000-0.0443 \times 13,000$ & 9,825 \\
Stripping & 5.3\% of CV MSRP & $0.053 \times 13,000$ & 690 \\
Adaptation & Actual shop estimate & 3,000 & 3,000 \\
EV drive & Same as OEM & 1,785 & 1,785 \\
Final assembly & 5\% of CV MSRP & $0.05 \times 13,000$ & 650 \\
Total conversion & Sum of above items & & 15,950 \\
Shop overhead & Stripping and assembly & $690+650$ & 1,340 \\
EV drive overhead & 0.5 x EV drive & $0.5 \times 1,785$ & 895 \\
Total (excl. battery) & Conversion + overhead & & 18,185 \\
& & & \\
\hline
\end{tabular}

The MSRP, without batteries, is about 39\% higher than the MSRP of the equivalent CV, about $44 \%$ higher than the OEM-assembled, high-volume-case EV using an existing design, and about $37 \%$ higher than the best glider-based conversion.

\subsection{Summary of EV Costs}

The lowest cost of manufacture (and the lowest MSRP) for an EV is achieved by direct, high-volume OEM production. The cost is lower when the vehicle is based on an established high-volume platform rather than a totally new design. Production from specially designed gliders is also efficient and could have advantages when a variety of different EV options are desired. Conversion from conventional vehicles is inefficient and would be limited to very lowvolume production. The cost of producing a basic EV (without batteries) could eventually be somewhat lower than that of a CV, possibly much lower if the cost of the motor controller could be significantly reduced. However, it is unlikely that an EV with batteries will ever be cheaper than a CV. Table 8.4 compares MSRPs for the EVs produced by the different methods covered in this section.

The costs of the electric drive and battery are kept unchanged between low-, medium-, and high-volume production cases in Table 8.4. We have assumed that producers of electric drives and batteries will supply their products to several vehicle manufacturers, and the resulting volumes will be high enough to maintain the same cost.

The optimistically low markup of $15 \%$ for the battery pack represents a very favorable scenario for EVs. The base battery cost constitutes 27 to $41 \%$ of the total OEM cost (before markup) in Table 8.1, second only to the cost of common components. The battery pack is assumed to be delivered to the OEM ready for installation in the vehicle, requiring minimal handling and assembly. The OEM would incur very little additional cost on the battery pack; warranty costs are borne by the battery supplier. This situation is similar to that of aircraft assembly, in which jet engines are procured from outside and installed by the aircraft manufacturer. Also, heavy truck manufacturers install diesel engines from engine manufacturers and add a relatively low markup. In reality, the vehicle manufacturers vying for the EV market 
Table 8.4 CV and EV MSRP with 15\% EV Battery Cost Markup

\begin{tabular}{|c|c|c|c|c|c|}
\hline \multirow[b]{2}{*}{ Vehicle } & \multirow[b]{2}{*}{ Production Strategy } & \multicolumn{4}{|c|}{ MSRP (\$) } \\
\hline & & Volume & $\begin{array}{l}\text { Without } \\
\text { Battery }\end{array}$ & $\begin{array}{c}\text { With } \\
\text { Pb-Acid }\end{array}$ & $\begin{array}{c}\text { With } \\
\text { Ni-MH }\end{array}$ \\
\hline \multirow[t]{8}{*}{ Subcompact } & Conventional vehicle & High & 13,000 & $N A^{a}$ & NA \\
\hline & Existing design & High & 12,690 & 15,535 & 17,435 \\
\hline & & Low & 14,490 & 17,335 & 19,235 \\
\hline & New design & High & 13,590 & 16,435 & 18,335 \\
\hline & & Low & 16,990 & 19,835 & 21,735 \\
\hline & Glider & Medium & 13,325 & 16,170 & 18,070 \\
\hline & Glider (delete-only) & Medium & 13,960 & 16,805 & 18,705 \\
\hline & Conversion & Very low & 18,185 & 21,030 & 22,930 \\
\hline \multirow[t]{3}{*}{ Minivan } & Conventional vehicle & High & 20,500 & NA & NA \\
\hline & Existing design & High & 20,025 & 25,150 & 28,560 \\
\hline & & Low & 20,925 & 26,050 & 29,460 \\
\hline
\end{tabular}

a $\mathrm{NA}=$ not applicable.

will decide the actual markup for the battery pack. We believe that the markup will be lower than that for outsourced components (e.g., 50\%) because a high markup would drive EVs out of the market. It is possible that the markup will be between 15 and $50 \%$. We have analyzed an alternative scenario with a battery cost markup of 30\%; the results are presented in Table 8.5.

Table 8.5 CV and EV MSRP with 30\% EV Battery Cost Markup

\begin{tabular}{|c|c|c|c|c|c|}
\hline \multirow[b]{2}{*}{ Vehicle } & \multirow[b]{2}{*}{ Production Strategy } & \multicolumn{4}{|c|}{ MSRP (\$) } \\
\hline & & Volume & $\begin{array}{l}\text { Without } \\
\text { Battery }\end{array}$ & $\begin{array}{c}\text { With } \\
\text { Pb-Acid }\end{array}$ & $\begin{array}{c}\text { With } \\
\text { Ni-MH }\end{array}$ \\
\hline \multirow[t]{8}{*}{ Subcompact } & Conventional vehicle & High & 13,000 & $N A^{a}$ & NA \\
\hline & Existing design & High & 12,690 & 15,910 & 18,055 \\
\hline & & Low & 14,490 & 17,710 & 19,855 \\
\hline & New design & High & 13,590 & 16,810 & 18,955 \\
\hline & & Low & 16,990 & 20,210 & 22,355 \\
\hline & Glider & Medium & 13,325 & 16,545 & 18,690 \\
\hline & Glider (delete-only) & Medium & 13,960 & 17,180 & 19,325 \\
\hline & Conversion & Very low & 18,185 & 21,405 & 23,550 \\
\hline \multirow[t]{3}{*}{ Minivan } & Conventional vehicle & High & 20,500 & NA & NA \\
\hline & Existing design & High & 20,025 & 25,815 & 29,680 \\
\hline & & Low & 20,925 & 26,715 & 30,580 \\
\hline
\end{tabular}

\footnotetext{
a $\mathrm{NA}=$ not applicable.
} 


\subsection{References}

Ohba, S., 1997, Soleq, Inc., Chicago, Ill., personal communication.

Vyas, A.D., H.K. Ng, D.J. Santini, and J.L. Anderson, 1997, Electric and Hybrid Electric Vehicles: A Technology Assessment Based on a Two-Stage Delphi Study, Argonne National Laboratory Report ANL/ESD-36, Argonne, Ill. 


\section{Section 9 \\ Lifecycle Ownership Cost Analysis}

In Section 8, we estimated the initial cost of an EV, with and without batteries. The cost analysis thus far has been focused on initial vehicle cost. Aside from the initial cost, the lifetime cost of an EV to its owner needs to be ascertained. Lifetime cost includes amortized purchase price, operating costs, and other incidental costs. Operating costs include energy, battery costs, and maintenance costs. When these costs are converted to average annual or per-mile costs, we can compare them with similar costs for a CV. In computing the lifecycle costs, we exclude such vehicle-ownership-related costs as registration, insurance, and property taxes, assuming that these items would be the same for both CVs and EVs.

The cost estimates presented here are for subcompact EVs equipped with lead-acid and nickel-metal hydride batteries. The two battery types have different specific power and energy characteristics and different masses. Because the power required for accelerating the vehicle is a function of mass (see Appendix C), the powertrain component sizes would differ for different battery types. Also, the rate of energy consumption depends on vehicle mass and differs for different battery types. An EV can be characterized to meet some minimum performance requirement (e.g., zero-to-60-mph time), some minimum range requirement, or a combination of the two. In the calculation presented here, we have assumed that the subcompact EV would be able to accelerate from zero to $60 \mathrm{mph}$ in at least 12 seconds and that its battery pack would have an energy content of at least $15 \mathrm{kWh}$. A $15-\mathrm{kWh}$ lead-acid battery pack would be much heavier than a $15-\mathrm{kWh}$ nickel-metal hydride battery pack. The resulting increase in EV mass would require more power, and powertrain components would be rated accordingly. Thus, the costs of an EV - initial, operating, and battery - depend on the minimum performance design criteria and on the type of battery used. All these computations require several iterations, so a computerized model is developed to compute the lifecycle costs. The power and mass estimation procedure used in this model is described in Appendix C; an application of the model is summarized in Vyas et al. (1998). The sample calculations given here are based on the commoncomponents cost estimates developed in Section 3 (Section 3.1). The electric powertrain cost estimates developed in Section 5 are also used. The costs presented here account for mass and power feedback and therefore differ from the purchase price estimates developed in Section 8.

\subsection{Operating Costs}

The CV's operating costs include energy cost, periodic changing of oil and oil filter, lubrication, tire replacement, and routine maintenance. EVs do not require the changing of oil and oil filters, but they have an additional operating cost in batteries. The cost of initial and replacement battery packs constitutes a significant part of the EV's operating costs.

\subsubsection{Energy and Maintenance Costs}

The energy cost for a $\mathrm{CV}$ is dependent on motor fuel price and vehicle fuel economy. We used projections by DOE's Energy Information Administration (EIA) to arrive at the energy cost (EIA 1997). We assumed the subcompact CV to have fuel economies, as rated by the U.S. Environmental Protection Agency (EPA), of $31 \mathrm{mpg}$ at the time of EV introduction and 
$33 \mathrm{mpg}$ by the time more than $100,000 \mathrm{EVs}$ are sold (high volume). We also used a factor of 0.8 to arrive at the on-road fuel economy (Mintz et al. 1993). The energy cost would be very low for an EV because it does not idle, uses electricity stored in batteries only when needed, and has the potential to use regenerative braking. For the subcompact EV, we developed an energy consumption rate of $111 \mathrm{~W} \cdot \mathrm{h} / \mathrm{km}$ for each metric ton of vehicle mass at the time of EV introduction. We assumed the electric power train to improve its efficiency by $8 \%$, thereby lowering the vehicle energy-consumption rate to $102 \mathrm{~W} \cdot \mathrm{h} / \mathrm{km}$ per metric ton of vehicle mass, when more than 100,000 EVs are sold.

The actual energy-consumption rates were determined by applying the mass and power estimation procedure described in Appendix C. The lead-acid battery has lower specific energy compared to the nickel-metal hydride battery. We required the EV battery pack to have a minimum energy content of $15 \mathrm{kWh}$, so the lead-acid battery pack will have much higher power than that necessary for zero-to-60-mph acceleration in 12 seconds. However, a higher-power motor and controller will be necessary for the EV to take full advantage of this higher battery power; consequently, its purchase price will increase. In order to keep the EV's purchase price closer to that of the $\mathrm{CV}$, while providing similar performance, we established a lower limit of 10 seconds on the zero-to-60-mph acceleration time. The energy-consumption rate of $111 \mathrm{~W} \cdot \mathrm{h} / \mathrm{km}$ per metric ton at the time of EV introduction (stated above) is very comparable with that for the GM-EV1. GM's EV1 is rated to consume $30 \mathrm{kWh}$ per $161 \mathrm{~km}$ (100 miles) in the city and $25 \mathrm{kWh}$ on the highway. We used the EPA's usual 55/45\% split between city and highway driving to arrive at an energy-consumption rate of $27.8 \mathrm{kWh}$ per $161 \mathrm{~km}(100$ miles $)$. At $1,400 \mathrm{~kg}$ of vehicle and $136 \mathrm{~kg}$ of passenger mass, the energy consumption works out to $112.5 \mathrm{~W} \cdot \mathrm{h} / \mathrm{km}$ per metric ton of mass. In estimating electricity consumption, we assumed charger efficiencies of $85 \%$ initially and $88 \%$ at high volume. Off-peak electricity rates were used to arrive at the EV energy costs.

Aside from the projected improvements in powertrain and charger efficiency, EVs will also benefit from mass reduction. We assumed a $3 \%$ reduction in EV body and chassis mass between its introduction and when produced in high volume. Improvements in battery and electric drive technologies would also reduce the overall EV mass. The mass and power estimation procedure projected our ultra-light steel subcompact EV to have a mass of $1,367 \mathrm{~kg}$ at the time of introduction and $1,137 \mathrm{~kg}$ in high-volume production, both with the lead-acid battery. The corresponding estimates with the nickel-metal hydride battery were 1,226 and $1,052 \mathrm{~kg}$. The projected energy-consumption rates, at the electric meter, were $197 \mathrm{~W} \cdot \mathrm{h} / \mathrm{km}(317 \mathrm{~W} \cdot \mathrm{h} / \mathrm{mi})$ and $153 \mathrm{~W} \cdot \mathrm{h} / \mathrm{km}(246 \mathrm{~W} \cdot \mathrm{h} / \mathrm{mi})$ for the lead-acid battery, and $178 \mathrm{~W} \cdot \mathrm{h} / \mathrm{km}(287 \mathrm{~W} \cdot \mathrm{h} / \mathrm{mi})$ and $143 \mathrm{~W} \cdot \mathrm{h} / \mathrm{km}(230 \mathrm{~W} \cdot \mathrm{h} / \mathrm{mi})$ for the nickel-metal hydride battery, for the two points in time.

The American Automobile Manufacturers Association (AAMA) publishes information on CV operating costs (AAMA 1998), which we used for computing CV maintenance cost. The EV will not have any oil or oil-filter change requirements; we assumed this cost to be zero. An EV has fewer moving parts, and the electrical components are expected to have a long maintenancefree life. Consequently, we assumed that the EV's routine maintenance cost would be $20 \%$ of the CV's maintenance cost. The tire cost depends on the mass of the vehicle. Our subcompact EVs, at the time of their introduction, are $11 \%$ or $24 \%$ heavier than subcompact CVs, depending on the battery type. We assumed an $11 \%$ higher tire cost for the EVs. Table 9.1 shows estimates of 
Table 9.1 Estimated Energy and Maintenance Costs of Subcompact CV and EV

\begin{tabular}{|c|c|c|c|c|c|c|}
\hline \multirow[b]{2}{*}{ Item } & \multicolumn{2}{|r|}{ CV } & \multicolumn{2}{|c|}{$\begin{array}{l}\text { EV (with } \\
\text { Pb-acid) }\end{array}$} & \multicolumn{2}{|c|}{ EV (with Ni-MH) } \\
\hline & $\begin{array}{l}\text { At EV } \\
\text { Intro. }\end{array}$ & $\begin{array}{c}\text { At High } \\
\text { EV Volume }\end{array}$ & $\begin{array}{l}\text { At EV } \\
\text { Intro. }\end{array}$ & $\begin{array}{c}\text { At High } \\
\text { EV Volume }\end{array}$ & $\begin{array}{l}\text { At EV } \\
\text { Intro. }\end{array}$ & $\begin{array}{l}\text { At High } \\
\text { EV Volume }\end{array}$ \\
\hline \multicolumn{7}{|l|}{ Use rates and prices } \\
\hline Energy use rate (CV: mpg; EV: W.h/mi) & 31 & 33 & 317 & 246 & 287 & 230 \\
\hline On-road fuel economy factor & 0.80 & 0.80 & 1 & 1 & 1 & 1 \\
\hline Energy price (CV: \$/gal; EV: \$/kWh) & 1.23 & 1.28 & 0.055 & 0.055 & 0.055 & 0.055 \\
\hline \multicolumn{7}{|l|}{ Energy and maintenance costs } \\
\hline Energy cost $(\$ / \mathrm{mi})$ & 4.96 & 4.85 & 1.76 & 1.39 & 1.53 & 1.23 \\
\hline Oil, oil filter, and lubrication ( $\$ / \mathrm{mi})$ & 0.91 & 0.96 & 0.00 & 0.00 & 0.00 & 0.00 \\
\hline Routine maintenance $(\Phi / \mathrm{mi})$ & 2.64 & 2.76 & 0.53 & 0.55 & 0.53 & 0.55 \\
\hline Tires $(\$ / \mathrm{mi})$ & 1.42 & 1.49 & 1.56 & 1.64 & 1.56 & 1.64 \\
\hline Total energy and maintenance cost $(\Phi / \mathrm{mi})$ & 9.93 & 10.06 & 3.85 & 3.58 & 3.62 & 3.42 \\
\hline
\end{tabular}

various components of the energy and maintenance costs at the time of the EV's introduction and at high volume.

\subsubsection{EV Battery Cost}

The costs of the first and replacement battery packs are unique to EVs. The EV battery pack is a chemical device that loses its usefulness when it cannot sustain the processes through which it first stores electric power and later supplies it to the vehicle. A battery pack's usefulness is dependent on calendar time and on the number of charge-discharge cycles it can sustain. The U.S. Advanced Battery Consortium has set mid-term and long-term goals for both these lives, and a range of information is available on calendar and cycle lives of various battery technologies. For battery lives, we used the data from the battery technology advisory panel's report to the California Air Resources Board (CARB) (Kalhammer et al. 1995) and, where necessary, supplemented it with data from an Argonne National Laboratory (ANL) Delphi study (Vyas et al. 1997). As was done in Section 8, we considered two battery technologies, lead-acid and nickel-metal hydride. The advanced lead-acid battery is projected to have a calendar life of four years initially and six years over the long term (after 20 years); it is projected to have an initial cycle life of 600 cycles and a long-term life of 1,000 cycles. The nickel-metal hydride battery is projected to have a calendar life of six years initially and eight years over the long term; its projected cycle lives are 800 (initially) and 2000 (long-term) cycles.

A range of battery costs is presented in Section 6. To obtain these costs, we used material and manufacturing costs and then, either by using a multiplier or by addition of a fixed sum, estimated the final costs per kilowatt-hour. The analysis also presented cost information from several sources. For the lifecycle analysis in this section, we show costs at two points in time, initially and at EV volumes of $>100,000$. We used lead-acid battery costs of $\$ 165 / \mathrm{kWh}$ initially and $\$ 115 / \mathrm{kWh}$ over the long term. The initial and long-term costs of the nickel-metal hydride battery were taken to be $\$ 500 / \mathrm{kWh}$ and $\$ 240 / \mathrm{kWh}$, respectively. These costs represent the OEM 
costs and must be multiplied by a factor of 1.15 to arrive at the costs to consumers (see Section 8).

The extent of daily use of an EV depends on its range. However, its usage would be primarily for local driving. The 1995 Nationwide Personal Transportation Survey by the U.S. Department of Transportation shows that a vehicle is driven 40 miles $(64 \mathrm{~km})$ per day, on average (FHWA 1997). This average includes several long trips. Also, average annual vehicle usage is 11,800 miles (Davis 1998), which provides a daily average of 32 miles (52 km). In estimating average battery cost per mile, we assumed a vehicle-use rate of 30 miles $(48 \mathrm{~km})$ per day, which provides an annual usage of 11,000 miles. Both CVs and EVs are assumed to have the same annual usage and are expected to last 12 years (132,000 miles).

The energy-use rates in Table 9.1 were converted to energy-use rates from the battery by correcting for charger efficiency. A $15-\mathrm{kWh}$ lead-acid battery pack would provide a theoretical maximum range (100-0\% state of charge, or SOC) of 52 miles initially and 68 miles at high EV volume $(84-109 \mathrm{~km})$ and a usable range $(95-20 \%$ SOC) of 42-51 miles $(68-82 \mathrm{~km})$.

Consequently, the battery pack would require daily recharging, using one cycle per day and 365 cycles per year. A battery pack's cycle life increases if it is not consistently discharged to a very low state of charge. Because the lead-acid battery packs in our example would be discharged to only 40-50\% SOC level before recharging, they should last longer. We assumed a $40 \%$ increase in cycle life of the lead-acid battery pack initially and a $70 \%$ increase at high EV volume. Because of their high specific energy, nickel-metal hydride battery packs will have higher energy contents when they are sized to provide power for zero-to-60-mph acceleration times of 10-12 seconds. The power and mass estimation procedure projected an energy content of $25 \mathrm{kWh}$ initially (for 12 seconds zero-to-60-mph acceleration time). The future nickel-metal hydride battery packs would have lower energy content because of their improved specific power and lower power requirements as a result of reduced vehicle mass. We ensured that these lower energy contents would not cause any reduction in EV range; we lowered the zero-to-60-mph acceleration time from 12 seconds to 10.3 seconds to achieve this goal. The resulting maximum range was 106 miles $(170 \mathrm{~km})$, and the usable range was 79 miles $(127 \mathrm{~km})$. This increased range would not require daily charging. Consequently, we increased the cycle lives of nickel-metal hydride battery packs by $165 \%$. The increases in lead-acid and nickel-metal hydride battery cycle lives ensure that these batteries last through the same number of miles as they would if EVs were driven their full usable range between chargings. The cycle lives for the two battery types were converted from number of cycles to number of years, and battery packs were replaced at the end of the shorter of the two lives, calendar or cycle.

The battery technology would continue to improve during the life of an EV. We assume that these improvements would be linear in nature and that all of them would take place during the first 10 years. Thus, the replacement battery packs for an EV purchased during the early years would have improved life and cost characteristics over the initial battery pack. The battery pack characteristics for the long-term EVs were assumed to remain constant. To compute net present value, the costs of the replacement battery packs were discounted at $4 \%$ (excluding inflation) and the costs of all battery packs, initial and replacement, were converted to average cost per mile. The battery pack cost computations are shown in Table 9.2. The average costs in the table were 
Table 9.2 Subcompact EV: Initial and Replacement Battery Pack Costs

\begin{tabular}{|c|c|c|c|c|c|}
\hline & & \multicolumn{2}{|c|}{ Lead-Acid Battery } & \multicolumn{2}{|c|}{ Ni-MH Battery } \\
\hline \multicolumn{2}{|l|}{ Item } & $\begin{array}{c}\text { At EV } \\
\text { Introduction }\end{array}$ & $\begin{array}{l}\text { At High } \\
\text { EV Volume }\end{array}$ & $\begin{array}{c}\text { At EV } \\
\text { Introduction }\end{array}$ & $\begin{array}{l}\text { At High } \\
\text { EV Volume }\end{array}$ \\
\hline \multicolumn{6}{|l|}{ Battery cost and life } \\
\hline \multirow[t]{2}{*}{ First battery pack: } & Cost $(\$)$ & 2,846 & 1,984 & 14,318 & 5,713 \\
\hline & Life (yr) & 2.3 & 4.7 & 5.8 & 8.0 \\
\hline \multicolumn{2}{|c|}{ Second battery pack: Cost $(\$)$} & 2,648 & 1,984 & 9,993 & 5,713 \\
\hline & Life (yr) & 2.8 & 4.7 & 7.2 & 8.0 \\
\hline \multirow[t]{2}{*}{ Third battery pack: } & Cost $(\$)$ & 2,402 & 1,984 & & \\
\hline & Life (yr) & 3.5 & 4.7 & & \\
\hline \multirow[t]{2}{*}{ Fourth battery pack: } & Cost $(\$)$ & 2,099 & & & \\
\hline & Life (yr) & 4.3 & & & \\
\hline \multicolumn{6}{|l|}{ Average cost } \\
\hline \multicolumn{2}{|c|}{ Discounted avg. cost $(\$ / y r)$} & 874 & 475 & 2,235 & 849 \\
\hline \multicolumn{2}{|l|}{ Average cost/mile $(\Phi)$} & 7.94 & 4.32 & 20.32 & 7.71 \\
\hline
\end{tabular}

computed on the assumption that the last battery pack would be used such that the consumer would pay only for the part of its life used. The consumer would be able to sell the battery pack and retrieve the cost of unused battery life when the vehicle is scrapped. (Alternatively, we can assume a used battery market, where the consumer would be able to buy a battery pack to match the remaining vehicle life.)

\subsection{Amortized Purchase Price}

In order to arrive at the total lifecycle cost to the owner of an EV, the purchase price must be discounted and converted to average annual and per-mile costs. The purchase price used here excludes batteries, since the cost of the first battery pack is included in the operating costs.

In Section 8, we estimated the EV purchase price under several alternative production methods. A few vehicle manufacturers have introduced electric vehicles that are based on new designs. However, these vehicles were produced in very low volumes of less than 500. When produced in volumes of close to 10,000, the manufacturers may either adapt an existing platform or select a new design. We selected an approach in which we added the electric drive cost to the common components' MSRP contribution of \$10,010 (from Table 8.2). In this lifecycle cost analysis, we characterized our subcompact EVs to meet three conditions: to have a battery pack with minimum energy content of $15 \mathrm{kWh}$, to have zero-to-60-mph acceleration times in the range of 10-12 seconds, and to have no decline in range between the two analysis points in time (e.g., time of introduction and high-volume production). Because of these conditions, the electric drive characteristics differed among the four EVs analyzed (two battery types at two points in time). Table 9.3 summarizes EV characteristics and MSRP contribution by various components. 
Table 9.3 Subcompact EV Powertrain Characteristics and Purchase Price

\begin{tabular}{|c|c|c|c|c|}
\hline \multirow[b]{2}{*}{ Item } & \multicolumn{2}{|c|}{ EV (with Pb-acid) } & \multicolumn{2}{|c|}{ EV (with Ni-MH) } \\
\hline & $\begin{array}{l}\text { At EV } \\
\text { Intro. }\end{array}$ & $\begin{array}{c}\text { At High } \\
\text { EV Volume }\end{array}$ & $\begin{array}{l}\text { At EV } \\
\text { Intro. }\end{array}$ & $\begin{array}{c}\text { At High } \\
\text { EV Volume }\end{array}$ \\
\hline \multicolumn{5}{|l|}{ Powertrain characteristics } \\
\hline Induction-motor peak power (kW) & 79 & 61 & 61 & 60 \\
\hline Battery power (kW) & 108 & 94 & 83 & 69 \\
\hline Battery energy (kWh) & 15.0 & 15.0 & 24.9 & 20.7 \\
\hline \multicolumn{5}{|l|}{ MSRP contribution (\$) } \\
\hline Common components $(\$)$ & 10,010 & 10,010 & 10,010 & 10,010 \\
\hline Controller (\$) & 5,095 & 1,940 & 3,935 & 1,910 \\
\hline Motor $(\$)$ & 1,795 & 1,020 & 1,380 & 750 \\
\hline Gear drive $(\$)$ & 550 & 455 & 450 & 385 \\
\hline Air-conditioning drive $(\$)$ & 135 & 115 & 135 & 115 \\
\hline Total excluding battery $(\$)$ & 17,585 & 13,540 & 15,910 & 13,170 \\
\hline Amortized cost ( $\$ / \mathrm{mi})$ & 17.03 & 13.12 & 15.41 & 12.76 \\
\hline
\end{tabular}

\subsection{Total Lifecycle Costs}

Both the EV and CV would have some scrappage value at the end of their useful lives. We assumed these values to be nearly identical and ignored them in our calculations. For the EV, we assumed that the battery pack would have some value and that this value would be recovered. Table 9.4 summarizes the estimated lifecycle ownership costs (excluding registration and insurance).

Table 9.4 Lifecycle Ownership Costs of Subcompact CV and EV (c/mi)

\begin{tabular}{|c|c|c|c|c|c|c|}
\hline \multirow[b]{2}{*}{ Cost Item } & \multicolumn{2}{|r|}{ CV } & \multicolumn{2}{|c|}{ EV (with Pb-acid) } & \multicolumn{2}{|c|}{ EV (with Ni-MH) } \\
\hline & $\begin{array}{l}\text { At EV } \\
\text { Intro. }\end{array}$ & $\begin{array}{c}\text { At High } \\
\text { EV Volume }\end{array}$ & $\begin{array}{l}\text { At EV } \\
\text { Intro. }\end{array}$ & $\begin{array}{c}\text { At High } \\
\text { EV Volume }\end{array}$ & $\begin{array}{l}\text { At EV } \\
\text { Intro. }\end{array}$ & $\begin{array}{c}\text { At High } \\
\text { EV Volume }\end{array}$ \\
\hline Amortized purchase price & 12.59 & 12.59 & 17.03 & 13.12 & 15.41 & 12.76 \\
\hline Energy and maintenance cost & 9.93 & 10.06 & 3.85 & 3.58 & 3.62 & 3.42 \\
\hline Battery cost & & & 7.94 & 4.32 & 20.32 & 7.71 \\
\hline Total & 22.52 & 22.65 & 28.82 & 21.02 & 39.35 & 23.89 \\
\hline
\end{tabular}




\subsection{Other Costs}

Looking beyond the out-of-pocket costs summarized in Table 9.4, a battery charger is an additional cost item for the EV. A charger would add nearly $0.5-1.0$ cents per mile to the lifecycle ownership cost initially and $0.25-0.5$ cents per mile at high production volume.

In comparing $\mathrm{CVs}$ and $\mathrm{EVs}$, their dissimilarities in refueling infrastructure and range between refueling should also be considered. The perceived (negative) values of limited refueling infrastructure and range have been analyzed by researchers (Bunch et al. 1991; Tompkins et al. 1998). According to Bunch et al., an average consumer values the utility of a $10 \%$ refueling infrastructure (i.e., having only one EV refueling station per ten gasoline refueling stations) as equivalent to $-\$ 8,000$. No utility value was provided for availability of home refueling. Tompkins et al. estimated a utility value of $-\$ 7,500$ for a $10 \%$ refueling infrastructure (with no home refueling option) and one of $+\$ 2,300$ for home refueling. The findings by Tompkins et al. indicate that the availability of home refueling would be a positive aspect, equivalent to a $\$ 2,300$ premium. Our incremental EV prices (amounts in excess of CV prices) at high production volume (including battery, but excluding charger) are $\$ 2,500$ for the lead-acid case and \$5,900 for the nickel-metal hydride case. Consumers who have the home refueling option could view EVs with lead-acid batteries favorably if the vehicle's limited range is not a problem. The limited refueling infrastructure would affect the level of acceptance only during the introductory years. We assume that by the time high-volume production was achieved, the refueling infrastructure would no longer be limited.

Our EVs with lead-acid batteries have a range of 52 miles initially and 68 miles at high production volume. The range increases to 106 miles (both initially and at high production volume) with the nickel-metal hydride battery. Bunch et al. estimated the perceived penalty for limitation to a 75 -mile range as equivalent to $-\$ 16,000$ and that for a 106-mile range as equivalent to $-\$ 13,000$. The corresponding estimates by Tompkins et al. are $-\$ 8,100$ and $-\$ 7,000$, respectively. These high penalties for shorter range indicate that EVs would be significantly less attractive to average consumers. Perception of higher quality, reliability, prestige, and other benefits among vehicle brands results in price differences between similar vehicles. However, these differences are less than $\$ 1,000$ for the base versions and $\$ 2,000$ to $\$ 2,500$ for the luxury versions of subcompact cars (for example, Dodge Neon and Toyota Corolla). In such cases, the higher-priced versions are perceived as offering greater utility to the consumer. Asking customers to accept a shorter range is equivalent to asking them to forgo something without any price reductions. The EV owner is forced to arrange his/her schedule to stay within the vehicle's range. The average consumer purchases vehicles to satisfy both short and long trip needs. If EVs cannot satisfy the long trip needs, then they must be marketed as niche vehicles, catering to some special needs of households or to those few households that have no occasion for a range in excess of 75-100 miles.

\subsection{Summary of Lifecycle Ownership Cost Analysis}

A subcompact CV would have a substantial advantage over an initial EV in terms of lifetime ownership costs. The CV has a lower amortized purchase price and does not have any battery pack cost. The electric powertrain is simple and has significant cost reduction potential when 
produced in high volumes. Given our optimistic assumptions about low manufacturing cost and long-term cost reduction potential for the electric drive, the EV's amortized purchase price (excluding battery) could be very similar to the CV's, but only at production volumes of 100,000 or more. The estimated energy and maintenance costs, both initially and at high volume, are lower for the EV. However, the initial EVs do not have a lifecycle cost advantage when the battery cost is added. If the projected advances in battery performance and cost materialize, the EV with lead-acid battery could have a slightly lower lifecycle cost than the CV at high-volume production. Thus, the battery pack cost must be reduced and the battery life improved for the EV to be cost-competitive. The EVs characterized in this example have very limited range (42-79 miles) and, consequently, would be used for local driving only. Consumers perceive the limited range negatively, and consequently the size of the EV market would be small. The inherent contradiction in these estimates is that EVs would have to be produced in high volumes for many years before they could become cost-competitive with CVs. In view of the high early costs and low EV range, several years of high-volume production would appear unlikely in the absence of regulations or some kind of subsidy.

\subsection{References}

AAMA, 1998, AAMA Motor Vehicle Facts and Figures '97, American Automobile Manufacturers Association, Detroit, Mich.

Bunch, D.S., et al., 1991, Demand for Clean-Fuel Personal Vehicles in California: A DiscreteChoice Stated Preference Survey, Institute of Transportation Studies, University of California at Irvine, Report UCI-ITS-WP-91-8, Irvine, Calif.

Davis, S.C., 1998, Transportation Energy Data Book: Edition 18, Oak Ridge National Laboratory Report ORNL-6941, Oak Ridge, Tenn.

EIA, 1997, Annual Energy Outlook 1998 with Projections through 2020, U.S. Department of Energy, Energy Information Administration, Report DOE/EIA-0383(98), Washington, D.C.

FHWA, 1997, 1995 NPTS Data File: Compact Disk and Code Book, U.S. Department of Transportation, Federal Highway Administration, Washington, D.C.

Kalhammer, F.R., A. Kozawa, C.B. Moyer, and B.B. Owens, 1995, Performance and Availability of Batteries for Electric Vehicles: Report of the Battery Technology Advisory Panel, California Air Resources Board, El Monte, Calif.

Mintz, M., A.D. Vyas, and L.A. Conley, 1993, Differences between EPA-Test and In-Use Fuel Economy: Are the Correction Factors Correct?, Transportation Research Record No. 1416, pp. 124-130, Transportation Research Board, Washington, D.C.

Tompkins, M., et al., 1998, "Determinants of Alternative Fuel Vehicle Choice in the Continental United States," Transportation Research Record No. 1641, pp. 130-138, Transportation Research Board, Washington, D.C. 
Vyas, A.D., H.K. Ng, D.J. Santini, and J.L. Anderson, 1997, Electric and Hybrid Electric Vehicles: A Technology Assessment Based on a Two-Stage Delphi Study, Argonne National Laboratory Report ANL/ESD-36, Argonne, Ill.

Vyas, A., R. Cuenca, and L. Gaines, 1998, An Assessment of Electric Vehicle Life Cycle Costs to Consumers, Proceedings of the 1998 Total Life Cycle Conference, pp. 161-172, SAE International Report P-339, Warrendale, Penn. 


\section{Section 10 Summary and Conclusions}

An evaluation of future EV production and operating costs is presented in this report. The cost estimates presented here are for high-volume production. The cost structure of an EV component is assumed to be similar to that of an equivalent CV component. First, the material contents of EV components are analyzed, and then material costs are estimated. Labor and plant overhead are added to obtain manufacturing costs. Divisional and corporate overheads and other margins typical of automotive practice are added next to obtain MSRP. Three separate sets of factors representing recovery rates for overhead expenses are estimated for components manufactured in-house, those procured from outside suppliers, and those for the battery. Several alternative methods of EV body and chassis production are investigated, each resulting in its own cost estimate, but only one set of cost estimates is developed for the EV powertrain components. The purpose of the analysis is to present the long-term, high-volume costs that could become feasible once the initial problems associated with introducing a new product are resolved and both learning and production volume benefits are realized. The following conclusions and observations are reached from the analysis:

1. The initial cost (i.e., purchase price) of the EV is projected to be higher than that of the $\mathrm{CV}$, even under the most favorable assumptions. The basic EV (excluding battery) could possibly be produced at a slightly lower cost than the $\mathrm{CV}$, but the high cost of the battery pack contributes substantially to the EV's cost.

2. The long-term operating cost of the EV would be comparable with that of the CV, despite the projected low fuel prices. The initial costs will be higher, even under the most optimistic assumptions. Although the energy cost is much lower for the EV, the battery replacement cost would more than offset this advantage. Only after a decade or more of continuous development and volume building would the EV be able to show a slight advantage over the $\mathrm{CV}$ with respect to operating costs.

3. Given the EV's high costs during the initial years and only marginal advantage at high production volumes, it would be difficult to economically justify the adoption of EVs by a large segment of vehicle buyers. The resulting absence of steady demand would make attainment of the high production levels assumed in this analysis very difficult. Only strong incentives or strictly enforced regulations could lead to high EV sales.

4. The EV's advantages of zero tailpipe emissions, quiet operation, energy efficiency, and use of nonpetroleum fuels are largely offset by its practical shortcomings of high cost and shorter range. The issues of refueling time and charger costs are not addressed in this study.

5. The lowest-cost EV production is obtained when an OEM uses an existing CV platform as the base. If the EV is produced by using a new platform, its cost increases by nearly $7 \%$. However, a specially designed new platform could offer advantages in terms of occupant comfort and vehicle operation and maintenance. The analysis did not assign 
any monetary value to these differences between existing and specially designed platforms.

6. Assembling the EV from a well-designed glider could be a cost-effective production method at medium volumes.

7. Conversion from a $\mathrm{CV}$, an uneconomical way to produce the $\mathrm{EV}$, would be applicable only to very-low-volume production.

8. The leading energy storage alternative for the EV, an electrochemical battery, involves high initial and replacement costs. Several battery types are under development, but their future costs to consumers are uncertain. The costs presented here are from published information on two well-researched battery types.

9. The convenience of home refueling is an advantage for the EV. However, that option is available only to people with private recharging facilities. Others will have to rely on public recharging facilities, which would be scarce during the introductory years. Because consumers assign a substantial penalty to the lack of refueling infrastructure, the need for private recharging facilities could limit the new and used EV markets during the introductory phase.

10. All the leading battery technologies have limited calendar and cycle lives. These limitations significantly reduce the economic viability of the EV. With the battery technologies currently available, an EV will require one or more battery replacements during its service life, adding substantially to its operating cost.

11. High-performance batteries, those with high specific energy and long cycle lives, require special high-quality materials and specialized manufacturing processes. These requirements make such batteries very expensive.

12. Aside from cost, the mass and bulk of an EV battery pack constrain its power and energy storage capacity. A high-performance $(100-\mathrm{W} \cdot \mathrm{h}, 250-\mathrm{W} / \mathrm{kg})$ battery pack with an energy storage capacity equivalent to only one U.S. gallon of gasoline would weigh nearly $746 \mathrm{lb}$ and occupy a volume of 47 gallons. Such a battery pack would provide $85 \mathrm{~kW}$ (113 hp) of power. The increased vehicle mass associated with the large battery pack would consume more energy to move the vehicle. Although lightweight materials can be used to reduce vehicle mass, their use also increases a vehicle's cost.

13. The cost of the EV powertrain and control systems would be very comparable with that of the $\mathrm{CV}$ powertrain under high-volume EV production. While the electric traction motor and gear drive of the EV are much cheaper, more compact, and lighter, the electronic controller is very expensive, offsetting the cost advantage even under the optimistic assumptions used here. As a result, the basic EV (excluding battery) would cost almost the same as the CV. 


\section{Appendix A Vehicle Body Materials}

Present-day manufacturing technology for passenger cars and light trucks relies almost exclusively on sheet steel as the main material for body component fabrication. A passenger vehicle's body-in-white (unpainted metal) typically includes one main structural member (the unibody), plus two front fenders and several closures (such as doors, hood, and deck lid). The unibody is the single largest component in cars and minivans. It encloses the passenger compartment and provides the necessary structure on which to mount the drivetrain and chassis components. The closures and fenders are less structural in nature (although doors have important structural functions for crashworthiness), their main function being as covers for the various access openings. The almost universal practice is to form the individual parts of the body-in-white from sheet steel on stamping presses and then join them together by spot-welding. This process of body manufacture is very cost-effective and particularly well suited for mass production. Sheet steel, one of the least expensive engineering materials, is delivered at the plant at a cost of \$0.40-0.50 per pound. Sheet forming through stamping produces complete parts at the rate of several units per minute. Cars are assembled in a highly mechanized process at a rate of nearly one car per minute (GM car assembly lines produce 55-70 units/hr, Ford 48-66, and Chrysler 51-61). Consequently, the component production rate has to be at least $1 \mathrm{unit} / \mathrm{min}$, or preferably much higher. Spot-welding is also a highly productive process, well suited for automation. The average car body includes 3,000-4,000 welds, but since the process is broken down into many stations, it is not difficult to achieve the necessary overall production rates. Individual sheet metal parts are joined together at feeder stations into more complex subunits, which may then be joined to still more units before they enter the main body assembly shop. Within the shop, the entire body is put together, usually with the help of such highly automated equipment as robots. From the assembly shop, the body goes on to the paint shop, where it is properly coated and readied to go to the final assembly line.

\section{A.1 Candidate Lightweight Materials}

Although a passenger vehicle body made of steel is very practical and cost-effective, it is also relatively heavy. Other materials offer the possibility of a much lighter body with comparable functionality, though not necessarily at an equivalent cost. Two types of such lighterweight materials have been seriously considered: aluminum and polymer composites (PC).

Aluminum was used in passenger vehicle bodies early in the beginning of automobile production, when it competed on equal terms with wood, steel, and fabric (steel became the predominant body material in the mid-1920s). Over the years, it has been used in selected vehicles (1923 Pierce Arrow, 1932 Stutz, 1953 Panhard Dyna, 1990 Honda NSX, 1995 Audi A8). Polymerbased composites are more recent, and their use in passenger vehicles has been limited primarily to nonstructural members (outer skin panels, fenders, closures) in conjunction with steel structures. The composites used in most production vehicles (Corvette, Fiero, Saturn, Viper) have been reinforced primarily with fiberglass, which is not a high-performance fiber. As a result, weight savings have been modest, the main criteria for composites' selection being reduced tooling cost and manufacturing flexibility. However, polymer-based composites with high-performance reinforcing fibers (carbon/graphite and kevlar), which have been widely used 
in experimental vehicles and racecars, have a significant mass reduction potential in structural body applications.

\section{A.1.1 Aluminum}

The manufacturing technology for aluminum-intensive passenger vehicle bodies is fairly well defined, but it is certainly not as well developed as that for steel bodies, which have been in production for about 80 years. Aluminum-intensive vehicle bodies can be produced by using two different structural design approaches, stamped sheet and space frame. A vehicle body made from stamped aluminum sheet is very similar to the equivalent stamped steel sheet body. The main difference between aluminum and steel sheet body manufacture is in the joining. Aluminum is more difficult to spot-weld; therefore, a combination of welding and bonding or mechanical joining (rivets, clinching) and bonding is often used. However, the characteristics of steel and aluminum stamped-sheet bodies are very similar, both in the nature (and cost) of their tooling and in their suitability for mass production.

Space-frame-type aluminum bodies, however, are quite different from those made from steel. A space-frame vehicle body relies primarily on an internal structure (the space frame proper) to provide the necessary strength and rigidity. The space-frame structure is then covered with a set of external (skin) panels, which have rather secondary structural functions (if any). The Fiero and Saturn automobiles were/are fabricated this way, with an internal space frame made from stamped steel sheet parts, and skin panels molded from various polymer-composite materials. The Viper roadster also employs an internal space-frame structure with molded polymer-composite skin panels, but the former is made primarily from welded steel tubing segments, as in a NASCAR racer. The aluminum space-frame structures for passenger vehicles are somewhat like the one used in the Viper; they primarily employ extruded aluminum segments that are welded and/or bonded together. Aluminum is relatively easy to extrude, even into complex cross sections, so it becomes a natural choice for vehicle space-frame structures. On the other hand, steel is not easily extruded, especially into complex cross sections. What makes stamped components far more practical is that steel is suitable for them. However, when volumes are very small, as in the Viper, the use of simple round or square steel tubing is cheaper than stamping, which involves high tooling costs.

The Audi A8 passenger car uses a space-frame structure made primarily from extruded aluminum segments and aluminum die casting nodes, welded/bonded together at the node points; the structure is then covered with riveted/bonded aluminum sheet skin. The Chrysler Prowler retro street rod employs a chassis frame structure made primarily from welded extruded aluminum components, with a stamped aluminum sheet body mounted on top. In either case, the use of extrusions makes the characteristics of aluminum space (or chassis) frames quite different from those made of stamped steel. The high cost and long life of stamping dies are best for highvolume production (in terms of economic justification), while the much lower investment in extrusion dies allows economical aluminum structural frame manufacturing at much lower production rates. On the other hand, the relatively short life and lower productivity of extrusion tooling makes high-volume production less practical. Therefore, for lower unit production costs, high-volume production of aluminum (or steel) bodies should be based on the stamping process 
(welded and/or bonded), whereas for low-volume production, bodies based on extruded component structures are generally preferred.

\section{A.1.2 Polymer Composites}

The technology of manufacturing advanced polymer-composite-intensive passenger vehicle bodies is not as well defined as that of aluminum-intensive manufacture. Experience with PCintensive vehicles of any kind is very limited, and experience with even a modest level of production is nonexistent. The few vehicles that use any significant amount of advanced PCs have been made essentially by hand lay-up techniques borrowed from the aerospace industry by Bugatti and others (Automotive Engineering 1993). That type of manufacturing process is unsuitable for passenger vehicles because of its high cost and low volume capacity. The manufacturing processes currently proposed are based on resin-transfer molding (RTM), which is faster and less labor-intensive than hand lay-up. However, RTM is still slow compared to conventional steel fabrication processes. In addition, the RTM process cannot utilize fiber orientation as efficiently as the hand lay-up process does. Consequently, there is some deterioration in the structural performance as well. Still, the best alternative envisioned so far for advanced PC vehicle body manufacture is based on RTM production of a small number of major body components, which are bonded by means of adhesives to form a complete body assembly. The reinforcing material would be carbon/graphite fibers, and the polymer matrix would be either vinylester or a thermoplastic resin with foam cores added at strategic locations.

\section{A.2 Cost of Lightweight Materials}

The impacts of lightweight-material use on the cost of the passenger vehicle body are twofold: raw material cost and process-related cost (including labor). The bulk of a conventional vehicle body is made from mild steel sheet, one of the lowest-cost engineering materials available ( $\$ 0.40 / \mathrm{lb})$. Sheet aluminum costs nearly four times as much $(\sim \$ 1.50 / \mathrm{lb})$. Aluminum extrusions and castings (both used in space-frame-type bodies) are somewhat less expensive $(\sim 1 / \mathrm{lb})$. Carbon-reinforcing fiber sells for about $\$ 8-10 / \mathrm{lb}$, and the resin for the matrix sells for $\$ 1-2 / \mathrm{lb}$. The resulting composite, with $50 \%$ fiber content, would cost $\$ 4.50-6.00 / \mathrm{lb}$. Even though the actual amount of material (in pounds) used is less, the cost of these lower-density alternatives would be higher. For instance, an aluminum body can be designed to perform comparably to a steel body (rigidity, strength, crashworthiness) yet weigh only about 50-55\% as much. That means the aluminum body requires only about half the amount of material, but since aluminum costs about four times as much as steel, the raw material cost (assuming the same amount of scrap) would still be roughly twice as high. A well-designed polymer-composite body might weigh only $40-45 \%$ as much as a comparably performing steel body, but with raw material costs 11.25-15 times higher (per pound), the material cost for the body would still be 4.5 to 6 times higher (at the same scrap rate). If the molding process produced very little scrap (hand lay-up has high scrap rates), then some additional savings would accrue, perhaps lowering the raw material cost to 3-4 times as much as steel. The amount of steel required to make one mid-size car body (assuming 50\% scrap) may cost around \$500. Therefore, the per-vehicle premium introduced by the cost of the raw lightweight materials (not counting process costs) could be on the order of $\$ 500$ for aluminum sheet and $\$ 1,000$ to $\$ 1,500$ for advanced polymers. 
Each of these materials has a process-related cost associated with it. A conventional midsize car steel body-in-white costs about $\$ 1500$ to make, so the process-related costs are about $\$ 1000$. Two processes are being considered in the case of aluminum: stamped sheet and space frame. In the case of stamped sheet aluminum, the process-related cost would be either identical to that of steel or higher by $10 \%$ because of additional forming and handling complexities. In the case of space-frame bodies, a significant relative reduction in process-related cost is possible for low-volume production (under 100,000 units/yr), primarily because of lower tooling cost and lower scrap rates. At higher production rates, the process-related cost of space-frame-type bodies could be equal to or lower than that of conventional steel bodies. The process-related cost of PC bodies is far more speculative than that of aluminum bodies. In general, this cost is expected to be higher for labor (because of high molding times) and lower for tooling and assembly (because of parts consolidation); the net result is expected to be about even with the cost of steel body processing.

The mass reduction potentials for aluminum and $\mathrm{PC}$ are different. Although the density ratio of steel is nearly 2.7 times that of aluminum, the mass reduction potential is lower because of rigidity and strength requirements. One pound of aluminum can replace 1.7 to $1.9 \mathrm{lb}$ of steel, where rigidity is the primary requirement. When a component is designed for strength, the replacement potential increases to $2 \mathrm{lb}$ of steel or more, depending on the requirements (Stodolsky et al. 1995). A PC-intensive vehicle is projected to have slightly higher mass reduction potential. Table A.1 compares the mass reduction potentials of aluminum and PC with respect to the conventional steel body-in-white. Lightweight materials can be substituted in other subgroups, too, and a lighter body and chassis would necessitate smaller components. The resulting maximum potential for primary and secondary mass reduction has been estimated as $31 \%$ for aluminum and $40 \%$ for PC (Stodolsky et al. 1995).

Table A.1 Mass Reduction Potential and Costs of Lightweight Materials

\begin{tabular}{|lccc|}
\hline \multicolumn{1}{|c}{ Body Material } & Mass (\%) & $\begin{array}{c}\text { Raw Material } \\
\text { Cost (\%) }\end{array}$ & $\begin{array}{c}\text { Total Mfg. } \\
\text { Cost (\%) }\end{array}$ \\
\hline Steel & 100 & 100 & 100 \\
Aluminum (stamped) & $50-55$ & 200 & 140 \\
Aluminum (space frame) & $55-60$ & 150 & 120 \\
Polymer composites & $40-45$ & 350 & 180 \\
& & & \\
\hline
\end{tabular}

\section{A.3 References}

Automotive Engineering, 1993, Warrendale, Penn., p. 77 (May).

Stodolsky, F., A. Vyas, and R. Cuenca, 1995, "Lightweight Materials in the Light-Duty Passenger Vehicle Market: Their Market Penetration Potential and Impacts," presented at the Second World Car Conference, University of California at Riverside, Riverside, Calif. 


\section{Appendix B \\ Battery Designs and Materials}

\section{B.1 Advanced Lead-Acid Battery}

Lead-acid (Pb-acid) batteries are used for automotive electrical systems, and information about their production is available. These batteries are also recycled commercially. The production and recycling processes for materials in conventional lead-acid batteries can be used with minimal changes for advanced EV batteries. Therefore, costs of manufacturing these batteries can be estimated. The battery lifetime is up to 80,000 miles, so at least one replacement would generally be necessary over an EV's lifetime (Moore 1994).

\section{B.1.1 Battery Design}

The Horizon EV battery, developed by Electrosource of Austin, Texas, and BDM Technologies, is an advanced lead-acid battery ready for limited commercial production. This battery has an energy density of over $45 \mathrm{~W} \cdot \mathrm{h} / \mathrm{kg}$. It uses electrodes produced by co-extruding "an alloy of lead onto a high tensile strength core material, making a small diameter, dimensionally stable wire that is woven into lightweight bipolar mesh grids" (Electrosource 1993). The core can be graphite or fiberglass (Moore 1994). The electrodes are coated with a proprietary paste and assembled horizontally into batteries. The paste is reportedly made from refined lead dust and dilute sulfuric acid. For the negative electrode, a small amount $(\sim 1 \%)$ of carbon black, barium sulfate, and lignin-sulfonate is added. For the positive electrode, about $0.03 \%$ of a polymer, such as polypropylene, or possibly glass fiber is added (Geomet Technologies 1993). Fiberglass mats between the porous electrodes separate them and hold the acid electrolyte, which is all absorbed in the mats and electrodes.

\section{B.1.2 Battery Materials}

Because even advanced lead-acid batteries have the lowest energy density of the batteries considered, they use the largest mass of materials. At $50 \mathrm{~W} \cdot \mathrm{h} / \mathrm{kg}$, a $25-\mathrm{kWh}$ battery module would weigh $500 \mathrm{~kg}(1100 \mathrm{lb})$. The materials inside advanced lead-acid batteries are lead, lead oxide, acid, and fiberglass mats. The containers/covers are generally polypropylene (PP), but steel can also be used. Aluminum trays were considered, but lightweight steel was determined to be cheaper. Approximate material composition and material prices for advanced lead-acid batteries are shown in Table B.1. Specific information about the major materials follows.

Lead. Lead, like many other metals, is traded as a commodity. Its price, therefore, is subject to wide fluctuations. In 1994, the monthly average New York price ranged from $\$ 0.34$ to $\$ 0.44$; since 1980, the average has ranged from a low of $\$ 0.19$ to a high of $\$ 0.51$. For any material subject to such large price variations, long-term contracts or other mechanisms for stabilizing price would encourage use. Worldwide lead reserves are large, and the infrastructure for recycling is already in place, so the supply of lead should not be an issue in battery selection. 


\begin{tabular}{|c|c|c|c|}
\hline Material & Weight $\%$ & Price (\$/lb) & Cost (\$/kWh) \\
\hline Lead & 69 & $0.34-0.44$ & $10.3-13.4$ \\
\hline Electrolyte & 22 & & \\
\hline Sulfuric acid (pure) & 7.9 & $0.01-0.04$ & $0.04-0.14$ \\
\hline Water & 14.1 & $<0.05$ & $>0.31$ \\
\hline Case and cover (PP) & 6.1 & $0.38-0.52$ & $1.02-1.40$ \\
\hline Separators (glass mat) & 2.1 & $0.7-1.10$ & $0.65-1.02$ \\
\hline Other & 0.8 & 0.5 (est.) & 0.18 \\
\hline Total & 100 & & $12.51-16.40$ \\
\hline
\end{tabular}

Sulfuric Acid. Sulfuric acid can be produced from elemental sulfur or as a by-product of smelting metals from sulfide ores. In either case, the supply is abundant and the cost is only a few cents per pound, so electrolyte cost for lead-acid batteries is unimportant.

Polypropylene. Polypropylene (PP), made from natural gas liquids and various petroleum fractions, is produced in large volumes for various automotive and household purposes. The price varies by grade, but it is not particularly volatile. The infrastructure for recycling battery cases is already in place, although increased volume due to large numbers of EV batteries would necessitate capacity expansion. Neither price nor supply should be a major issue.

Fiberglass. The price of fiberglass also depends on the material grade, with high-strength continuous strands commanding the highest price. For instance, S-2 glass sold for $\$ 6.05 / \mathrm{lb}$ in 1996, and Owens Corning ZenTron was quoted at the time at $\$ 5.70 / \mathrm{lb}$ in truckload quantities (High Performance Composites 1996). These prices represent an upper bound for the cost of material for batteries, because there is no indication that specially high-performance fiberglass is required. Our cost estimate is based on typical prices for the lower grades. If the highest grades were required, the total cost of battery materials would be about one-third higher than our estimate; this would still leave lead-acid batteries with the lowest material costs of any of the batteries examined.

\section{B.2 Sodium-Sulfur Battery}

The Ford Ecostar was originally projected to use a sodium-sulfur (Na-S) battery, and the Audi Quattro used such a battery as part of its hybrid design. However, the only U.S. producer, Silent Power, went out of business in May 1996 (Rasmussen 1996). A noteworthy feature of the sodium-sulfur battery was that it operated at high temperature (at least $300-350^{\circ} \mathrm{C}$ ), which had to be maintained by insulation and/or heating from an outside source if the battery was not used daily. The battery was targeted for 1000-cycle life, which means that a replacement would probably have been needed over the vehicle life. 


\section{B.2.1 Battery Design}

The positive electrode was made of molten sulfur (graphite felt impregnated with S), and the negative electrode was molten sodium. Because sodium is extremely reactive, containing the materials was a crucial element of the battery design. Safety and regulatory issues were discussed in a series of reports by the National Renewable Energy Laboratory (Ohi 1992; Corbus 1992).

The battery consisted of multiple cells. Each cell contained a solid ceramic beta-alumina electrolyte, produced by electrophoretic deposition or isostatic pressing; this electrolyte was sealed to an alpha-alumina component that insulated, with a glass seal on the electrolyte tube. The individual cells were housed in cylindrical metallic cell casings ( $\mathrm{Al}$ or steel tubes) arranged in an array, with as many as 2000 in a double-walled thermal vacuum box. Banks of cells could be connected by mild steel plates.

\section{B.2.2 Battery Materials}

The energy density in batteries of this type is estimated to be $80-200 \mathrm{~W} \cdot \mathrm{h} / \mathrm{kg}$, up to four times that of conventional $\mathrm{Pb}$-acid batteries, so they would be relatively lightweight. The specific energy of the cells themselves might be even higher (up to a theoretical $760 \mathrm{~W} \cdot \mathrm{h} / \mathrm{kg}$ ), but the thermal enclosure would add considerable mass. At $100 \mathrm{~W} \cdot \mathrm{h} / \mathrm{kg}$, a $25-\mathrm{kWh}$ battery pack would weigh $250 \mathrm{~kg}(550 \mathrm{lb})$. The materials used included low-carbon steel, aluminum, stainless steel, copper, ceramics, sodium, sodium polysulfides, chromium, sulfur, alumina, and graphite. NREL estimated $\sim 40 \mathrm{~kg} \mathrm{Na}$ and $60 \mathrm{~kg} \mathrm{~S}$ for a 50-kWh battery (Corbus 1992). Another estimate put the relative masses at $\sim 12 \% \mathrm{~S}, 6 \% \mathrm{Na}$, and $20 \%$ ceramics, with most of the remainder steel (DeLuchi 1991).

Because the battery operated at high temperature, plastics could not be used for the cell casings. The housing, with modules placed in steel or aluminum outer double-walled, evacuated cylindrical containers, represented a large fraction of the total battery weight. One source described the thermal enclosure as having a wall spacing of 1 in., with 0.01-in. stainless steel sheets separated by fiberglass insulation board (Haskins and Reitz 1986). Other separators would be possible. Approximate material composition and material prices for sodium-sulfur batteries are shown in Table B.2.

Sodium. Technical grades of sodium have sold for approximately $\$ 1.50 / \mathrm{lb}$, but Na-S battery electrode material must be of very high purity. In 1996, the high-purity material sold for $\$ 10-100 /$ lb (Rasmussen 1996). Mass sales would presumably be at the low end of this range. Recycling of Na-S batteries was expected to yield high-purity material, which would have helped to ensure that supply was not a problem.

Sulfur. Sulfur is an abundant, low-cost element that can either be mined or recovered from smelters and other industrial sources. Its contribution to battery cost is negligible. 


\begin{tabular}{|c|c|c|c|}
\hline Material & Weight \% & $\begin{array}{l}\text { Price } \\
(\$ / l b)\end{array}$ & $\begin{array}{c}\text { Cost } \\
(\$ / k W h)\end{array}$ \\
\hline $\begin{array}{l}\text { Sulfur } \\
\text { Graphite }\end{array}$ & 12 & $0.01-0.04$ & $0.03-0.11$ \\
\hline Sodium & 8 & $10-100$ & $17.60-176.00$ \\
\hline Ceramics & 20 & 140 & 616.00 \\
\hline Steel & $<60$ & $0.18-0.28$ & $<2.38-3.70$ \\
\hline Fiberglass & & $0.7-1.10$ & \\
\hline Total & & & $635-794$ \\
\hline
\end{tabular}

Beta-Alumina Electrolyte. The material used in the electrolyte is a ceramic in the sodium aluminate class, $\mathrm{Na}_{2} \mathrm{O} \cdot \mathrm{XAl}_{2} \mathrm{O}_{3}$, where the value of $\mathrm{X}$ varied from 5 to 11 for the different compounds under consideration. The first few process steps (mining of bauxite, refining, and production of alumina) were similar to those used for production of primary aluminum. The ceramic production added significant additional cost. To produce the electrolyte, bauxite had to be reacted with sodium salts and sintered at $1600^{\circ} \mathrm{C}$ for $5 \mathrm{~min}$ to get the correct structure (Rasmussen 1994). After the reaction step, the electrolyte powder was pressed into tubes. The price for the ceramic electrolyte was high: a price of $\$ 0.10 / \mathrm{cm}^{2}$ (Rasmussen 1996) would translate to a per-pound cost of $\$ 140$, based on a thickness of $1 \mathrm{~mm}$ and a density of $3.25 \mathrm{~g} / \mathrm{cm}^{3}$. However, this was the price for a low-volume prototype material; there was nothing about the required product specifications that would have prevented the cost from dropping, perhaps to a few dollars per pound, in mass production. An earlier paper estimated electrolyte cost at \$0.01$0.03 / \mathrm{cm}^{2}$ (Miller et al. 1981). The electrolyte cost dominated Na-S battery material costs; therefore, such a cost reduction would have been necessary for mass-market penetration of this battery type.

Steel. The price of steel sheet varies between $\$ 0.18$ and $\$ 0.28 / 1 \mathrm{~b}$. Supply is not an issue, and the cost of steel was not a significant contributor to the Na-S battery's material cost.

\section{B.3 Nickel-Cadmium Battery}

Large nickel-cadmium (Ni-Cd) batteries are commercial for industrial uses. Although automotive battery design is likely to differ from industrial designs, some insights can be obtained. Several EV types have involved plans to use Ni-Cd batteries; these include the Mazda Miata, the Nissan FEV 2-seater, the Griffon van (SAFT battery), and the Peugeot 106 and Citroen AX, as well as hybrids with diesel power generators, and many others. The Chrysler TEVan (Caravan) has been tested with Ni-Cd batteries. A battery with a life of 2,000 cycles would last 6 to 10 years (Morrow 1995); therefore, it might not need replacement over some vehicles' lifetimes. 


\section{B.3.1 Battery Design}

The Ni-Cd battery can operate from $-40^{\circ} \mathrm{C}$ to $80^{\circ} \mathrm{C}$. Few design details are available in the literature. The active material in the sintered positive electrode is $\mathrm{Ni}(\mathrm{OH})_{2}$, but the overall composition is ferronickel, with nickel, iron, and sometimes graphite constituents. The negative electrode is made of cadmium and iron, compacted and plastic-bonded. Another design features "fiber-structured" electrodes. Potassium hydroxide $(\mathrm{KOH})$ is used as the electrolyte, and there are thin layers of separators in the array. The case is generally made from nickel-plated steel sheet, with sheet steel lids and bases; polypropylene cases are also possible.

\section{B.3.2 Battery Materials}

The Ni-Cd battery's energy density is not much higher than that of the advanced $\mathrm{Pb}$-acid battery. At $57 \mathrm{~W} \cdot \mathrm{h} / \mathrm{kg}$, a 25-kWh battery would weigh $439 \mathrm{~kg}$ (965 lb). New Ni-Cd batteries have been reported to have an energy density of $60-65 \mathrm{~W} \cdot \mathrm{h} / \mathrm{kg}$ (Morrow 1995), which would reduce the weight to as low as $385 \mathrm{~kg}(846 \mathrm{lb})$. The electrodes are nonreactive. The positive plates $\left[\mathrm{Ni}(\mathrm{OH})_{2}\right]$ typically may contain $22 \% \mathrm{Ni}(8 \%$ minimum $)$ if the nickel is on an iron or graphite substrate. Various designs are possible; some designs use nickel foam as the substrate, thereby requiring more nickel. The positive electrodes, which must contain less than $1 \% \mathrm{Cd}$, could possibly be reused. Various sources provide inconsistent estimates of overall material composition. The average Cd content of the battery is 15\% (Morrow 1995). Table B.3 provides estimates of nickel-cadmium material composition and material costs.

Cadmium. Cadmium (Cd) is a by-product of zinc ( $\mathrm{Zn}$ ) manufacture. Large-volume battery production could eventually strain the available supply and cause the price to rise. The Cadmium Association projected an adequate supply for at least 450,000 vehicles (Cook 1993). The price of cadmium fluctuates widely, ranging from $\$ 0.40$ to $\$ 2.35 / \mathrm{lb}$ in 1994 (monthly U.S. producer averages cited in Metal Statistics 1995). Price stabilization would help to enable market penetration of Ni-Cd batteries.

Nickel. Although nickel is produced in the United States, metal of sufficient purity for the original sintered electrode designs is only produced at two sites, both outside the country. This nickel is an extremely pure (>99.\%) powder form (INCO 123) produced by only one company in the world, at plants in Wales and Canada. A similar material is reportedly being produced in Siberia. It is produced by the carbonyl process, in which carbon monoxide (CO) is reacted with nickel at $120^{\circ} \mathrm{F}$ to form nickel carbonyl $\left(\mathrm{Ni}(\mathrm{CO})_{4}\right)$. The cobalt, copper, and iron impurities are left behind, and the nickel carbonyl is decomposed back to nickel at $450^{\circ} \mathrm{F}$. However, in the mid1990s, electrode designs were reportedly moving toward the use of nickel foam, which can be produced from commodity nickel shot (Gifford 1996). Prices for nickel mill products (e.g., plates and sheet) ranged from $\$ 8.55$ to $\$ 9.67 / \mathrm{lb}$ in 1994 (American Metals Market 1995). For use in batteries, such nickel must be processed into foam, selling some years ago for $\$ 30 / \mathrm{m}^{2}$, which at $500 \mathrm{~g} / \mathrm{m}^{2}$ translates to $\$ 27.30 / \mathrm{lb}$. In volume production, this price could be expected to come down to $\$ 15-20 / \mathrm{m}^{2}$, or $\$ 13.60-\$ 18.20 / \mathrm{lb}$ (Gifford 1996). Because the foam can be considered a partly fabricated product, its price was not used in estimating the raw materials cost. 


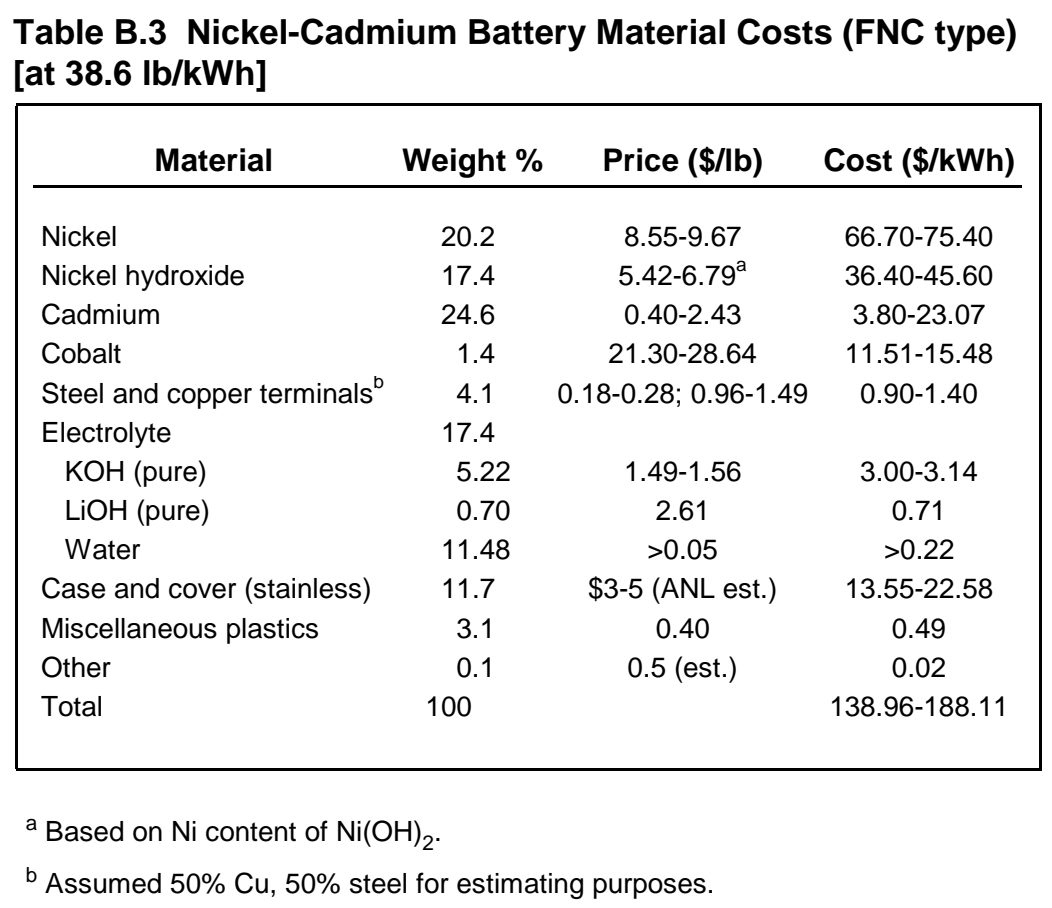

Potassium Hydroxide Electrolyte. Potassium hydroxide is a readily available commodity chemical. Its cost, at under $\$ 2 / \mathrm{lb}$, will not significantly affect the cost of $\mathrm{Ni}-\mathrm{Cd}$ or nickel-metal hydride battery materials.

\section{B.4 Nickel-Metal Hydride Battery}

Small nickel-metal hydride (Ni-MH) batteries have been in commercial use since 1987 for electronic equipment like computers and telephones. Vehicle batteries were expected to be ready for production by GM Ovonic (Troy, Mich.) in 1996; Hyundai expected to use the Ovonic battery in its EV. Ovonic claimed that the battery's life would be similar to that of the vehicle (Ovshinsky et al. 1993), so the battery would not need to be replaced; other estimates suggested that the battery would last only 3-5 years (Morrow 1995). Other manufacturers are also developing Ni-MH batteries.

\section{B.4.1 Battery Design}

This type of battery does not operate at high temperatures, but it does need some cooling because it is sealed and pressurized. As was the case with the Ni-Cd battery, the positive electrode is composed of nickel hydroxide, $\mathrm{Ni}(\mathrm{OH})_{2}$. The negative electrode is made from one of several specially engineered metal hydrides that are multiple-alloy metal matrix composites, using rare earths or vanadium, nickel, titanium, zirconium, chromium, and manganese. These composites are amorphous, meaning that the atoms are in disarray, rather than being aligned. The electrolyte is $30 \%$ aqueous potassium hydroxide, referred to as "starved" because there is no free electrolyte; rather, it is all entrained in porous electrodes or polypropylene separators. The individual cells are sealed, prismatic containers, typically made of stainless steel. Several 
different designs are available, differing primarily in the hydride composition; the design used by Ovonic is designated as the $\mathrm{AB}_{2}$ type; that by SAFT, the $\mathrm{AB}_{5}$.

In the Ovonic design, the electrodes are thin flat plates, separated by insertion in porous polypropylene bag separators that are stacked in multilayer sandwiches. A stack of electrodes forms a battery cell $(\sim 4 \times 7 \times 1$ in., with a mass of $1600 \mathrm{~g})$. Each cell has two terminals coming out of the top, on small nylon disk spacers. The case is stainless, 4 mils thick, with a green plastic shrink-wrapped cover. The cells are assembled into six 12-V modules, which are placed in the battery-pack trays. The trays, which would be designed by the auto manufacturer, could be made of ABS plastic or aluminum.

\section{B.4.2 Battery Materials}

A high energy density of $70-80 \mathrm{~W} \cdot \mathrm{h} / \mathrm{kg}$ will result in a relatively compact, lightweight battery. A $25-\mathrm{kWh}$ battery would weigh about $330 \mathrm{~kg}(730 \mathrm{lb})$. Existing technology could raise the energy density to over $120 \mathrm{~W} \cdot \mathrm{h} / \mathrm{kg}$, and advanced materials and configurations have been projected by the developer as having the potential to achieve up to $500 \mathrm{~W} \cdot \mathrm{h} / \mathrm{kg}$ (Ovshinsky et al. 1994). Such a major breakthrough could lower the weight of an EV battery pack to about $100 \mathrm{lb}$.

Published estimates of materials in Ni-MH batteries differ in the quantities of $\mathrm{KOH}$ electrolyte needed, the composition of the hydride electrode (whether or not iron is the substrate for the hydride electrode), and the amount of steel in the case. This is not surprising, given that different designs are being considered at this stage. Tables B.4 and B.5 provide estimated material composition and material costs for the $\mathrm{AB}_{2}$ and $\mathrm{AB}_{5}$ designs, respectively.

Nickel. The nickel electrodes in Ni-MH batteries are essentially the same as those in Ni-Cd batteries. The Ovonic positive electrode uses thin flat plates of nickel foam, with $\mathrm{Ni}(\mathrm{OH})_{2}$ on the surface.

Table B.4 $\quad \mathrm{AB}_{2}$ Nickel-Metal Hydride Battery Material Costs [at $29 \mathrm{lb} / \mathrm{kWh}$ ]

\begin{tabular}{|lccc|}
\hline \multicolumn{1}{|c}{ Material } & Weight $\%$ & Price $\mathbf{( \$ / ~ l b )}$ & Cost $\mathbf{( \$ / k W h )}$ \\
\hline Nickel & 16.4 & $8.55-9.67$ & $40.66-45.99$ \\
Nickel hydroxide & 12.1 & $5.42-6.79$ & $19.02-23.83$ \\
Metal hydride (V, Zr, Ti, Cr, Al) & 12.9 & $4.50-6.80$ & $16.83-25.44$ \\
Separators (PP) & 5.0 & $0.38-0.52^{\mathrm{a}}$ & $0.55-0.75$ \\
Electrolyte & 9.0 & & \\
$\quad$ KOH (pure) & 3.0 & $1.49-1.56$ & $1.30-1.36$ \\
Water & 6.0 & $>0.05$ & $>0.09$ \\
Iron & 14.5 & $<0.17$ & $>0.71$ \\
Stainless steel & 29 & $3-5$ & $25.23-42.05$ \\
Other & 1.1 & $0.5(\mathrm{est})$. & 0.16 \\
Total & 100 & & $104.55-141.84$ \\
& & & \\
\hline
\end{tabular}

a From Chemical Marketing Reporter (1996). 
Table B.5 AB $_{5}$ Nickel-Metal Hydride Battery Material Costs [38.4 lb/kWh]

\begin{tabular}{|c|c|c|c|}
\hline Material & Weight \% & Price (\$/lb) & Cost (\$/kWh) \\
\hline \multicolumn{4}{|l|}{ Nickel Electrode } \\
\hline Nickel hydroxide & 18 & $5.42-6.79$ & $36.86-46.17$ \\
\hline Cobalt hydroxide & 2.0 & 13.51-18.04 & $10.81-14.43$ \\
\hline Nickel (for foam sheet) & 8.6 & $8.55-9.67(13.6-18.2)^{a}$ & $28.22-31.91(44.88-60.06)$ \\
\hline Subtotal & 28.4 & & $75.89-92.50(92.55-120.66)$ \\
\hline \multicolumn{4}{|l|}{ Hydride Electrode } \\
\hline Hydride alloy (MmNiCoMnAl) & 24.7 & 9.52 & 90.44 \\
\hline Copper (processed) & 3.9 & $0.96-1.49$ & $1.44-2.24$ \\
\hline Collector & 3.4 & {$[7.05]^{b}$} & {$[9.17]$} \\
\hline Binder & & & {$[2.50]$} \\
\hline Subtotal & 32.0 & & $103.55-104.35$ \\
\hline \multicolumn{4}{|l|}{ Other Materials } \\
\hline Separator (PP?) & 1.0 & $0.38-0.52^{\mathrm{C}}(10.43)$ & $0.15-0.21(4.17)$ \\
\hline Electrolyte $(30 \% \mathrm{KOH})$ & 21.4 & $0.45-0.47$ & $3.69-3.85$ \\
\hline Cell case (Ni-plated steel) & 10.4 & $0.18-0.28$ & $0.72-1.12$ \\
\hline Terminals/hardware & 4.7 & $0.96-1.49$ & $1.73-2.68$ \\
\hline Miscellaneous & 2.3 & [18.52] & [16.67] \\
\hline Scrap & & & {$[9.17]$} \\
\hline Subtotal & 39.3 & & $32.13-33.70(36.25-37.66)$ \\
\hline Total & 100 & & $211.6-230.6(232.35-262.67)$ \\
\hline
\end{tabular}

\footnotetext{
a Parentheses indicate price for fabricated product (foam sheet or separator).

b Square brackets indicate price of unspecified material (Klein and Salkind 1993).

${ }^{\mathrm{c}}$ From Chemical Marketing Reporter (1996).
}

Metal Hydride Electrode. The different Ni-MH battery designs differ mainly in the composition of the metal hydride negative electrode. The $\mathrm{AB}_{5}$ type uses a rare-earth Misch metal (typically $\mathrm{LaNi}_{5}$, with naturally occurring rare-earth combinations that can include $\mathrm{Ce}, \mathrm{Nd}$, and $\operatorname{Pr}$ ), and the $\mathrm{AB}_{2}$ uses a vanadium-rich refractory alloy. The cost of the $\mathrm{AB}_{5} \mathrm{MH}$ alloy is considerably greater than that of the $\mathrm{AB}_{2}$ alloy, and this makes the $\mathrm{AB}_{5}$ material about $40 \%$ more expensive than the $\mathrm{AB}_{2}$. Relative elemental weights for an $\mathrm{AB}_{2}$ negative electrode might be 22.7-40.9\% V, 20.5-35.9\% Ni, 20.2-25.4\% Zr, 8.4-16\% Ti, and 0-1\% Mn. The negative electrode powder from scrap $\mathrm{AB}_{5}$ consumer cells was found to contain typically $33 \%$ rare earth, $60 \%$ transition metals, and 7\% other metals (Mn, Al) by weight (Lyman and Palmer 1994).

The flat plate hydride electrode of the Ovonic battery consists of an amorphous or polycrystalline hydride powder pressed onto a woven nickel grid that serves as its base. The alloy is produced by vacuum induction melting, which is relatively energy-intensive because of the high temperatures required to melt $\mathrm{V}$ and $\mathrm{Zr}$. The alloy is very hard and is only partially broken down before hydriding. After the hydride is produced, the material can be more easily ground to a powder for pressing onto the electrode. In the mid-1990s, the raw material cost was approximately $\$ 6.80 / \mathrm{lb}$, based on pure London Metal Exchange prices, but a lower cost ( $\sim 4.50 / \mathrm{lb}$ ) could probably be obtained by making use of purchased alloys (Gifford 1996). These 
materials are readily available, so no major change in the price is expected as battery production volume increases.

\section{B.5 References}

“1996 SAMPE Highlights: Fiber,” 1996, in High Performance Composites, 4(3):50 (May/June).

Chemical Marketing Reporter, 1996, "Chemical Prices for Week Ending April 26, 1996,"

Chemical Marketing Reporter 249(18) (April 29).

Cook, M., 1993, “Cadmium: Supply, Demand and the Electric Vehicle,” Ninth International Minor Metals Seminar, Budapest, Hungary (May 5-7).

Corbus, D., 1992, Environmental, Health, and Safety Issues of Sodium-Sulfur Batteries for Electric and Hybrid Vehicles, Volume II: Battery Recycling and Disposal, National Renewable Energy Laboratory Report NREL/TP-262-4680 (Sept.).

DeLuchi, M., 1991, Emissions of Greenhouse Gases from the Use of Transportation Fuels and Electricity, Argonne National Laboratory Report ANL/ESD/TM-22.

Electrosource, 1993, "Technical Summary, Horizon Advanced Battery Technology," Electrosource, Austin, Texas.

Geomet Technologies, Inc., 1993, Nickel-Cadmium Batteries for Electric Vehicles - Life-Cycle Environmental and Safety Issues, Germantown, Md., prepared for Electric Power Research Institute, GEOMET IE-2629 (Dec.).

Gifford, P., 1996, GM Ovonic, Troy, Mich., personal communication (May).

Haskins, H., and G. Reitz, 1986, "Sodium-Sulfur Battery Development for an Advanced Vehicle Powertrain (ETX)," Eighth International Electric Vehicle Symposium (Oct. 1986), in Electric Vehicles: A Decade of Transition, Society of Automotive Engineers PT-40 (1992).

Klein, M., and A.J. Salkind, 1993, "Design and Cost Analysis of a Nickel-Metal Hydride EV Battery," in Extended Abstracts, 183rd Electrochemical Society Meeting, Honolulu, Hawaii (May).

Lyman, J.W., and G.R. Palmer, 1994, "Recycling of Nickel-Metal Hydride Battery Scrap," 186th Meeting of the Electrochemical Society, Miami Beach, Fla. (Oct.).

Metal Statistics 1995: The Statistical Guide to North American Metals, American Metals Market, New York, N.Y.

Miller, G.R., B.J. McEntire, and R.S. Gordon, 1981, "Production Economics — The Driving Force behind the Development of Beta-Alumina Ceramic Electrolytes," in Processing of Metal and Ceramic Powders, Metallurgical Society of AIME, Louisville, Ky. (Oct. 12-14). 
Moore, T., 1994, “Producing a Near-Term EV Battery,” EPRI Journal, pp. 6-13 (April/May).

Morrow, H., 1995, The International Cadmium Association, Washington, D.C., personal communication (Feb.).

Ohi, J., 1992, Environmental, Health, and Safety Issues of Sodium-Sulfur Batteries for Electric and Hybrid Vehicles, Volume I: Cell and Battery Safety, National Renewable Energy Laboratory Report NREL/TP-262-4678 (Sept.).

Ovshinsky, S., et al., 1993, “A Nickel Metal Hydride Battery for Electric Vehicles,” Science, 260:176-181 (April).

Ovshinsky, S.R., et al., 1994, "Ovonic NiMH Batteries for Portable and EV Applications," Eleventh Seminar on Primary and Secondary Battery Technology and Application, Fort Lauderdale, Fla. (March 1).

Rasmussen, J., 1994, Silent Power, Salt Lake City, Utah, personal communication (Aug.).

Rasmussen, J., 1996, Silent Power, Salt Lake City, Utah, personal communication (May). 


\section{Appendix C \\ EV Component Sizing}

The computations of EV powertrain size and costs in the body of this report have been based on assumed power ratings. The power requirements can be estimated, depending on the vehicle mass and its performance requirements. In this appendix, we present such a procedure, which is part of a computerized model developed at ANL (Vyas et al. 1998; Vyas and Cuenca 1999).

\section{C.1 Power and Mass Estimation Procedure}

First, we develop a theoretical model for estimating the acceleration power requirements. We then estimate the power requirement for each component (motor and battery pack) and the resulting vehicle mass.

\section{C.1.1 Acceleration Power Estimation}

Performance requirements are usually specified in terms of time required to accelerate from zero to $60 \mathrm{mph}$. The following relationship is used to estimate the instantaneous acceleration power requirement $P_{a}$ for an EV that has mass $M_{v}$ and is accelerating on a flat road:

$$
P_{a}=M_{v} v \frac{d v}{d t}+M_{v} C_{r} g v+\frac{1}{2} \rho A C_{d} v^{3}
$$

where

$$
\begin{aligned}
& v \quad=\text { Vehicle speed } \\
& \rho \quad=\text { Air density }, \\
& A \quad=\text { Vehicle frontal area, } \\
& C_{d}=\text { Coefficient of aerodynamic drag, } \\
& g \quad=\text { Gravity, and } \\
& C_{r}=\text { Coefficient of rolling resistance. }
\end{aligned}
$$

The power in Equation 1 is at the wheels. After the acceleration power is determined, the drivetrain components must be sized to allow for losses at various levels. Since the vehicle is accelerating from a stop to a specified speed $v_{m}$, the average acceleration power requirements can be estimated by integrating Equation 1 from zero to $v_{m}$.

$$
P_{a}^{*}=\frac{M_{v}}{t_{m}}\left\{\frac{1}{2} v_{m}^{2}+C_{r} g \int_{0}^{t_{m}} v d t\right\}+\frac{\rho A C_{d}}{2 t_{m}} \int_{0}^{t_{m}} v^{3} d t
$$


where $P_{a}^{*}$ is the average power required to reach speed $v$ and $t_{m}$ is the time taken to reach the specified speed $v_{m}$.

For any specified final speed $v_{m}$ and vehicle characteristics $M_{v}, C_{r}, A$, and $C_{d}$, the speed $v$ in Equation 2 is a function of time $t$. Under conditions of smooth acceleration, the approximate speed and time relationship can be plotted as shown in Figure C.1. Since the vehicle speed and time relationship can be reasonably approximated by a hyperbolic function, speed $v$ in Equation 2 can be expressed as:

$$
v=v_{m}\left(\frac{t}{t_{m}}\right)^{x}
$$

On the basis of empirical statistical approximation, the exponent $x$ in the above equation has a value in the range of $0.5-0.6$ for $0-60 \mathrm{mph}$ acceleration times of 8-12 seconds, with the higher value of $x$ corresponding to the shorter acceleration time.

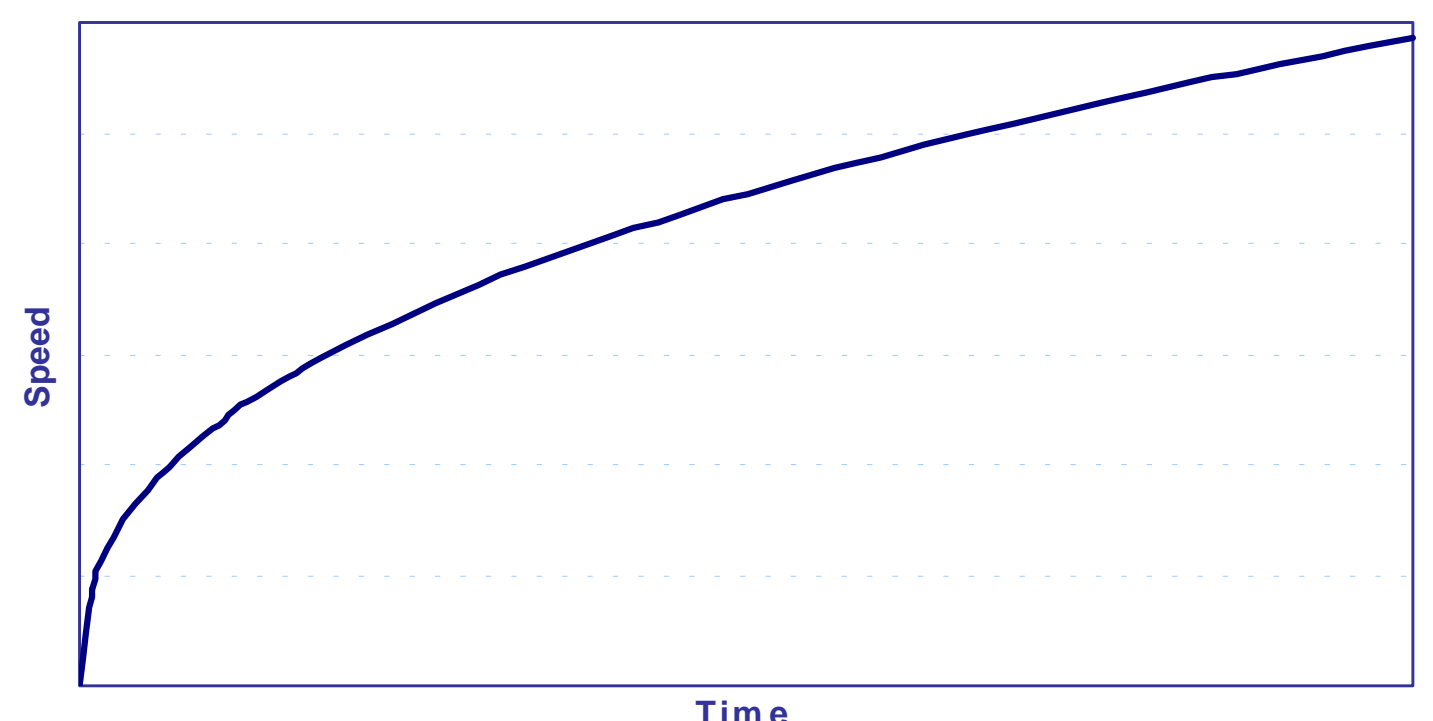

Figure C.1 Vehicle Speed and Time Relationship during Acceleration

Two approaches were explored for computing the acceleration power requirements: (1) by integrating Equation 2 with Equation 3, substituting speed $v$, and (2) by solving the instantaneous power equation (Equation 1) between time $t_{m}$ and $t_{m}+0.1$. The first approach provides an average value for the acceleration power, while the second approach provides the power required for accelerating through the specified upper speed $v_{m}$.

In the first approach, Equation 2 can be integrated by substituting the speed-time relationship from Equation 3. The integrated equation can be simplified as shown below.

$$
P_{a}=a_{1} M_{v}+b_{1}
$$


where

$$
\begin{aligned}
& a_{1}=\frac{v_{m}^{2}}{2 t_{m}}+\frac{C_{r} g}{t_{m}} \int_{0}^{t_{m}} v d t=\frac{v_{m}^{2}}{2 t_{m}}+\frac{1}{1+x} C_{r} g v_{m} \text { and } \\
& b_{1}=\frac{\rho A C_{d}}{2 t_{m}} \int_{0}^{t_{m}} v^{3} d t=\frac{1}{2(1+3 x)} \rho A C_{d} v_{m}^{3}
\end{aligned}
$$

Equation 4 shows that the acceleration power has two parts; one is multiplied by vehicle mass, and the other is fixed, depending on physical vehicle attributes other than mass. The term $a_{1}$ is a function of acceleration specifications (i.e., maximum speed and time needed to reach it) and rolling resistance. The term $b_{1}$ represents power required to overcome aerodynamic drag and is a function of drag coefficient and frontal area. The aerodynamic power requirement does not depend on vehicle mass.

The second approach would provide an estimate of the passing power requirement at the upper limit (or target) acceleration speed. Instantaneous power requirements increase with speed, so the assessment of power needed at the target speed provides an estimate of the peak motor (for $\mathrm{EV}$ ) or engine (for CV) power needed to reach the target speed $\left(v_{m}\right)$ in the specified time $\left(t_{m}\right)$. When used for estimating the acceleration power requirements of a $\mathrm{CV}$, the implicit assumption in this approach is that the vehicle target speed is achieved under a gearing setup that puts the $\mathrm{CV}$ engine at its maximum power ("red line").

Equation 1 is used for this approach. The value of $v$ is $v_{m}$ here, the value of $d v$ can be obtained from Equation 3, and $d t$ has a value of 0.1. The equation can be used in the following form:

$$
\begin{aligned}
P_{a} & =M_{v} v_{m}\left[v_{m}\left(\frac{t_{m}+0.1}{t_{m}}\right)^{x}-v_{m}\left(\frac{t_{m}}{t_{m}}\right)^{x}\right] \div 0.1+\frac{1}{2} \rho A C_{d} v_{m}^{3}+M_{v} C_{r} g v_{m} \\
& =M_{v} \frac{v_{m}^{2}}{0.1}\left[\left(\frac{t_{m}+0.1}{t_{m}}\right)^{x}-1\right]+M_{v} C_{r} g v_{m}+\frac{1}{2} \rho A C_{d} v_{m}^{3}
\end{aligned}
$$

We are interested in the effects of changes in the battery pack and electric powertrain power and mass while holding vehicle characteristics other than mass constant. Therefore, it is useful to express this equation in a form similar to that of Equation 4.

$$
P_{a}=a M_{v}+b
$$


where

$$
\begin{aligned}
& a=\frac{v_{m}^{2}}{0.1}\left[\left(\frac{t_{m}+0.1}{t_{m}}\right)^{x}-1\right]+C_{r} g v_{m} \text { and } \\
& b=\frac{1}{2} \rho A C_{d} v_{m}^{3}
\end{aligned}
$$

\section{C.1.2 Mass Estimation}

An electric vehicle has three distinct mass groups: (1) body and chassis, (2) drivetrain, and (3) battery pack. The body and chassis groups for the EV would be nearly identical to those of the $\mathrm{CV}$. The conventional vehicle mass and contributions by individual group have been analyzed earlier (Stodolsky et al. 1995a; OTA 1995). Conventional steel vehicles have 73-74\% of the total vehicle mass in their body and chassis groups. The use of ultra-light steel would reduce the total vehicle mass by $10-12 \%$, while use of aluminum would reduce the total mass by 31\% (Stodolsky et al. 1995a; OTA 1996; AISI 1998). In the case of an EV, a motor and a controller, a battery pack, and a gear-drive replace the conventional engine and transmission. Also, some load (representing passengers and luggage) is added for power computations. The total inertial mass $M_{v}$ is expressed as follows:

$$
M_{v}=M_{b}+M_{c h}+M_{d t}+M_{l}
$$

where

$$
\begin{aligned}
& M_{b}=\text { Body mass, } \\
& M_{c h}=\text { Chassis mass, } \\
& M_{d t}=\text { Drivetrain mass, and } \\
& M_{l}=\text { Load. }
\end{aligned}
$$

The body and chassis mass, $M_{b}$ and $M_{c h}$, depend on vehicle design; their sum $M_{f}$ is treated as fixed. Discussions in Sections 7 and 8 address the reasonableness of this assumption.

The drivetrain has several components, each with its own efficiency and specific power. The efficiency helps determine the power rating for the component, and the specific power, its mass. The drivetrain mass is specified as

$$
M_{d t}=M_{b a t}+M_{m o t}+M_{g d}
$$


where

$$
\begin{aligned}
& M_{b a t}=\text { Battery mass } \\
& M_{m o t}=\text { Motor and controller mass, and } \\
& M_{g d}=\text { Gear-drive mass. }
\end{aligned}
$$

Let $S_{b a t}, S_{m o t}$, and $S_{g d}$ be the specific power for each of the five components and $P_{b a t}, P_{m o t}$, and $P_{g d}$ be the power ratings. Then the mass of each component can be computed as power divided by specific power.

$$
\begin{gathered}
M_{b a t}=P_{b a t} / S_{b a t} \\
M_{m o t}=P_{m o t} / S_{m o t} \\
M_{g d}=P_{g d} / S_{g d}
\end{gathered}
$$

These mass and specific power values are for the complete component assembly, including auxiliary and/or supporting units. As indicated, the motor assembly includes the controller.

\section{C.1.3 Component Power Rating}

The acceleration power estimate from the procedure described above is for power delivered at the wheels. Each component has its own power conversion efficiency, and some losses are involved in mechanical components, such as bearings. A design factor, $k$, is used to account for other losses, delays in power transfer, and contingencies. In an EV, the motor delivers all the required power through the gear drive.

Let $\eta_{\text {mot }}$ be the average power efficiency of the motor and controller and $\eta_{g d}$ that for the gear drive. These efficiencies are for the component assemblies, including supporting units. The formula for computing acceleration power requirement $P_{a}$ is specified in Equation 8 . The component power ratings for an $\mathrm{EV}$ can be computed as follows:

$$
\begin{aligned}
& P_{m o t}=P_{a} / \eta_{g d} \\
& P_{b a t}=P_{a} / \eta_{g d} \eta_{m o t}
\end{aligned}
$$

Equation 8 for power computation requires that the vehicle's inertial mass $M_{v}$ be known. However, the vehicle's inertial mass has four contributors (see Equation 11): body, chassis, drivetrain, and load. The body and chassis masses as modeled here depend on the type of vehicle (i.e., subcompact or minivan) and type of material (i.e., conventional steel, ultra-light steel, or aluminum). The drivetrain mass depends on power requirements and equipment type (assuming that the materials that provide the most effective performance are used). The load is usually fixed and can be taken from the U.S. Environmental Protection Agency's (USEPA's) test protocol. 
Note that the vehicle power and mass computations depend, in part, on the drivetrain component mass.

\section{C.1.4 Total EV Mass}

The total vehicle mass $\mathbf{M}_{\mathrm{veh}}$ is defined as:

$$
M_{v e h}=M_{f}+M_{d t}
$$

where

$$
\begin{aligned}
& M_{f}=\text { Fixed mass (i.e. sum of body and chassis mass) and } \\
& M_{d t}=\text { Drivetrain mass. }
\end{aligned}
$$

Let $P_{a}=$ Power requirements for acceleration,

$M_{c} \quad=$ Mass of drivetrain component "c,"

$P_{c}=$ Power rating of drivetrain component "c,"

$S_{c} \quad=$ Specific power of drivetrain component "c," and

$\eta_{c}=$ Efficiency of drivetrain component "c."

Then the drivetrain mass is estimated as shown below.

$$
\begin{aligned}
& M_{d t}=M_{m o t}+M_{b a t}+M_{g d} \\
& =\frac{P_{m o t}}{S_{m o t}}+\frac{P_{b a t}}{S_{b a t}}+\frac{P_{g d}}{S_{g d}} \\
& =\frac{P_{a}}{\eta_{g d} S_{m o t}}+\frac{P_{a}}{\eta_{g d} \eta_{m o t} S_{b a t}}+\frac{P_{a}}{\eta_{g d} S_{g d}} \\
& =P_{a}\left(\frac{1}{\eta_{g d} S_{m o t}}+\frac{1}{\eta_{g d} \eta_{m o t} S_{b a t}}+\frac{1}{\eta_{g d} S_{g d}}\right) \\
& =e P_{a}
\end{aligned}
$$

where

$$
e=\frac{1}{\eta_{g d}}\left(\frac{1}{S_{m o t}}+\frac{1}{\eta_{m o t} S_{b a t}}+\frac{1}{S_{g d}}\right)
$$


Total vehicle mass, then is given by

$$
\begin{aligned}
M_{v e h} & =M_{f}+M_{d t} \\
& =M_{f}+e P_{a}
\end{aligned}
$$

Note that the power value $P_{a}$ is computed with the inertial mass value, which includes some load, when applying Equation 8. The design factor $k$ is applied as follows to account for other losses:

$$
M_{v e h}=M_{f}+k e\left[a\left(M_{v e h}+M_{a l o a d}\right)+b\right]
$$

where $M_{\text {aload }}$ is the load carried during acceleration. Then

$$
\begin{aligned}
& M_{v e h}-k e a M_{v e h}=M_{f}+k e\left(a M_{a l o a d}+b\right), \text { so } \\
& M_{v e h}=\frac{M_{f}+k e\left(a M_{a l o a d}+b\right)}{1-k e a}
\end{aligned}
$$

\section{C.2 Application of the Procedure}

The following example demonstrates the application of the above-described power and mass computing procedure to the subcompact car. Data used in the example were gathered from several sources and were complemented with technical judgment in some cases.

\section{C.2.1 Subcompact EV}

The EV in this application is assumed to be a subcompact car. In 1997, the average mass of a subcompact was $1,089 \mathrm{~kg}(2,400 \mathrm{lb})$. Assuming that future cars at the time of EV introduction will be $2 \%$ lighter, we can assign a mass of $1,067 \mathrm{~kg}(2,352 \mathrm{lb})$. We assume that the sum of body and chassis mass contributes $73.5 \%$ of the total vehicle mass (Stodolsky et al. 1995a). An EV's body and chassis are assumed to have 5\% higher mass than a CV's because of the additional components needed for power electronics and stiffeners to support the battery pack. The resulting body and chassis mass values are shown in Table C.1. Three body types are listed in Table C.1:

(1) conventional steel body, (2) ultra-light steel body, and (3) maximum aluminum body. An ultralight steel vehicle would weigh $11 \%$ less than its conventional steel counterpart, and a maximum aluminum vehicle would weigh $31 \%$ less than its conventional steel counterpart (AISI 1998; Stodolsky et al. 1995b). Assuming that future vehicles become lighter at a rate of $1 \%$ every five years, we have also presented the body and chassis mass for a subcompact EV after 20 years.

The current subcompact cars are 65 in. wide and 52 in. tall. These dimensions were kept unchanged in this analysis. A factor is applied to the vehicle cross section to account for ground clearance and side curvatures. This factor was taken as 0.83 at the time of EV introduction and 0.80 after 20 years. The resulting frontal area ranged from 1.84 to $1.77 \mathrm{~m}^{2}$. We also assume that future cars will have much lower aerodynamic drag coefficients and that their tires will have very low rolling resistance. Table C. 1 also lists aerodynamic and rolling resistance parameters. 
Some design criteria are necessary for computing power requirements. The vehicle is required to accelerate from zero to $60 \mathrm{mph}(26.82 \mathrm{~m} / \mathrm{s})$ in some fixed time. Table C.1 lists the acceleration requirements and vehicle loading during acceleration. The acceleration load of $136 \mathrm{~kg}$ is from the USEPA's standard procedure.

Table C.1 Subcompact EV Physical Characteristics and
Design Parameters
\begin{tabular}{|crr|}
\hline & $\begin{array}{c}\text { At EV } \\
\text { Introduction }\end{array}$ & $\begin{array}{r}\text { At High } \\
\text { Volume }\end{array}$ \\
\hline \multicolumn{1}{|c}{ Characteristics } & & \\
\hline Body and chassis mass, kg (lb) & $823(1,815)$ & $791(1,744)$ \\
Conventional steel body & $733(1,616)$ & $704(1,552)$ \\
Ultralight steel body & $568(1,253)$ & $546(1,203)$ \\
Maximum aluminum body & 1.84 & 1.77 \\
Aerodynamic and rolling factors & 0.30 & 0.27 \\
Frontal area (m ${ }^{2}$ ) & 0.0085 & 0.0075 \\
Coefficient of drag (Cd) & & \\
Coefficient of rolling resistance (Cr) & 16 & 16 \\
Design parameters & 136 & 136 \\
Time to accelerate from zero to 60 mph (s) & & \\
Loading during acceleration (kg) & & \\
\hline
\end{tabular}

\section{C.2.2 Battery}

Two battery types are selected for this example, advanced lead-acid and nickel-metal hydride. The lead-acid battery was the initial choice for GM's EV1 vehicles before being replaced by nickelmetal hydride. The nickel-metal hydride battery was also selected for Toyota's RAV-4 EV. The battery data from Section 6 of this report are used for both the battery types initially. The future data are projected by using our interpretation of battery performance information in a report by Kalhammer et al. to the California Air Resources Board. Table C. 2 shows the selected battery characteristics.

Table C.2 Battery Characteristics for the Subcompact EV

\begin{tabular}{|lcccccc|}
\hline & \multicolumn{2}{c}{ Lead-Acid } & & \multicolumn{2}{c|}{ Ni-MH } \\
\cline { 2 - 3 } \cline { 5 - 6 } \multicolumn{1}{c}{ Characteristic } & $\begin{array}{c}\text { At EV } \\
\text { Introduction }\end{array}$ & $\begin{array}{c}\text { At High } \\
\text { Volume }\end{array}$ & & $\begin{array}{c}\text { At EV } \\
\text { Introduction }\end{array}$ & $\begin{array}{c}\text { At High } \\
\text { Volume }\end{array}$ \\
\hline Specific power at $20 \%$ SOC $(\mathrm{W} / \mathrm{kg})$ & 250 & 300 & & 250 & 300 \\
Specific energy $(\mathrm{W} \cdot \mathrm{h} / \mathrm{kg})$ & 45 & 50 & & 75 & 130 \\
& & & & \\
\hline
\end{tabular}




\section{C.2.3 Component-Specific Power and Efficiencies}

The power computation procedure requires specific power and efficiency information for each drivetrain component. Table C.3 lists the values used in this analysis. We analyzed data on Unique Mobility motor SR218H and controller CA40-300L. The motor has a peak specific power of $1,110 \mathrm{~W} / \mathrm{kg}$, and the two units have a combined specific power of $875 \mathrm{~W} / \mathrm{kg}$. We assumed a $10 \%$ increase in the specific power by the time EVs are introduced in the thousands. The efficiencies are used in computing power requirements for various components. The power requirements represent peak values, and the efficiencies are those at these peak outputs. The components are most efficient at the peak output, so higher efficiencies are selected in our analysis.

Table C.3 Specific Power and Efficiency Values for Drivetrain Components

\begin{tabular}{|ccc|}
\hline Component & $\begin{array}{c}\text { At EV } \\
\text { Introduction }\end{array}$ & $\begin{array}{c}\text { At High } \\
\text { Volume }\end{array}$ \\
\hline $\begin{array}{l}\text { Specific power (W/kg) } \\
\text { Motor with controller }\end{array}$ & 960 & 1,035 \\
$\begin{array}{l}\text { Gear drive } \\
\text { Efficiency (\%) } \\
\text { Motor with controller } \\
\text { Gear drive }\end{array}$ & 3,850 & 4,150 \\
& 90 & 94 \\
\hline
\end{tabular}

\section{C.2.4 Power and Mass Computations}

In this example, a subcompact EV with an ultra-light steel body is analyzed. Values for such fixed parameters as gravity and air density are taken from standard physical tables. The value for gravity is $9.8 \mathrm{~m} / \mathrm{s}^{2}$ and air density is $1.23 \mathrm{~kg} / \mathrm{m}^{3}$. Also, a design factor $k$ is applied in computing power to account for other mechanical losses, delays in power transmission, and contingencies. The value of $k$ is 1.1 in this example.

The procedure is applied to the early subcompact EV, which is assumed to be equipped with the lead-acid battery. The vehicle accelerates from zero to $60 \mathrm{mph}$ in 16 seconds. The value of exponent $x$ (in Equation 3) is set at 0.5.

The power requirement $P_{a}$ for acceleration from zero to $60 \mathrm{mph}(26.82 \mathrm{~m} / \mathrm{s})=k\left(a M_{v}+b\right)$.

$$
\begin{aligned}
a= & \frac{v_{m}^{2}}{0.1}\left[\left(\frac{t_{m}+0.1}{t_{m}}\right)^{x}-1\right]+C_{r} g v_{m}=\frac{26.82^{2}}{0.1}\left[\left(\frac{16+0.1}{16}\right)^{0.5}-1\right]+0.0085 \times 9.8 \times 26.82 \\
& =22.44+2.24=24.7 \mathrm{~W} / \mathrm{kg}
\end{aligned}
$$




$$
\begin{aligned}
& b=\frac{1}{2} \rho A C_{d} v_{m}^{3}=\frac{1}{2} \times 1.23 \times 1.84 \times 0.3 \times 26.82^{3}=6549.2 \mathrm{~W} \\
& M_{v e h}=\frac{M_{f}+k e\left(a M_{a l o a d}+b\right)}{1-k e a} \\
& e=\frac{1}{\eta_{g d}}\left(\frac{1}{S_{m o t}}+\frac{1}{\eta_{m o t} S_{b a t}}+\frac{1}{S_{g d}}\right)=\frac{1}{0.92}\left(\frac{1}{960}+\frac{1}{0.9 \times 250}+\frac{1}{3850}\right)=6.25 \times 10^{-3} \\
& M_{v e h}=\frac{733+1.1 \times 6.25 \times 10^{-3}(24.7 \times 136+6549.2)}{1-1.1 \times 6.25 \times 10^{-3} \times 24.7}=965 \mathrm{~kg} \\
& P_{a}=k\left(a M_{v}+b\right)=1.1[24.7 \times(965+136)+6549.2]=37,118 \mathrm{~W}=38 \mathrm{~kW} \\
& P_{m o t}=P_{a} / \eta_{g d}=38 / 0.92=42 \mathrm{~kW} \\
& P_{b a t}=P_{a} / \eta_{m o t} \eta_{g d}=42 / 0.9 \times 0.92=51 \mathrm{~kW} \\
& M_{m o t}=P_{m o t} / S_{m o t}=42000 / 960=44 \mathrm{~kg} \\
& M_{b a t}=P_{b a t} / S_{b a t}=51000 / 250=204 \mathrm{~kg} \\
& M_{g d}=P_{a} / S_{g d}=38000 / 3850=10 \mathrm{~kg}
\end{aligned}
$$

The total vehicle mass $=733+44+204+10=991 \mathrm{~kg}$. This total vehicle mass is $36 \mathrm{~kg}(3.7 \%)$ higher than the first approximation. This first round of estimates can be used in a second round, and so on until convergence is reached. An iterative procedure that uses a convergence criterion is employed in the computerized procedure.

\section{C.3 References}

American Iron and Steel Institute, 1998, UltraLight Steel Auto Body Final Report, Washington, D.C.

Office of Technology Assessment, 1995, Advanced Automotive Technology: Visions of a SuperEfficient Family Car, U.S. Congress, OTA Report OTA-ETT-638, Washington, D.C.

Stodolsky, F., A. Vyas, and R. Cuenca, 1995a, "Lightweight Materials in the Light-Duty Passenger Vehicle Market: Their Market Penetration Potential and Impacts," presented at the Second World Car Conference, University of California at Riverside, Riverside, Calif.

Stodolsky, F., A. Vyas, R. Cuenca, and L. Gaines, 1995b, "Life-Cycle Energy Savings Potential from Aluminum-Intensive Vehicles," Proceedings of the 1995 Total Life Cycle Conference, SAE International Report P-293, Warrendale, Pa. 
Vyas, A., R. Cuenca, and L. Gaines, 1998, “An Assessment of Electric Vehicle Life Cycle Costs to Consumers," Proceedings of the 1998 Total Life Cycle Conference, pp. 161-172, SAE International Report P-339, Warrendale, Pa.

Vyas, A., and R. Cuenca, 1999, “An Electric Vehicle Cost Estimation Methodology,” Presented at the Seventy-Eighth Annual Meeting of the Transportation Research Board, Washington, D.C. 


\section{Distribution}

\section{Internal}

F. Bennett

R.M. Cuenca

L.L. Gaines

G. Griparis

\section{External}

U.S. Department of Energy, Office of Scientific and Technical Information (2)

P.D. Patterson, U.S. Dept. of Energy Office of Transportation Technologies (30)

ANL-E Library

ANL-W Library
M. Hale

L.R. Johnson

D.J. Santini

A. Vyas (208) 